AN ANALYSIS OF COHORT MODELS IN TECHNICAL EDUCATION AT KANSAS CITY KANSAS COMMUNITY COLLEGE

$\begin{gathered}\text { A Dissertation } \\ \text { presented to }\end{gathered}$
the Faculty of the Graduate School
at the University of Missouri-Columbia
In Partial Fulfillment
of the Requirements for the Degree
Doctor of Education
Tina Marie Church Lewandowski
br. Sandy Hutchinson, Dissertation Supervisor
Dissertation in Practice

May 2021 
(C) Copyright by Tina Church Lewandowski 2021 
All Rights Reserved

The undersigned, appointed by the dean of the Graduate School, have examined the dissertation entitled

\section{AN ANALYSIS OF COHORT MODELS IN TECHNICAL EDUCATION AT KANSAS CITY KANSAS COMMUNITY COLLEGE}

Presented by Tina Church Lewandowski a candidate for the degree of doctor of education moreover, hereby certify that, in their opinion, is worthy of acceptance.

Dr. Sandy Hutchinson

Dr. Barbara N. Martin

Dr. Heather L. Staples

Dr. Steve Ritter 


\section{ACKNOWLEDGEMENTS}

This project has been completed in part thanks to my dissertation chair, Dr. Sandy Hutchinson and dissertation committee members. I appreciate their time, dedication, and shared ideas that contributed to this project. A special thanks to Dr. Heather Staples, who helped guide me through this project and always believed in me. I would also like to thank my parents, Tommy and Linda Church, and sisters, Micaela Lenhart and Ginger Church, and grandparents, Ervin and Jerri Bugh and Shirley Church, for the years of support and encouragement they have provided me during my academic career. Lastly, I would like to thank my husband, Dr. Joseph D. Lewandowski, for making so many things possible and our children, Miles and Sabina, who were the motivation to complete this project. 


\section{$\underline{\text { Table Of Contents }}$}

Acknowledgments ii

List of Tables X

List of Figures xi

ABSTRACT _ _ Xii

SECTION ONE ___ 1

Introduction to the Background of the Study ___ 2

Statement of the Problem ___ 3

Purpose of the Study _ 4

Research Questions ___ 5

Conceptual Theoretical Frameworks ___ 6

Philosophical Worldviews _ـ 10

Design of the Study ___ 11

Setting __ 11

Method___ 12

Participants

Data Analysis ___ 17

Credibility of the Study ___ 18

Definition of Key Terms _ـ 20

Significances of Study ___ 21

Results _ 22

Research Questions ___ 22

Connections to Conceptual/Theoretical Framework __ 22 
Participants and Data Collection __ 24

Presentation of the Data __ 30

Research Question One ___ 31

Research Question Two __ 32

Research Question Three ___ 34

Research Question Four __ 36

Research Question Five ___ 37

Research Question Six ___ 41

Research Question Seven ___ 45

Research Question Eight ___ 47

Discussion of Findings __ 49

Conclusions

Recommendations _ـ 53

Recommendation One: Prior enrollment academic testing and program interest _ 54

Recommendation Two: Career and internship placement ___ 55

Recommendation Three: Part-time enrollment options for postsecondary students

Recommendation Four: Clear pathways for students to transition from high school to postsecondary status _ 57

Recommendation Five: Support for minority student ___ 58

Summary _

SECTION TWO _ 59 
Introduction

History of the Organization _ـ 60

KCKCC Technical Education Center cohort programs __ 62

Organizational Analysis _ 66

Structural Frame _ 67

Political Frame — 69

Human Resource Frame __ 71

Symbolic Frame __ 73

Implications for Research in the Practitioner Setting___ 74

Leadership Analysis __ 75

Introduction

Leader-Member Exchange Theory ___ 75

Path-Goal Theory __ 77

Summary _ـ 79

SECTION THREE __ 80

Introduction — 81

Research about Cohort Models _ـ 81

Cohort Description __ 81

Cohort Defined___ 81

Cohort Structure and Design __ 82

Cohort Environment__ 85

Cohort Curriculum _ 87

Cohort Funding Consideration 
Student and Faculty Characteristics ___ 90

Cohort Demographics___ 90

Student Characteristics ___ 92

Cohort Faculty ___ 94

Connectedness and Relationships ___ 96

Student Connectedness ___ 96

Faculty-Student Relationships ___ 97

Faculty Mentor Relationship ___ 99

Cohorts as Groups

Cohort Group Dynamics __ 100

Cohort Community _ـ 101

Group Learning and Support ___ 104

Online Learning __ 107

Challenges _ـ 108

Overcoming Challenges ___ 111

Cohort Program Outcomes ___ 112

Leadership __ 112

Academic Outcomes___ 113

Persistence, Retention, and Program Completion ___ 115

Employment Outcomes __ 119

Summary _ـ 120

SECTION FOUR _ 122

Introduction _ـ 123 
Kansas City Kansas Community College Dean's Council

slide presentation

SECTION FIVE

Journal article submission statement

Title Page

Abstract

Introduction

Materials and method

Method 154

Research Questions 154

Participants and data collection 155

Data analysis 157

Results 157

Research Question One: Is graduation of a TEC cohort program independent of a student's level (high school and postsecondary)?

Research Question Two: What are the reasons for students' continued enrollment in the TEC cohort program?

Research Question Three: What forms of support within the TEC cohort program encouraged students' program completion?

Research Question Four: According to students, why do TEC cohort models support program completion?

Research Question Five: According to the TEC cohort faculty, what supportive contributions do they perceive should be provided to students? 
Discussion

Conclusion

Recommendations

Recommendation One: Prior enrollment academic testing and

program interest

Recommendation Two: Career and internship placement 176

Recommendation Three: Part-time enrollment options for postsecondary students 176

Recommendation Four: Clear pathways for students to transition from

high school to postsecondary status 178

Journal Article References 180

Tables 183

Figures 185

SECTION SIX 186

Introduction 187

Leadership theory 187

Dissertation project reflection 193

Summary 194

REFERENCES 196

Appendix 209

APPENDIX A 210

A1: Student survey questions 211

A2: Faculty interview questions 215 
A3: Student interview questions

APPENDIX B

B1: University of Missouri IRB approval

C1: Student survey consent with waiver of documentation/assent

C2: Faculty and student consent with waiver of documentation/assent for virtual interview

C3: Parental consent form for students under age 18 224

APPENDIX D 226

D1: Kansas City Kansas Community College Technical Education Certificate Cohort Programs 227

VITA 228 


\section{LIST OF TABLES}

Table

1. Age of TEC Cohort Program Participants

2. Chi-Square Test for Graduation based on TEC Cohort Student Level

3. TEC Cohort Program High School and Postsecondary Student Actual and Expected Graduation Status

4. TEC Cohort Program Participant Race and Ethnicity Actual and Expected Graduation Status

5. TEC Cohort Program Participant Age Actual and Expected

Graduation Status 35

6. TEC Cohort Program Generational Age Actual and Expected

Graduation Status 36

7. TEC Cohort Program Gender Actual and Expected Graduation Status 37 


\section{LIST OF FIGURES}

1. Gender of TEC Cohort Program Subjects

2. High School or Postsecondary TEC Cohort Program Student Levels of 


\begin{abstract}
This mixed method study was conducted to gain a better understanding of technical educational center (TEC) cohort programs at a midwestern urban community college. In a cohort model, the students start a program and progress through the curriculum together until completion (Bista \& Cox, 2014). Specifically, the study focused on two student types, high school students who were taking college courses and postsecondary students as well as the TEC cohort faculty. The TEC cohort model was examined to learn more about the graduation rates, continued program enrollment, and student support systems. Due to a gap in the literature about cohort models in relationship to race, ethnicity, and gender, those aspects were also studied. The results of the study found that postsecondary students graduated at a higher rate than high school students. Relationships developed throughout the cohort among classmates and with the faculty were indicated as a contributing factor to program completion. Other themes included cohort model structure, hands-on learning, career opportunities, and student attitudes. The study concluded with a set of four recommendations.
\end{abstract}


SECTION ONE

INTRODUCTION TO THE DISSERTATION-IN-PRACTICE 


\section{Introduction to the Background of the Study}

Most students start college with the expectation of completing a program that will help them obtain the skills necessary for a job. For many students, this academic journey is not easy, and many roadblocks prevent them from achieving their goals (Pfund, Bono, \& Hill, 2020). Enrollment management in higher education focuses on a variety of areas, including recruitment, retention, and graduation (Hossler \& Kalsbeek, 2008). This study focused specifically on the continuation of enrollment, meaning retention and program completion. In addition, this research examined the relationships formed, faculty mentorship, and community learning for specific demographics of the students in technical education programs at a community college.

To help students complete technical certificate programs at Kansas City Kansas Community College (KCKCC), this study was initiated. The TEC programs at KKCC are cohort-based programs. In a cohort model, the students start a program and progress through the curriculum together until completion (Bista \& Cox, 2014). Cohort models promote retention, increase graduation rates, and contribute to the success of students (Lei, Gorelick, Short, Smallwood, \& Wright-Porter, 2011). Therefore, as an effort to increase degree completion, universities have adopted cohort education models (Unzueta, Moores-Abdool, \& Donet, 2010). This study of the cohort TEC programs at KCKCC was developed to provide insight into what encourages students to complete the program. The students enrolled in the TEC program were comprised of high school students who were dual enrolling in college who are enrolled at the high school level as well as postsecondary students. The postsecondary students were a mix of traditional and 
non-traditional students who had graduated from high school or earned a general education diploma (GED). The demographics of KCKCC cohort students were examined to gain insight into the need for student retention and program completion. In support of this research, past literature indicated the cohort model of course delivery promotes retention, increases graduation rates, contributes to student success (Lei et al., 2011), and is respective of student needs (Preis, Gorogan, Sherman, \& Beaty, 2007).

\section{Statement of the Problem}

The problem surrounding this research project was based primarily on the gaps within research on cohort models. Much of the cohort research focused on newly created cohorts, cohort programs compared to non-cohort programs, cohort structure, and faculty and student relationships (Barnett, Basom, Yerkes, \& Norris, 2000; Barnett \& Muse, 1993; Maher 2005; Nimer 2009; Potthoff, Frederickson, Batenhorst, \& Tracy, 2001; Unzueta, Moores-Abdool, \& Donet, 2010). However, there was a gap in research about cohort models based on student types. Research conducted on high school students enrolled alongside postsecondary students in college cohort programs is nonexistent. Additionally, there was not a substantial amount of research devoted to the race, ethnicity, or gender of students in cohort programs. Due to this gap, there has not been any focus on their program retention and completion rates, nor has research been conducted about their formed relationships of support, community learning, or faculty mentoring that all are capstones of cohort programs.

Retention can be a challenge since students face many life decisions and have responsibilities outside of college (Hadfield, 2003). Adult learners have external obligations to overcome to remain in college. For instance, many of the students at 
KCKCC have full-time jobs and family responsibilities. These students commonly take a semester off to manage their personal responsibilities and fail to re-enroll in courses or complete their program. Retention is critical for overall student success and higher education institutional goal assessment. For students to have opportunities to start or advance within their career, a completed certificate or degree is often necessary. A partially completed credential or completion of a few college courses is not as valuable as a completed credential (Matheny, Chan, \& Wang, 2015). Therefore, it is essential for institutions to have a clear understanding of what factors lead to student success so they can help support students to complete their programs.

\section{Purpose of the Study}

The goal of this mixed-method study was to gain a better understanding of educational cohort models at Kansas City Kanas Community College's Technical Education Center. This understanding will assist the administration and faculty at $\mathrm{KCKCC}$ as they make more strategic decisions regarding the structure and organization of TEC programs.

The knowledge gained will be considered to identify sources of support to promote retention and program completion at the KCKCC. The understanding of retention of the various student groups of the TEC cohort programs is anticipated to have an impact on many outcomes of TEC programs. These outcomes include the types of resources each group might require, student-to-student and faculty-to-student connectedness, and what barriers prevent program completion. Academic programs at KCKCC TEC are expected to meet goals concerning minimum enrollments, retention, and graduation rates, all while working to ensure the students have a positive educational 
experience. The TEC programs are also expected to provide students with the necessary skills for employment.

\section{Research Questions}

The following research questions guided this study:

\section{Quantitative Research Questions}

1. Is graduation of a TEC cohort program independent of a student's level (high school and postsecondary)?

2. Is graduation of a TEC cohort program independent of a student's race/ethnicity?

3. Is graduation of a TEC cohort program independent of a student's age at the start of the program?

4. Is graduation of a TEC cohort program independent of a student's gender?

\section{Qualitative Research Questions}

5. What are the reasons for students' continued enrollment in the TEC cohort program?

6. What forms of support within the TEC cohort program encouraged students' program completion?

7. According to students, why do TEC cohort models support program completion?

8. What supportive contributions do TEC cohort faculty perceive should be provided to students?

The answers to these research questions will provide an understanding of the contributing factors and inhibitions of retention and graduation rates among the student groups within the cohort technical education programs at Kansas City Kansas Community College. 


\section{Conceptual and Theoretical Frameworks}

To guide this study, Bolman and Deal's (2017) four organizational frames served as the fundamental foundation for cohort models. These frames include (1) structural, (2) human resource, (3) political, and (4) symbolic. The structural frame focuses on organizing groups and teams to achieve results (Bolman \& Deal, 2017). Satisfying human needs, human resource management, and interpersonal group dynamics all make up the human resources frame (Bolman \& Deal, 2017). The political frame deals with power, conflict, and competition for scarce resources (Bolman \& Deal, 2017). Lastly, the symbolic frame focuses on culture, rituals, and ceremonies (Bolman \& Deal, 2017). The four-frame approach is a way to organize situations and perceptions by grouping similar concepts together. Each frame has an underlying imprint in the cohort model. Since each of the four frames is evident in this study, potential solutions for problems have been identified using the assumptions surrounding each frame (Bolman \& Deal, 2017). Furthermore, the results of the research questions each reside in the four frames.

Research conducted by Bentley, Zhao, Reames, and Reed (2004) related the assumptions of the four frames to the cohort model and correlated cohort outcomes to each of the frames. Concerning the structural frame, the cohort model allows for strategic planning to equate the division of labor. Knowing the projection of how many students continue enrollment and program completion can enhance an institution's ability to predict enrollments with fewer dropouts or withdraws, which may influence scheduling, class size, and faculty loads. Furthermore, the minimum amount of resources needed can be anticipated, along with the schedule of courses and faculty assignments. 
The structural frame resonates directly with the curriculum computation of the program and the course offering organization. The structural frame promotes efficiency by utilizing a well-organized structure and well-defined rules. One structural assumption is achieved goals and objectives (Bolman \& Deal, 2017). The cohort model is related to the structural frame because of the clearly defined roles and designed relationships (Bentley et al., 2004). Each person involved in the cohort will have a distinct role with outlined responsibilities and objectives. According to Bolman and Deal's (2017) structural frame, program size and age, core process, environment, strategy and goals, information technology, and the nature of the workforce should be considered. For a cohort program to operate smoothly, consideration of these factors should be a top priority.

The human resource frame is solely about the people (Bolman \& Deal, 2017). Human needs are controversial in some academic circles (Bolman \& Deal, 2017) since everyone has a unique level of need and may respond differently to human resources. The individuals involved in a cohort model act as a family and the faculty members support the students while the students support each other (Bentley et al., 2004). This study had three main groups of individuals: (1) high school students, (2) postsecondary students, and (3) faculty. Since postsecondary students are adults, they have added responsibilities, such as serving as a primary care giver, employment obligations, and financial commitments. These responsibilities pose challenges to their studies and program completion. High school students are still enrolled in high school and have enrolled in the college TEC program at the same time. These students also have a multitude of responsibilities to consider, as they are still navigating their high school 
curriculum and extracurricular activities. Additionally, high school students have family obligations and part-time jobs to balance along with their academic studies. Therefore, it is essential to consider how their basic needs outside of the classroom must be fulfilled before they can be successful students.

The political framework is evident as the program consisted of high school students and postsecondary students. The high school students were students who attended high school in the area also serving the college. For instance, the largest high school in KCKCC's service is the Unified School District (USD) 500. KCKCC has a memorandum of understanding with the district outlining the services KCKCC will provide their students who are still in high school and enroll in college courses with KCKCC. Therefore, it is assumed that KCKCC would give preference to the USD 500 students. This practice limited the number of seats allocated for students from other high schools and postsecondary students. The allocation of scarce recourses typically leads to competition for limited resources (Bolman \& Deal, 2017). In this study, the TEC program seats are considered a scarce resource, as there are a fixed number of seats for each program. According to accreditation standards, many programs have a maximum number of students allowed based on available faculty. The examination of program completion rates among the high school students and the postsecondary students, the number of seats designated for each group should be reviewed to determine which group would be more likely to complete the program. Another connection was identified by Bentley, Zhao, Reames, and Reed (2004) between the cohort model and the political frame since the faculty and students unite to work under common group philosophy. 
The symbolic frame also has a role in this study. Aside from certificate attainment, the cohort model provides a cultural experience by creating traditions and values (Bentley et al., 2004). The ritual of graduation is an obvious symbolic area of the cohort model. The importance is not necessarily placed on what happens but what it means (Bolman \& Deal, 2017). With this noted, the TEC faculty work in conjunction to formulate a remarkable experience for the students. The meaningful experience promoted a positive culture that was shared with others, which made the program attractive to potential students.

Shifting the focus to retention and degree completion, Tinto (1993) discussed how student learning best occurs when social and intellectual support is integrated into a student's daily life. Moreover, effective programs established personal bonds among students, faculty, and staff members. Tinto's work helped to support the need for cohort models because cohorts provided connectedness for students to one another and with the faculty, and connectedness promotes program retention.

Since the postsecondary students were adults, the adult learning theory was important to consider. Adults approach education and learning differently than younger students. Learning for adults included case studies, problem-solving activities, and group discussion to allow the students to relate their education directly to the workplace and see the value of what they are learning (Brayman, Grey, \& Stearns, 2010). Adult learning theory should be considered when faculty develop the curriculum for the program and individual courses. 


\section{Philosophical Worldviews}

A philosophical worldview was the guiding action based on a set of assumptions (Creswell, 2013). This study has assumptions from four worldviews, including (1) postpositivism, (2) constructivism, (3) transformative, and (4) pragmatism. However, the pragmatism worldview was the primary view that guides this study. According to Creswell (2013), the pragmatic worldview is concerned with the application of what works, consequences of actions, problem-centered, and real-world practiceoriented. This study examined the influences of cohort models to determine what worked from each student type compared to one another. This real-world situation and the knowledge gained can be applied directly to TEC programs at community colleges and Technical Education Centers. The cohort programs are already in place, and the knowledge gained from them can be applied to the cohort program.

Another perspective considered was the postmodern feminist perspective. This perspective is not a significant driving force of the study. However, the researcher was cognizant of the experiences of women in the cohort program. A few advantages of the postmodern feminist perspective included the (1) understanding of gender as a legitimate category to be analyzed, (2) importance of subjective experiences from the women in the cohort, and (3) balances of power between instructors and students. Specifically, how female students interacted with instructors and other male/female students. Several of the TEC programs, such as the welding, construction, and auto collision programs, to name a few, are traditionally composed of more male than female students. Therefore, a female in one of the traditionally male dominated programs is viewed as a minority in that program. 


\section{Design of the Study}

\section{Setting}

The research was conducted at an urban community college technical education center located in Kansas City, Kansas. KCKCC offers courses at the Technical Education Center which is located one mile away from the main campus. According to the KCKCC's webpage (kckcc.edu), as of 2020, KCKCC served approximately 5,361 undergraduate and technical education domestic and international students. Of the total student population, $60.4 \%$ were female, $39.6 \%$ were male, and 4,946 were Kansas residents, while 378 were Missouri residents. KCKCC's student body was made of $43.4 \%$ white, 20.2\% Black/African American, and 24.6\% Hispanic students. The age demographics were as follows: under 18 years old, 16.1\%; 18-19 years old, 24.1\%; 20-21 years old, 13.8\%; 22-24 years old, 10.3\%; 25-29 years old, 12.2\%; 30-34 years old, 7.2\%; 35-39 years old, 5.4\%; 40-49 years old, 5.4\%; 50-64 years old, 3.6\%, and 65 and older, $2.1 \%$.

While KCKCC offers associate degrees, the TEC center cohort programs are certificate programs. Upon program completion, the student earns a certificate in a specific technical area such as building engineering maintenance technology, construction technology, cosmetology, culinary arts, fire science, machine technology, office assistant, or welding technology. A student may apply credits earned for a certificate toward an associate degree outside of the cohort program. For this study, only KCKCC TEC certificate cohort programs were examined. Most TEC center programs are cohorts based on specific completion times ranging from four (4) to 14 months. There are five evening cohort programs at TEC which take 24 months to complete. 


\section{Method}

A mixed-methods design was formulated to address the research questions for this study. Mixed methods research incorporates both qualitative and quantitative approaches (Creswell, 2014). The mixed-method design consisted of a quantitative analysis that explored the past data of high school and postsecondary students within the TEC cohort programs. A qualitative analysis examined the student survey, which consisted primarily of open-ended questions (see Appendix A1), faculty interviews (see Appendix A2), and student interviews (see Appendix A3).

Before the study, the researcher secured Institutional Review Board (IRB) approval from the University of Missouri (see Appendix B1) and research permission from Kansas City Kansas Community College. This study required an exempt review application since the study is of minimal risk to the participants. Even though there were participants under age 18 , the research did not propose a significant amount of risk to justify a higher level of review. Participants were required to review consent information and give their consent in order to participate. The consent to participate section consisted of the following: (1) name and purpose of the study, (2) procedures, (3) benefits for participation, (4) payment information, (5) confidentiality, (6) identification of surveyors, and (7) ability to withdraw or stop participation at any time without penalty (Fink, 2013).

Prior to participation, all participants were informed about their rights to cease participation at any time without penalty via the informed consent and assent acknowledgment. For the student survey, students received an email inviting them to participate in the survey and interview. The informed consent was provided with the email. Additionally, the informed consent/assent was embedded in the beginning of the 
student survey. The student agreed to the consent prior to moving forward to participate in the survey (see Appendix C1). If they did not agree, the survey ended. Participants were also allowed to exit the survey at any time without penalty regardless of how far they had progressed through the survey. The participant again received the informed consent/assent (see Appendix C2) prior to scheduling the interview. Students could stop participation in the interview at any time without penalty.

High school students under age 18 were required to have parental consent to participate in the survey and a virtual interview (see Appendix C3). Parents who agreed to allow their child to participate in the survey and a virtual interview emailed the signed informed consent to the researcher. The parent provided the student's email address in order for the student to participate. Once the parent returned the informed consent to the researcher, the researcher emailed the survey link and interview signup link to the student's provided email address. The consent/assent information was shared in the email request. However, the student did still have the option not to participate even if the student's parents or guardian had agreed to allow them to participate.

Faculty were given informed consent (see Appendix C2) prior to scheduling the virtual interview. Once the interview was scheduled, the consent/assent was provided to the faculty member before the interview. The faculty was able to request to end the interview at any time without penalty.

To answer the qualitative research questions, a Microsoft Office 365 forms survey was sent to students who have completed a KCKCC TEC program, students who were currently enrolled in the TEC cohort programs, and students who had stopped out of a TEC program. Only one survey per student was allowed to be submitted, and the results 
of the survey were electronically recorded in the researcher's Microsoft Office 365 drive files. The results were anonymous. The Microsoft Office 365 drive was password protected, as were the computers that accessed the drive. The survey consisted of basic demographic information that included both open and closed-ended questions, along with multiple-choice questions. The majority of the surveys relied on multiple-choice questions because they have proven to be more efficient and reliable (Fink, 2013). Openended questions on the survey gave the respondents a chance to express their opinions in their own words (Fink, 2013). The survey was intended to be short, no more than 15 to 20 minutes. The collected data were extracted from the Microsoft Office 365 drive and uploaded to Microsoft Excel for basic analysis of the non-open-ended questions. These basic analyses consisted of percentages of totals and averages. The open-ended questions were reviewed and examined for common themes.

Before the survey was sent to the student groups, the questions were pilot tested to ensure the data produced useful results (Fink, 2013). The individuals who were asked to participate in the pilot test were reminded that participation is not mandatory. Before participation, each person was given an informed consent document (see Appendix C1) to review, and they had the option to stop participation at any time. Pilot test participants were employees of KCKCC. Specifically, KCKCC faculty and staff who worked closely with the TEC programs and high school students. Each of the individuals had a specific understanding of higher education and provided valuable feedback regarding the clarity of the questions. Having the opportunity to test the survey before the actual participation helped to ensure the survey questions were understandable. 
Students also had the opportunity to participate in a virtual interview and share information about their experience in one of the 15 TEC cohort programs. Students were invited to sign up for an interview session at the same time they were invited to participate in the survey. The email request included a link for the participant to select a time to be interviewed. Also, students who participated in the survey received an autogenerated message upon completion of the survey providing the interview signup link for the students to select an interview time. Before the start of the interview, the researcher presented the consent/assent (Appendix C2) and reminded the participants they could end the interview at any time without penalty. The researcher asked questions about the student's experience in the TEC cohort program to better understand the overall responses from the survey. The interviews lasted approximately 15-20 minutes and took place virtually utilizing Microsoft Teams. The discussion was recorded and transcribed. The researcher reviewed the interviews to identify common themes.

The additional qualitative research questions were answered by conducting TEC individual faculty interviews of the 15 TEC cohort programs. The faculty were asked to discuss their experience related to the curriculum planning and the course offering of cohort models that they oversee. Faculty were asked to reflect on the interactions with the students and the interactions between the students within the cohort program. The interviews were conducted in a virtual format over Microsoft Teams and lasted approximately 30 minutes. The discussion focused on the faculty's experience with the (1) curricular structure of the program, (2) history of the TEC cohort program, (3) student connectedness, (4) course delivery options, (5) schedule of courses, (6) strengths, and (7) future goals of the programs. Participation in interviews was voluntary and faculty were 
given an informed consent form before participation. To examine the quantitative research questions, the researcher reviewed past and current KCKCC TEC student data since 2008. Specifically, the report examined what programs students were enrolled in, whether or not students graduated from their program, race, gender, ethnicity, and age. This information was provided by KCKCC's Institutional Research team. Statistical analysis was used to explore the data and analyze the program completion of both groups over time.

\section{Participants}

Participants were selected using a convenience sample defined by Fink (2013). Participants were divided into quota samples, which are subgroups in specific portions (Fink, 2013). The study participants consisted of KCKCC TEC students, including high school students and postsecondary students $(\mathrm{n}=3308)$. Students could participate in the study regardless of their progress in the program, so currently enrolled, returning students, graduated, and stop-out students could participate.

Participants were identified based on TEC certificate program admission. This information was housed in the Ellucian Database System used by KCKCC for all student record keeping. KCKCC's Intuitional Research department provided graduation reports to determine the students who had successfully completed TEC programs, including demographic information. Student email addresses were included in the report, and students were contacted via their official KCKCC student email address.

A total of 3601 emails were sent to students over age 18 requesting participation in the survey and interview. A total of 42 students participated in the survey, and three (3) participated in the student interviews. High School counselors were emailed and asked to 
contact the parents of 204 students that were under age 18 to request permission for their student to participate in the survey and interview. One student under age 18 participated in the survey.

The TEC faculty members of the TEC programs for both high school and postsecondary students were included in the study. These individuals have met the Higher Learning Commission (HLC) regional accreditation standards to teach at the community college undergraduate level. The minimum standards include an earned master's degree in the content area or a master's degree in any discipline, plus 18 hours in the content area. Additionally, the faculty at KCKCC was all part of the KCKCC Faculty Association, meaning the faculty are union members. There are 29 faculty members associated with the 15 TEC programs. The faculty were emailed and asked to participate in a virtual interview. A total of ten (10) faculty participated in virtual interviews. Many faculty were instructors within the same program, and some programs did not have any faculty participants.

\section{Data Analysis}

All quantitative data were coded and stored in a statistical analysis software system. Basic descriptive statistics were extracted from the demographic information provided by respondents. This information consisted of frequency statistics. Normality was assumed since the data consisted of more than 30 subjects.

For the historical data provided by KCKCC, the specific statistical analysis was determined based on the data collected. For each of the four research questions, Pearson's chi-square test was used. The data used to answer each question was categorical, and a chi-squared test was used to determine if a relationship existed between 
two categorical variables (Field, 2013). Chi-square tests compare frequencies in certain categories to the frequencies that would be expected in each category by chance (Field, 2013).

The qualitative analysis of the interviews and open-ended survey questions was guided by Merriam's (2009) data analysis techniques. This approach suggested an open coding process that involves reading the responses to find segments of data that relate to the research questions. The segments were considered units, and the units were compared to one another to identify systemic and meaningful categories, followed by sorting the types of data to be mutually exclusive. After the categories and subcategories were identified, then the interrelationships and links between groups were examined to determine a corresponding concept, theory, or model.

\section{Credibility of the Study}

To determine the credibility of the study, a holistic viewpoint of all aspects of the study should be considered. This study did not examine the information from one perspective, but several methods were utilized: (1) survey, (2) obtained data set, (3) student interviews, and (4) faculty interviews. These various methods all contributed to the mixed method study design. Creswell (2014) argued that mixed method studies provide a stronger understanding of the problem rather than quantitative or qualitative methods alone.

Specifically, considering the quantitative data, the vast number of subjects lends itself to data integrity over fewer subjects. For example, this study had 3308 subjects for data analysis rather than only ten subjects. The fewer number of participants has the potential to limit the study's generalizability in quantitative research. The data set 
received by KCKCC was reviewed and coded. During the review, any data errors were reviewed and corrected, if needed. The coding and data error corrections were documented. Describing and documenting the processes is critical for data credibility (Creswell, 2014). The statistical analysis was conducted using SPSS rather than hand calculations to reduce the chance of errors. Also, the statistical analysis was performed with a 99\% confidence level rather than the standard $95 \%$ confidence level. The higher confidence level demonstrated the strength of the results.

Qualitative data were gathered utilizing two different methods, interviews, and surveys, for two different populations, students and faculty of the TEC cohort program. The interviews took place virtually rather than face to face, which allowed the participants to select the location of the interview for themselves. The participants all seemed comfortable and relaxed in their chosen settings. Their level of comfort would indicate they were providing authentic answers (Cope, 2014). The responses provided from the faculty interviews, student interviews, and open-ended survey questions were all similar in nature. When the responses are consistent, data dependability presence can be considered (Cope, 2014). A total of ten TEC cohort program faculty participated in the interviews. The faculty who participated did not represent all the TEC programs. Only three TEC cohort program students participated in interviews. This is not many student participants, and it cannot be assumed that the responses from the students are transferable to the entire TEC cohort program of students. The survey had 42 participants. Since more than 30 individuals participated, the normality of the data can be assumed. When reviewing the responses to identify themes, the researcher's bias or viewpoints did not impede the interpretation, and the findings were derived directly from 
the data. To demonstrate this practice, quotes should be shared in the results (Cope, 2014).

Overall, the data were collected in a thorough manner. However, given more time, the number of participants could have been increased. The participants were invited to participate and multiple invitations to participate were sent, along with reminder messages to those who agreed to participate. The research did try not to overwhelm the participants with too many repeated requests. Since the researcher is an employee of the institution studied, it was important that the participants did not feel coerced or that there was an imbalance of power. The data analysis was free of bias.

\section{Definitions of Key Terms}

Cohorts/cohort model/cohort program: A cohort model is a structure used for academic programming. Students start the academic program at the same time, and they continue to enroll in a set of predetermined courses for the duration of the program until completion (Lei, et. al, 2011). The cohort model allows students to start a program and progress through the curriculum together until completion (Bista \& Cox, 2014).

Dual Enrollment: Classes in which the high school students travel to the college campus to take courses prior to graduation during the academic year or in summer (KBOR 8 b 1 vii) and classes in which college faculty travel to the high school to teach separate courses to high school students (KBOR 8b 1 vii).

High school students: Students who are enrolled in TEC programs who have not graduated high school or earned their general education diploma (GED).

Learning communities: A learning community is similar to a cohort, consisting of a group of students who start a program together, proceed through the program, and 
conclude at approximately the same time (Maher, 2005). In this study, learning communities are used synonymously with cohort models.

Non-Cohort program: Opposite of a cohort program. A program that allows students to enroll in courses required for a program in any order and the students are not required to progress through the academic requirements together.

Postsecondary Students: Students enrolled in a college program who have graduated high school or earned their GED.

Retention: Students' continual enrollment from one semester to the next until completing the degree (Hagedorn, 2005).

\section{Significance of the Study}

This study will lead to a greater understanding of the retention for students in the TEC programs at KCKCC and the inhibiting factors of program completion. The knowledge gained from this study will provide a more in-depth understanding of TEC cohort program completion. With this information, $\mathrm{KCKCC}$ will be able to develop a more strategic approach for allocating for resources each student to better enable them to complete their programs. This information will help more students overcome barriers and achieve their goals. Currently, KCKCC makes educational assumptions and uses past literature and ideas from other colleagues about how to promote student success and retention within the TEC cohort programs. However, with the information gained from this study, KCKCC will know specifically what resources students find helpful in the cohort program or what obstacles should be addressed. By taking strategic action based on the research findings, more students should have a greater opportunity to complete their TEC cohort program. 


\section{Research Questions}

The research questions guiding this study were as follows:

1. Is graduation of a TEC cohort program independent of a student's level (high school and postsecondary)?

2. Is graduation of a TEC cohort program independent of a student's race/ethnicity?

3. Is graduation of a TEC cohort program independent of a student's age at the start of the program?

4. Is graduation of a TEC cohort program independent of a student's gender?

5. What are the reasons for students' continued enrollment in the TEC cohort program?

6. What forms of support within the TEC cohort program encouraged students' program completion?

7. According to students, why do TEC cohort models support program completion?

8. What supportive contributions do TEC cohort faculty perceive should be provided to students?

\section{Connections to Conceptual/Theoretical Framework}

The theoretical frameworks that guided this study were based on Bolman and Deal's (2017) four organizational frames and Tinto's (1993) retention theory. Just as the theories guided the study, the results from the study correspond with the frameworks as well. Additionally, the results were also supported by the adult learning theory, which was initially thought to be more of a supportive theory.

The study results were supported by Bolman and Deal's four organizational frames, (1) structural, (2) human resource, (3) political, and (4) symbolic. However, the two most supported frames were the structural and human resources frames. 
Overwhelmingly, the interviews and surveys all revealed the importance of relationships. The participants discussed how the relationships evolved among the different student levels and how students remained in contact after completing the program. Faculty and student relationships were also a continual theme from both students and faculty. The human resource frame is focused solely on the people and their relationships (Bolman \& Deal, 2017), which is in tandem with the survey results. The structure of a cohort is the core of the model. Cohorts are all about defined structure and specific role responsibilities. Therefore, it was not a surprise that the structural frame was apparent in the results. Not only was the program structure mentioned, but it was clear that a breakdown in the structure for high school students transitioning to the postsecondary level led to challenges in program completion. Consequently, several recommendations are rooted in the structural framework.

Retention theory centers on the necessities for degree completion and focuses on establishing personal bonds coupled with intellectual support (Tinto, 1993). Relationships and the bonds formed from those relationships were a continual theme in the results. Additionally, both students and faculty reported the academic challenges that students had to overcome within the program in the interviews. Together these results are indicative of the retention theory, whereas one aspect of the theory is lacking. Exclusively, academic ability is a challenge for the students. Therefore, the coupling needed for the retention theory to actively retain students is dysfunctional. Consequently, another recommendation was established based on Tinto's retention theory.

Lastly, adult learning theory was not anticipated as a strong theoretical framework. However, it was apparent when reviewing the data. The postsecondary 
students showed significant differences from the high school students. The theoretical frameworks that guided this study were based on Bolman and Deal's (2017) four organizational frames and Tinto's (1993) retention theory. Just as the theories guided the study, the results from the study correspond with the frameworks as well. Additionally, the results were also supported by the adult learning theory, which was initially thought to be more of a supportive theory.

\section{Participants and Data Collection}

One set of participants in this study of TEC cohort programs were faculty members of the KCKCC TEC program. The faculty were invited to participate in individual virtual interviews. The TEC program at KCKCC has 29 faculty, and ten of the 29 participated in the study. The ten faculty members represented the following TEC programs: automotive technology, building and property maintenance, commercial and residential equipment technology, culinary arts, machine technology, welding technology, and computer information systems technology. Unfortunately, not all the TEC programs were represented by the faculty. Two of the programs, automotive technology, and culinary arts, had multiple faculty members participate in the study.

The other set of participants in this study were students enrolled in a KCKCC TEC program between the fall of 2009 and the fall of 2020 . The students were invited to participate in an interview and survey. Students over the age of 18 were emailed twice requesting participation, and students under age 18 were only contacted after parental consent was obtained. The survey was an electronic survey with a link to the survey embedded in the email for students. A total of 42 students participated in the student survey. Of the 42 participants, one was under the age of 18; there were 19 females, 21 
males, and one participant listed "other" for gender. For race, 16 participants were Black or African American, 14 were white, one was Asian, one was multi-racial, and nine listed "other" for race. For ethnicity, five participants were Hispanic/Latino and 34 were NonHispanic. Three students participated in a virtual one-on-on interview. Two of the students completed two TEC programs. Two students started TEC programs as high school students. Lastly, Kansas City Kansas Community College provided a data set of students enrolled in TEC programs from the fall of 2009 until fall 2020 that was used to address four of the research questions. The report included student gender, race/ethnicity, birthdate, and graduation status as well as if the students were high school or postsecondary. Of the subjects represented in the data set, $25.4 \%$ were female and $74.6 \%$ were male, as represented in Figure 1. 
Figure 1

\section{Gender of TEC Cohort Program Subjects}

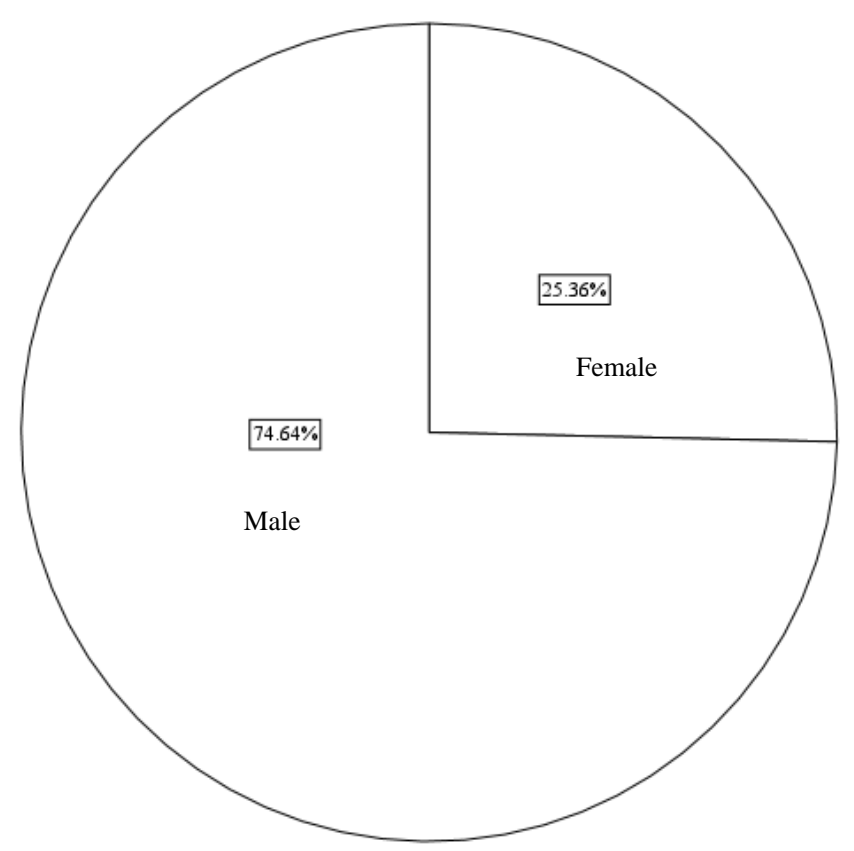

Figure 2 represented the student level when the student started the program, $34.85 \%$ were high school students, whereas $65.15 \%$ were postsecondary students.

Figure 2

High School or Postsecondary TEC Cohort Program Student Levels of Participants

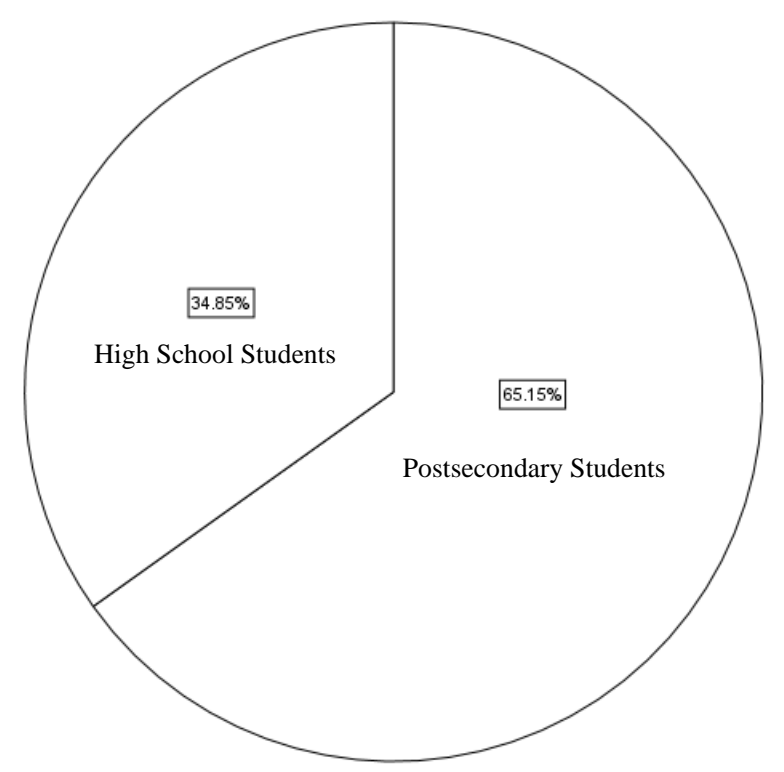


Participants ranged in age from 14 years old to over 70 years old. The majority of participants were between the age of $15-19$, followed by participants ages $20-24$, see Table 1.

Table 1

Age of TEC Cohort Program Participants

\begin{tabular}{|lr|}
\hline Age & Total Participants \\
\hline $10-14$ & 1 \\
\hline $15-19$ & 1738 \\
\hline $20-24$ & 529 \\
\hline $25-29$ & 322 \\
\hline $30-34$ & 231 \\
\hline $35-39$ & 166 \\
\hline $40-44$ & 98 \\
\hline $45-49$ & 80 \\
\hline $50-54$ & 69 \\
\hline $55-59$ & 47 \\
\hline $60-64$ & 18 \\
\hline $65-69$ & 5 \\
\hline $70-74$ & 1 \\
\hline Age not provided & 3 \\
\hline
\end{tabular}

The data were first reviewed for duplicate entries based on the semester of enrollment. Ultimately, the subject's first semester of enrollment was recorded along with the high school or postsecondary student type, gender, race/ethnicity, birthdate, program enrollment, graduation status. Records of 27 subjects who stopped enrollment and later re-enrolled in a TEC program after one year of non-attendance remained in the dataset. Students who had not enrolled in one year were considered inactive at KCKCC. Participants whose last record of enrollment was within one year of the analysis (fall 2020, spring 2020, or summer 2020) were excluded from the study. These students were 
considered active and had not yet had a chance to graduate from a TEC program or go more than one year without enrollment. A total of 123 records of participants were enrolled in more than one TEC program and remained in the data set.

Upon review of the participants' student level, high school or postsecondary, six records were corrected. Those records started with an initial entry of postsecondary student status for the participant and then switched to a high school student status for the subsequent semesters of enrollment in the same program. It is impossible for a student status to shift from postsecondary then to high school student status. However, it is standard for student status to change from high school to postsecondary when the student graduates from high school and continues enrollment.

It is worth noting that the data set combined race and ethnicity. The labels for race/ethnicity were standard labels used for Integrated Postsecondary Education Data System (IPEDS) reporting. Since ethnicity was combined with race, the data could not be separated as race information was not provided for the ethnicity of participants. It is recognized that Hispanic is not a race but an ethnicity. Students reported as nonresident aliens (NRA) were recorded as unknown. NRA is not an identifiable race or ethnicity. Due to the low numbers of American Alaska Native and Hawaiian Pacific Islander, those two races were combined into one category.

To determine age, a simple formula was used. The first date of classes was entered for the first semester of enrollment for each participant. Then a formula was used to calculate the participants' age based on the start of the program and birthdate. Based on the participants' birth year, they were also coded based on their respective generations. Four generations were used, (1) baby boomer generation were those born 
between 1943-1960, (2) generation X were those born between 1961-1981, (3) millennial generation were those born between 1982-2003, and (4) generation z was those born after 2003 (Strauss \& Howe, 1991).

The final four research questions were qualitative. From the data set provided by KCKCC, the researcher was able to use participants' birthdates to determine their current age. Students who were under age 18 were not sent the standard email request for participation in the study. The high school counselors were contacted and asked to email the parents of students who were enrolled in a TEC program to request participation from their students. If the parent agreed to allow the student to participate, the parent was asked to send a consent form to the researcher with the student's email address. The researcher then emailed the student with the request to participate information. There were 204 students under age 18 that the researcher was unable to reach out to directly. Those who were age 18 and older were emailed twice and asked to participate in the study by completing a survey and participating in a virtual interview. The researcher emailed a total of 3601 students for participation. KCKCC student emails and personal emails were provided, and both were emailed. The email included the link to the survey and a link to Microsoft Bookings. The link for Microsoft Bookings allowed participants to select a virtual interview time with the researcher. Once a time was selected, the participant and researcher received confirmation and a link to a Microsoft teams video meeting. The email also included an informed consent document. Prior to participation, informed consent was again provided.

Faculty teaching in the TEC cohort were emailed and invited to participate in a virtual interview with the researcher. A total of 29 faculty were emailed five times, ten 
faculty members participated. Several others responded that they were unable to participate due to time constraints. The faculty received the same Microsoft Bookings link and were instructed to select an interview time. Once a time was selected, a confirmation email with the Microsoft Teams virtual meeting link was sent to the faculty member and researcher. The email also included an informed consent document. The faculty gave informed consent prior to participation in the interview. All faculty and student interviews were recorded. The recordings provided a transcription that was coded for themes. The student survey was mainly open-ended questions.

\section{Presentation of the Data}

Presented in this section are the results of the study. The results included both quantitative and qualitative analysis. The first four research questions were quantitative and the last four questions were qualitative. The quantitative research questions were analyzed using a Chi-square test of independence. A chi-square statistic was selected to answer the research questions because the data set included categorical and nominal data. According to Field (2012), categorical data are data the fall into a category and nominal data are data that are represented by numbers. Additionally, chi-square statistic measures how a model compares to actual data; therefore, the statistic compares expected results to actual results (Field, 2012). The expected results were determined by utilizing a weighted average. Chi-square statistics are reported with degrees of freedom and sample size (in parentheses), the Pearson chi-square value, and the significance level. The significance level in the SPSS software systems defaults to $95 \%$. However, for this study, a 99\% significance level was used as that is a lower likelihood of Type I error, meaning producing a significant result when the Null Hypothesis is true. 


\section{Research Question One}

Is graduation of a TEC cohort program independent of a student's level (high school and postsecondary)?

To answer research question one, a Chi-square test of independence was used. Based on the results of the Chi-square test of independence found in Table 2, this study indicated the number of students who graduated from a TEC cohort program differed by high school and postsecondary levels, $\chi^{2}(1, \mathrm{~N}=3308)=114.27, \mathrm{p}<.001$.

Table 2

Chi-Square Test for Graduation based on TEC Cohort Program Student Level

\begin{tabular}{lc|c|c|c|c|} 
& Value & df & $\begin{array}{c}\text { Asymptotic } \\
\text { Significance } \\
\text { (2-sided) }\end{array}$ & $\begin{array}{c}\text { Exact Sig. } \\
\text { (2-sided) }\end{array}$ & $\begin{array}{c}\text { Exact Sig. } \\
\text { (1-sided) }\end{array}$ \\
\hline Pearson Chi-Square & 114.269 & 1 & .000 & .000 & .000 \\
\hline
\end{tabular}

Since the $p$-value is less than our chosen significance level $(\alpha=0.01)$, we can reject the null hypothesis and conclude that there is an association between high school and postsecondary student level and whether or not they graduated from a TEC cohort program. The data shown in Table 3 revealed postsecondary students were more likely to graduate than were high school students. Postsecondary students graduated 1643 students, whereas only 1509 postsecondary students were expected to graduate. Additionally, fewer postsecondary students did not graduate (512) than were expected not to graduate (647). For the high school students only 673 students graduated, whereas 808 students were expected to graduate. Also, there were more high school students who did not graduate (480) than expected (346). The expected values were gained from the results of the Person's Chi-Square. 
Table 3

TEC Cohort Program High School and Postsecondary Student Actual and Expected Graduation Status

\begin{tabular}{llccc}
\hline & & Not Graduated & Graduated & Total \\
\hline Postsecondary Students & Actual Count & 512 & 1643 & 2155 \\
& Expected Count & 647 & 1509 & 2155 \\
& & & & \\
\hline High School Students & Actual Count & 480 & 673 & 1153 \\
& Expected Count & 346 & 808 & 1153 \\
& & & & 3308 \\
\hline Total & Actual Count & 992 & 2316 & 3308 \\
& Expected Count & 992 & & \\
\hline
\end{tabular}

\section{Research Question Two}

Is graduation of a TEC cohort program independent of a student's racelethnicity?

A chi-square test of independence was performed to examine the relation between students' race/ethnicity and whether the students graduated or not from a TEC cohort program. The relation between these variables was significant, $\chi^{2}(6, \mathrm{~N}=3308)=51.91$, $\mathrm{p}<.001$. Since the $\mathrm{p}$-value $(\mathrm{p}<0.01)$ is less than our chosen significance level $(\alpha=$ 0.01), we can reject the null hypothesis and conclude that there is an association between students' race/ethnicity and whether they graduated from a TEC cohort program. Specifically, data in Table 4 reflected that more students who were White (934) graduated more than expected (856) and more Asian students (102) graduated than expected (95). Students who reported more than one race graduated as expected (101). Less Black/African American students (545) graduated than expected (558). Similarly, 
Hispanic students (489) graduated less than expected (543). Lastly, the unknown students (129) graduated less than expected (147).

Table 4

TEC Cohort Program Participant Race and Ethnicity Actual and Expected Graduation Status

\begin{tabular}{|c|c|c|c|c|}
\hline & & Graduated & Not Graduated & Total \\
\hline \multirow{2}{*}{$\begin{array}{l}\text { American } \\
\text { Alaska Native } \\
\text { or Hawaiian } \\
\text { Pacific Islander }\end{array}$} & Actual Count & 9 & 16 & 25 \\
\hline & $\begin{array}{l}\text { Expected } \\
\text { Count }\end{array}$ & 8 & 18 & 25 \\
\hline \multirow[t]{2}{*}{ Asian } & Actual Count & 33 & 102 & 135 \\
\hline & $\begin{array}{l}\text { Expected } \\
\text { Count }\end{array}$ & 41 & 95 & 135 \\
\hline \multirow{2}{*}{$\begin{array}{l}\text { Black or African } \\
\text { American }\end{array}$} & Actual Count & 252 & 545 & 797 \\
\hline & $\begin{array}{l}\text { Expected } \\
\text { Count }\end{array}$ & 239 & 558 & 797 \\
\hline \multirow[t]{2}{*}{ Hispanic* } & Actual Count & 286 & 489 & 775 \\
\hline & $\begin{array}{l}\text { Expected } \\
\text { Count }\end{array}$ & 232 & 543 & 775 \\
\hline \multirow[t]{2}{*}{ Multi-racial } & Actual Count & 44 & 101 & 145 \\
\hline & $\begin{array}{l}\text { Expected } \\
\text { Count }\end{array}$ & 44 & 102 & 145 \\
\hline \multirow[t]{2}{*}{ Unknown } & Actual Count & 80 & 129 & 209 \\
\hline & $\begin{array}{l}\text { Expected } \\
\text { Count }\end{array}$ & 63 & 146 & 209 \\
\hline \multirow[t]{2}{*}{ White } & Actual Count & 288 & 934 & 1222 \\
\hline & $\begin{array}{l}\text { Expected } \\
\text { Count }\end{array}$ & 367 & 856 & 1222 \\
\hline \multirow[t]{2}{*}{ Total } & Actual Count & 992 & 2316 & 3308 \\
\hline & $\begin{array}{l}\text { Expected } \\
\text { Count }\end{array}$ & 992 & 2316 & 3308 \\
\hline
\end{tabular}

Note: *designates ethnicity. 


\section{Research Question Three}

Is graduation of a TEC cohort program independent of a student's age at the start of the program?

A chi-square test of independence was used to determine if there were a significant relationship between students' age when they started a TEC cohort program and whether or not they graduated from a TEC cohort program, $\chi^{2}(12, \mathrm{~N}=3305)=$ $124.12, \mathrm{p}<.001$. Since the $\mathrm{p}$-value is less than our chosen significance level $(\alpha=0.01)$, we can reject the null hypothesis and conclude there is an association between students' age and whether they graduated from a TEC cohort program. As can be seen by the frequencies cross-tabulated in Table 5, students who were 19 and younger did not graduate as expected. The students between ages 20 and 59 graduated at higher level than expected and students who were 60 and older graduated at a level that was relatively close to expected. 
Table 5

TEC Cohort Program Participant Age Actual and Expected Graduation Status

\begin{tabular}{|c|c|c|c|c|c|}
\hline & & & Not Graduated & Graduated & Total \\
\hline Age & $10-$ & Actual Count & 0 & 1 & 1 \\
\hline \multirow[t]{25}{*}{ Coded } & 14 & Expected Count & .3 & .7 & 1 \\
\hline & $15-$ & Actual Count & 658 & 1080 & 1738 \\
\hline & 19 & Expected Count & 522 & 1216 & 1738 \\
\hline & $20-$ & Actual Count & 132 & 397 & 529 \\
\hline & 24 & Expected Count & 159 & 370 & 529 \\
\hline & $25-$ & Actual Count & 73 & 249 & 322 \\
\hline & 29 & Expected Count & 97 & 225 & 322 \\
\hline & $30-$ & Actual Count & 48 & 183 & 231 \\
\hline & 34 & Expected Count & 69 & 162 & 231 \\
\hline & $35-$ & Actual Count & 30 & 136 & 166 \\
\hline & 39 & Expected Count & 50 & 116 & 166 \\
\hline & $40-$ & Actual Count & 15 & 83 & 98 \\
\hline & 44 & Expected Count & 29 & 67 & 98 \\
\hline & $45-$ & Actual Count & 15 & 65 & 80 \\
\hline & 49 & Expected Count & 24 & 56 & 80 \\
\hline & $50-$ & Actual Count & 9 & 60 & 69 \\
\hline & 54 & Expected Count & 21 & 48 & 69 \\
\hline & $55-$ & Actual Count & 4 & 43 & 47 \\
\hline & 59 & Expected Count & 14 & 33 & 47 \\
\hline & $60-$ & Actual Count & 6 & 12 & 18 \\
\hline & 64 & Expected Count & 5 & 13 & 18 \\
\hline & $65-$ & Actual Count & 1 & 4 & 5 \\
\hline & 69 & Expected Count & 2 & 4 & 5 \\
\hline & $70-$ & Actual Count & 1 & 0 & 1 \\
\hline & 74 & Expected Count & 1 & 1 & 1 \\
\hline \multirow[t]{2}{*}{ Total } & & Actual Count & 992 & 2313 & 3305 \\
\hline & & Expected Count & 992.0 & 2313.0 & 3305 \\
\hline
\end{tabular}

The trend seen in these data resulted in further analysis of age by looking at generation. A chi-square test of independence was used to determine if there was a significant relationship between students' generational age and whether or not they graduated from 
a TEC program, $\chi^{2}(3, \mathrm{~N}=3305)=204.28, \mathrm{p}<.001$. More baby boomers graduated (89) than expected (67), similarly more generation X students graduated (390) than expected (313). However, less millennials graduated (1835) than expected (1896). For generation $\mathrm{Z}$ students, zero graduated and 35 were expected to graduate, see Table 6 .

Table 6

TEC Cohort Program Generational Age Actual and Expected Graduation Status

\begin{tabular}{llrrr}
\hline & & Not Graduated & Graduated & Total \\
\hline Baby & Actual Count & 9 & 89 & 98 \\
Boomers & Expected Count & 30 & 69 & 98 \\
\hline \multirow{2}{*}{ Generation X } & Actual Count & 59 & 390 & 449 \\
& Expected Count & 135 & 314 & 449 \\
\hline \multirow{2}{*}{ Millennial } & Actual Count & 874 & 1834 & 2708 \\
& Expected Count & 813 & 1895 & 2708 \\
\hline \multirow{2}{*}{ Generation Z Z } & Actual Count & 50 & 0 & 50 \\
& Expected Count & 15 & 35.0 & 50 \\
\hline \multirow{2}{*}{ Total } & Actual Count & 992 & 2313 & 3305 \\
& Expected Count & 992 & 2313 & 3305 \\
\hline
\end{tabular}

\section{Research Question Four}

Is graduation of a TEC cohort program independent of a student's gender?

A chi-square test of independence was performed to examine the relation between students' gender and whether or not the students graduated from a TEC cohort program. The relation between these variables was not significant, $\chi^{2}(1, \mathrm{~N}=3308)=3.17, \mathrm{p}=$ .075. Since the $p$-value is greater than our chosen significance level $(\alpha=0.01)$, we fail to reject the null hypothesis as the results do not provide support for a relationship between gender and graduation. The frequencies are noted in Table 7. While there are minor differences, these variations are not significant. 
Table 7

TEC Cohort Program Gender Actual and Expected Graduation Status

\begin{tabular}{lllll}
\hline & & Not Graduated & Graduated & Total \\
\hline Female & Actual Count & 272 & 567 & 839 \\
& Expected Count & 252 & 587 & 839 \\
\hline Male & Actual Count & 720 & 1749 & 2469 \\
& Expected Count & 740 & 1729 & 2469 \\
\hline \multirow{2}{*}{ Total } & Actual Count & 992 & 2316 & 3308 \\
& Expected Count & 992 & 2316 & 3308 \\
\hline
\end{tabular}

\section{Research Question Five}

What are the reasons for students' continued enrollment in the TEC cohort program?

To answer this qualitative research question, the researcher interviewed ten KCKCC TEC cohort TEC faculty members and three students. Simultaneously, an openended survey was sent to KCKCC TEC cohort students, a total of 42 students participated in the survey. The students who participated in the survey were enrolled, completed, or had not taken a course within one year out of a KCKCC TEC cohort program.

After the conclusion of all the interviews, the responses were transcribed and reviewed for themes. Several themes emerged about students' reasons for continued enrollment in a TEC cohort program. For example, the faculty believed the TEC cohort program provided students with hands-on learning opportunities and experiences. The faculty also mentioned that many of the students in the program preferred hands-on learning rather than traditional academic learning. Therefore, the TEC programs were a good fit with their strong hands-on approach. The students' responses from the survey supported the faculty in this regard. Students mentioned that the hands-on training, program training, and learned skills provided motivation for their continued enrollment in the program. 
Another theme that appeared was the cohort structure as a reason for students' continued enrollment. A faculty member said, "The cohort's concentrated structure actually saved students, because students are aware of the duration upfront, they are focused and motivated to continue." Students do not have to select courses each semester as the courses are pre-selected for them. Students do not have to worry about their schedule changing or accommodating a schedule adjustment each semester. They also noted how the program courses build on each other as the students' progress through the program. Some programs are able to have self-paced elements, which faculty thought students appreciated. One faculty member said, "I think students like to do it on their own time, make sure they master a skill before moving onto the next one." Other program faculty member said that there was not an opportunity for self-pacing and some students struggled to keep up. Another faculty member said, "Some students just cannot keep up, they fall behind for non-attendance, academic challenges, all kinds of reasons and they cannot get caught back up.”

Both students and faculty expressed that relationships were a reason for continued program enrollment. Students included friendships with fellow students as reasons for continuous enrollment in the program. The faculty observed similar interactions, including students forming friendships, helping each other out, and providing encouragement among each other. For instance, one faculty member discussed the importance of the students' relationships as he witnessed the friendship extending beyond the program. He observed students staying connected once they graduated and working in the desired industry. 
The dynamic between the high school students and postsecondary students was also discussed by the faculty who had both student types in class. Ultimately, the faculty indicated the students connected regardless of their student status. Some program faculty mentioned the secondary students tried to impress the postsecondary students. One faculty member said, "The postsecondary students avoided the high school students until group work required them to work together and bonds were eventually formed." Some program faculty discussed how postsecondary students would ask high school students for help and then connections started to develop. The faculty indicated group work was very important as it is mirrored workplace situations. Faculty did mention occasional tensions would take place between students; however, the tensions were resolved quickly. The surveys and interviews included competitions against other colleges, including how those experiences benefited students and encouraged continued enrollment. The competitions allow the students to continue to build strong relations with their classmates and receive direct support from their professors. Not only did the competitions enhance relationships, but they also created a sense of pride and loyalty to the TEC cohort program and KCKCC. A faculty member said, "The students get to work on a project of their own with another classmate, seeing some assistance, and they develop a sense of pride, loyalty, and establish a different kind connection."

Career options after program completion was a repeated theme from both students and faculty. Students shared that they wanted to complete the program to gain knowledge for employment or start their own business. For example, one student described how his culinary program had a classroom set up like a home kitchen for him to work so he could get comfortable being in other people's homes while making repairs. 
He said, "It was really nice to have an idea of what it would be like to work in a customer's home." Faculty expressed that they strive to provide students with real workplace settings and situations so they can experience it before employment. The main objective of this is to determine if this is the right career field and to help students be more comfortable when they start a job. One faculty member shared a story about a student who did not realize he was afraid of heights until he had to go up on a forklift. Afterward, the student had to determine if that was the right career field for him. Creating these situations is better for the students because they are in a controlled environment with support from the faculty and other students rather than in the workplace, according to faculty.

Completing the certificate to obtain an associate or bachelor's degree was sighted as a reason for continued enrollment by the faculty and students. The faculty mentioned high school students have an opportunity to earn college credits before they even graduate high school and they felt this provided opportunities to students. Many faculty members had stories about their students being accepted into advanced programs or universities and how much further ahead they were than other students. Students also mentioned they wanted to start what they finished and complete the certificate. Some students indicated they had future educational goals and the TEC cohort program was the foundation needed to achieve their goals.

Some faculty identified a student's attitude as a reason for students' continued program enrollment. One faculty member said, "I've seen students overcome repeated challenges to complete the program while other students are just looking for a reason to drop out of the program, even if that student is outstanding." Students tended to agree. 
Students' comments that supported the faculty observations included: "I wanted to make a dream a reality," "I've always wanted to do more for myself," and "I'm self-driven." Students also noted they valued the faculty and their own family or kids as reasons for continued TEC cohort program enrollment. One student who stopped out of the program indicated the TEC cohort program did not promote continuous enrollment for them as they were "only enrolling in the program because of personal interest."

\section{Research Question Six}

What forms of support within the TEC cohort program encouraged students' program completion?

Qualitative data obtained from the TEC cohort program faculty and student interviews, along with an open-ended student survey, was used to answer this research question. The faculty interviewed provided an array of support methods that were extended to students to help them complete the TEC cohort program. Many faculty shared KCKCC provided resources and external resources with students. They believed students had no idea what opportunities were open to them since many were firstgeneration college students and, according to faculty, "would have no way of knowing what they do not know." They thought it was their responsibility to share this information with students. Faculty also thought it was their obligation to provide real-life lessons for the students beyond the curriculum. They use of analogies and talk to them about future life planning outside of the students' careers. One faculty member said, "Without trying to sound like a parent, I try to use classroom situations and draw parallels to real-life scenarios and try to talk about how to make good choices." The faculty genuinely care about their students and want them to be successful. Since the faculty 
spend so much time with the students, they felt invested in the students. They can tell if something is wrong with the student and they will pull that student aside and have a conversation to check-in with the student. A faculty member said, "I look at their faces when they walk in the classroom and how they are walking, and I can tell if something is up with a student because I have really gotten to know the students." Many faculty members mentioned having side conversations with students to chat about goals and followed-up if there was a class conflict. The faculty said these side conversations were invaluable and allowed them to connect with the students. Also, students in the TEC cohort program from the USD 500 school district have assigned facilitators who regularly check in with faculty to see how students perform in class. The faculty mentioned this is another resource of support for high school students. Similarly, the high school students' parents contact the faculty for status updates. The faculty found the follow-up from the parents to be useful for high school students. A faculty member mentioned, "I got an email from a parent about a kid in class and I told them how the kid was really doing, then next day, I noticed a big difference in the kid, and he was back on track."

The TEC cohort program structure and assignments were described as tools to promote student support and program completion. One faculty member stated, "I believe the structure leads to success." They believed it was important for students to be aware of the ultimate goal and how each class helped the students achieve that goal. Students did not need to select their classes, and the faculty thought it was one less thing for them to worry about. However, the faculty mentioned the structure of the program also had some limitations. These limitations included (1) multiple cohorts in the program at once, (2) the variable amount of time the high school students and the postsecondary students 
spent in the program, and (3) the number of credits taught each semester. They did not mention that these challenges directly impacted the student's success.

Not only did the faculty consider the structure of the TEC cohort programs but they also discussed the assignments. Faculty all tried to deliver creative assignments that taught the curriculum and provided real-life learning lessons. Faculty in many programs tried to have customized projects for students or allow students to have a self-paced opportunity to work through the curriculum. However, not all programs were able to extend that mode of learning to students. All faculty thought students struggled with math and reading skills. A faculty member said, "it can be hard, some of these kids cannot even read or do basic math." Students agreed, as they mentioned that was the more challenging part of their programs during student interviews. To help support the students, the faculty worked to teach those skills practically. They realized their students are hands-on learners, so they have adapted their teaching style to include hands-on learning for math and reading. One instructor provided extra credit when a student found his intentional spelling errors. This faculty member said, "When I type up the recipe instructions for students, I intentionally have spelling errors in the recipe. When a student points out the spelling error to me, I give them extra credit. This is how I know they are reading." Many instructors ask the students to double or reduce their work as a way to introduce mathematical fractions. A faculty member said, "I will have the students double something or cut in half to build their confidence and let them see how fractions work." Faculty utilize group work activities to allow other students who understand the concepts an opportunity to explain to those who are still struggling. Frequently, hearing the information explained another way or by a classmate helps students grasp the 
information. A faculty member said, "sometimes they just need to hear it from someone else other than me to get it." Some faculty paired students specifically so one student could help another student. A faculty member shared a story about how he had two very talented students, and he did not allow them to work together until later in the semester. He said, "Students need to learn how to help others, and others needed to learn their techniques." He went on to say, "Later in the semester I did let those two students work together and they outpaced all the other student groups." However, this is not the only reason faculty use group work in their curriculum. Faculty claim students ultimately form groups on their own, so they use the natural group dynamics to simulate industry work-like atmospheres. The faculty said the students must work out personality differences and encourage each other, just like in the workplace.

Exposure to workplace simulations and settings was important to the faculty, and they thought job preparation helped to support students. The faculty supported students by receiving annual industry feedback to incorporate into their program to help students be prepared for employment. They also tried to provide students with opportunities to meet potential employers to network. One faculty member ran his program as much like a workplace as he could. He told the students, "earning an F grade would be the equivalent of getting fired."

Relationships were intertwined throughout many of the examples, but students and faculty mainly discussed student relationships. According to the student survey, $76 \%$ of students who graduated from the program experienced support provided by others encouraged them to continue in the TEC cohort program. The students revealed relationships with professors and classmates provided this encouragement. Ten of the 11 
students who were currently enrolled in a TEC cohort program believed the support provided by others encouraged them to continue the program. One student stated, "my classmates and teachers lift me up." As mentioned earlier, the faculty felt a strong connection to the students and developed a relationship with them. The students also build relationships with each other. A faculty member shared that a student climbed up a ladder and then had a panic attack and was afraid to move or come down. The students all rushed to help support the stranded student. They provided encouragement, and the student ultimately made it down the ladder. Another faculty member said, "students have group text messaging chats, and they send reminder notes about upcoming tests and to bring workbooks to class." These relationships help to provide encouragement and confidence for the students, according to faculty.

\section{Research Question Seven}

According to students, why do TEC cohort models support program completion?

The responses to this question were gathered from the TEC cohort student survey and the interviews of the three TEC cohort students. For the student interviews, all three students interviewed completed their program(s). Two of the students completed two different TEC programs. One student was female and the other two were males. Two students started the KCKCC TEC program as high school students. The postsecondary student was angry about his experience with KCKCC. He did not believe that he was treated fairly by the students and faculty in one TEC program. Despite these feelings, he still actively participated in the interview.

The top theme provided by the students to answer this research question was being part of a cohort because of the relationships formed. Students did not feel alone, as 
they were able to develop friendships with their classmates. They said their "classmates made it fun," and they "created bonds with each other." One student stated, "Working with the same group of students encouraged me to continue in the TEC program. I loved working with all of my peers and being able to learn from all of them and created a bond." The students enjoyed being with the same people. They said their classmates motivated them and helped to give them courage. A student said, "You see a lot of courage." Students liked how the cohort model kept everyone on the same page. A high school student directly mentioned the importance of forming relationships with postsecondary students. He said the postsecondary students provided important information and served as a guide.

Aside from the one student who had a negative experience with a faculty, students also discussed the positive relationships they experience with faculty. It should be noted that the dissatisfied student mentioned the faculty in his program was still very supportive. A student said, "The teachers were the ones that I always wanted to come back and learn more from." Other students mentioned how helpful the faculty were. Specifically, they provided support for student competitions and helped to build confidence. One student mentioned how a faculty member said she was "like a whole different girl after the first two semesters." She went on to talk about the confidence she had gained and how she was not as shy and more comfortable with students socially.

Lastly, students appreciated the program's hands-on experience, and they liked coming back to learn and experience more. Students appreciated how they had an opportunity to practice their skills and learn various techniques. They also enjoyed the workplace setting faculty created. One student said, "I would have even liked more 
opportunities for workplace situations, like working outside in the rain, snow, hot days, just to have more work-like experiences."

\section{Research Question Eight}

According to the TEC cohort faculty, what supportive contributions do they perceive should be provided to students?

To answer this research question, only the TEC cohort faculty interviews were considered since the question specifically focuses on the faculty's viewpoint about the supportive contributions they perceive should be provided to students. Many of their responses included a more profound or more elaborate version of the support, tools, techniques, regular program reviews, and current structure. For example, one faculty member said the "program's design was supportive to students," but several faculty also mentioned the "structure could be enhanced to serve students better." The faculty mentioned the amount of classroom and lab time makes it hard for them to offer office hours for students, particularly high school students. A faculty member said, "the high schools arrive on a bus from the school before class starts and they have to ride the bus back to school, so there is not any time outside of class, because they are not here outside of class." They also said it makes it more challenging to keep up with grading, picking up supplies, serving on committees, and so on. One faculty member said, "I teach up to 25 credit hours per semester, and I teach students in a face-to-face format every Monday through Friday from 7:30 am until 3:00 pm with an hour lunch break." Some of the faculty mentioned this structure is hard when there are multiple cohorts going on at once. This makes the student cohort model harder to follow and for the students to make connections and increase the number of credit hours taught by faculty. 
On the other hand, the faculty suggested having different levels for students because not all students are at the same level when they begin the cohort program. For some students, it is a struggle to keep up, some are at the appropriate level, and others are more advanced. Along similar lines, some faculty thought it would be beneficial for students to have two tracks, a full-time track, and a part-time track. The full-time track would be as the program is currently, and the part-time track would have fewer hours per semester but require more semesters for completion. The latter would allow students the opportunity to work while in the program. Many faculty said their students need financial assistance and cannot afford not to work. It was mentioned by a few faculty members that students could benefit from experience in some other related programs to broaden their skill sets. However, the faculty noted this would extend the program completion time for students. Yet, they thought the variety and skills learned would be useful for students.

All faculty mentioned that students could benefit from math and reading support. Some faculty said there are students who cannot read in the program. Placement testing is not required for program admissions for most of the KCKCC TEC programs. Many faculty thought it would be beneficial to have some minimum proficiency level. Also, more support for tutoring in math and reading beyond the classroom is definitely needed for students, according to faculty.

The faculty discussed the need for individual goal support for students, including life skills assistance, leadership skills, confidence building, and financial resources. All the faculty try to work these skills into the class. Still, many faculty members thought students need more knowledge and resources in these areas to be successful. One faculty 
member said, "These students have all kinds of challenges, money, support, kids, rides, health." The faculty try to help the students, but when the students do not attend class the faculty members are limited as to the help they can provide.

Lastly, the faculty mentioned the need for a formalized job placement opportunity for students who complete the program. The faculty believed that if the students knew the program would lead to guaranteed employment, students would be more likely to graduate. One faculty member said, "We are creating a workforce for tomorrow, so I always want to make sure we're doing things to help them get a job." Each program has different avenues they use to help students obtain employment, but they felt there was an opportunity to create a clear pathway to employment.

\section{Discussion of the Findings}

The principle outcomes of the study can be considered from the quantitative and qualitative analysis. Research questions one through four required a quantitative analysis, while questions five through eight were examined using a qualitative method. For the quantitative analysis, the three main contributing factors of the KCKCC TEC cohort students were present in those who graduated from a KCKCC TEC cohort program. Those factors were as follows (1) race/ethnicity, specifically white or Asian; (2) students' age ranging from 20-59; and (3) postsecondary student level. When considering race/ethnicity, students who were white, Asian, or multiracial were more likely to graduate than those who were African American or Black or Hispanic. Historically, African American or Black and Hispanic students have been underrepresented and this underrepresentation was observed in the results of this study. Students ages 20-59 directly correlate with the postsecondary level since all 
postsecondary students must have earned a high school diploma and are typically over age 18. The postsecondary students could be in a different place in their lives as adults with a more direct focus on their education providing more motivation to complete the KCKCC TEC cohort program than the high school students. At the same time, the high school students could be attending the program because they were directed to attend. While high school students might have more time, fewer distractions, less transportation issues, and more support for their education, much of this assistance tends to drop off after high school graduation. The high school students do not continue to complete the program at the same rate as the postsecondary students. A variety of factors could contribute to this educational halt. The qualitative analysis offers some possible inferences.

The qualitative analysis revealed three overarching themes that contributed to the KCKCC TEC program completion for students. The top four themes were (1) relationships with classmates and faculty, (2) student attitude/desire to meet goals, (3) academic preparedness/personal challenges, and (4) cohort structure. KCKCC TEC cohort faculty and students both indicated that relationships were a key factor that contributed to students' continued enrollment in the program and program completion. Relationships between students at the postsecondary and high school levels were shared repeatedly. Additionally, those relationships continued into transportable networks that students utilized after program completion. Yet again, the faculty and students both provided comments about the student's desire to complete the program as a reason for program completion. Students were goal-focused and had a focused attitude to complete the program. Many students indicated the skills they were learning were their passion. 
Other students who were not as focused or dedicated to the program were more likely to drop out of the program. Often, these were students who faced transportation, financial, or academic challenges and were all too willing to discontinue the program. Lastly, interweaved throughout the student and faculty responses was the cohort structure and curriculum.

Considering the connections between the qualitative and the quantitative data, the postsecondary students could be more focused and self-driven than the high school students. Each group of students faced challenges and academic difficulties. Both groups formed relationships with the faculty and other students of the same and different levels. However, these factors were not enough for the high school students to finish the program. For the high school students, their program downfall could happen during the transition from a high school student level to the postsecondary student level. The postsecondary students do not have this transition, and their program is much more concentrated. They attend all day every day for a shorter period, whereas the high school students attend half days every day for double the length of time. High school students might have fewer life responsibilities than postsecondary students. However, high school students become postsecondary students, and then they abruptly have adult responsibilities. Moreover, the high school students do not have to pay tuition for the KCKCC TEC programs, but when they transition to postsecondary student, they are responsible for the tuition. Federal financial aid is available to these students, but the process could seem too daunting and overwhelming for many students. All in all, there might be too many changes for the high school students to adjust to as they transition to the postsecondary status. Their priorities could change and no longer include education 
as predominantly. Ultimately, the program's structure is broken for the high school students, the relationships formed are not strong enough to prevail, the symbolism is no longer envisioned, and the commitment to the program is lost in the competition of reallife factors.

The results of this study are comparable to that of other cohort studies. The findings regarding relationship and group dynamics were prominent, just as in past studies (Nimmer, 2009; Scribner \& Donaldson, 2001; Seed, 2008; Sathe, 2009; Stearns, Margulus, \& Shinsky, 2012; Unzueta, Moores-Abdool, \& Donet, 2010). Faculty and student characteristics were all factors in this study, just as they were other cohort studies (Browne-Ferrigno \& Muth, 2004; Jaffee, 2010; Maher, 2005: McCarthy, Trenga, \& Weiner, 2005; Potthoff, Dinsmore, \& Moore, 2001; Santicola \& Morris, 2013; Scribner \& Donaldson, 2001). Lastly, the structure was a contributing factor in other cohort studies and this study (Barnett, et al., 2000; Lamb \& Jacob, 2009; Potthoff, et al., 2001; Unzueta, Moores-Abdool, \& Donet, 2010).

This study's challenges and limitations included a need to interview more of the faculty from the other KCKCC TEC programs that were not represented. Student interviews were lacking in participation. Interviews with more students and students from each level would have provided a richer understanding of the KCKCC TEC program experience. Lastly, more representation from students who dropped out of the KCKCC TEC cohort program would have been valuable.

Considering career attainment would be beneficial to consider in the future. Additionally, a longitudinal study specifically focusing on high school students who transition to postsecondary would be an excellent follow up to this study. This would 
allow for the possibility of a direct understanding of the students who have the most challenges in completing the program to determine the causes for dropping out of the program. It would also allow for the understanding of the reasons for program completion.

\section{Conclusion}

Not all the responses can be specifically attributed to the cohort model. Some responses could be due to the specific nature of the KCKCC TEC program or the students' high school or postsecondary levels. Nevertheless, the study was consistent with the current literature surrounding cohort models. Student and faculty characteristics, cohort program advantages and disadvantages, curricular and program organization, relationship dynamics, pedagogical focus were all elements of this study. The KCKCC TEC cohort programs have faculty members who are passionate about their disciplines and students. However, the program has some constraints due to the high school student type, service area demographics, and the Kansas Board of Regents (KBOR) requirements.

\section{Recommendations}

Based on the findings of this study, a few recommendations should be considered. Five recommendations emerged from the study, (1) prior enrollment academic testing and program interest, (2) career and internship placement, (3) part-time enrollment options for postsecondary students, (4) clear pathways for students to transition from high school to postsecondary status, and (5). The first two recommendations apply to high school and postsecondary students. The third applies mainly to postsecondary students, and the fourth directly relates to high school students. All recommendations would have an 
impact on the KCKCC TEC cohort faculty. The recommendations were developed based on the ultimate goal of KCKCC TEC program completion.

\section{Recommendation One: Prior enrollment academic testing and program interest}

Based on the comments about students' attitudes in the program it would be beneficial for students to learn more about the program before being enrolled in the program. This could happen through campus tours, program skill demonstration events, faculty information sessions, or requiring students to submit a narrative about their interest in the selected program. This will allow the high school students to determine if they are truly interested in the program. Some of these items are already in place but not required of all students for all programs. Specifically, the high school students appeared to need additional knowledge about the program rather than being automatically placed in the program without showing any interest.

Requiring placement testing or minimum earned grades in high school math or English would be useful to the students and for the faculty. Students and faculty both mentioned the challenges students face with math and reading. It might be advantageous to have a time limit on the minimum earned grades and offer placement testing to those with expired or lower grades. The specific recommendation about the minimum grade or test score necessary for success would need to be provided by the KCKCC TEC cohort program faculty. Alternatively, just requiring the student to complete the placement test without a minimum score would allow the faculty to ascertain students' incoming ability. Providing the faculty with this baseline academic level would allow the faculty to better plan their curriculum and identify resources the students need prior to the classes beginning. For students with lower scores or the inability to read, required tutoring could 
be provided. On the other hand, academically advanced students could be given more complex assignments or activities.

\section{Recommendation Two: Career and internship placement}

KCKCC TEC cohort programs are applied in nature, meaning the programs prepare students for employment immediately after they complete the program. According to KCKCC's website (https://www.kckcc.edu/academics/divisions/careertechnical-education/), the college referred to career and technical education as technical training and promoted rewarding employment as an outcome. Additionally, during the faculty interviews and the student survey, career opportunities were mentioned several times. Subsequently, career opportunities are of importance. Some programs assist students by utilizing faculty's field networks and experience to secure student employment prospects. Many of the faculty members mentioned they stay in contact with potential employers and adjust their curriculum according to the industry needs. However, there is no standard pathway directly to an internship experience or employment after completing a KCKCC TEC cohort program. Programs could have direct placement for students upon program completion. There could be a career fair, or students could go directly to the businesses on scheduled days and times to interview for various positions. Alternatively, some programs do not offer courses during the summer, and those programs could have summer internships for students. Students would appear to benefit from a forged pipeline of employment security. This opportunity could attract more students to the program and foster additional networking prospects. The faculty would need to be involved in utilizing their contacts to secure positions and internship opportunities for their students. Since KCKCC is a community college, the priority would 
be to develop career prospects with companies within the service area. By prioritizing these opportunities with a community focus, KCKCC's mission and vision would be supported. According to the college website, their mission is to, "Inspire individuals, and enrich our community one student at a time." Their vision is, "To be a national leader in academic excellence and partner of choice in the communities we serve," according to the college website (https://www.kckcc.edu/about/mission-vision-purpose.html).

\section{Recommendation Three: Part-time enrollment options for postsecondary students}

The KCKCC TEC cohort programs range from four months to two years of enrollment, depending on the program. The faculty mentioned the intense pace of the program could be a challenge for students. They also revealed how the class schedule makes it difficult for students to obtain employment outside the program. For some students, the full-time program is not an issue, and they do not need any other work. However, a part-time enrollment option could be advantageous for many students. Each program would have three tracks: a full-time track of postsecondary students, and two part-time tracks for morning and afternoon postsecondary and high school students. The high school students are currently on a part-time morning or afternoon track since they attend high school the other half of the day. The part-time track students would take longer to complete the program than the full-time track students. However, this might allow some postsecondary students the flexibility they need to be successful. This would provide the faculty with an opportunity to plan and organize their curriculum based on two options, full-time or part-time rather than high school or postsecondary student levels. These tracks would allow high school students to develop bonds with postsecondary students, as those students would be in their cohort for the program's 
duration. Lastly, it was revealed in the faculty interviews that many faculty make exceptions for postsecondary students and allow them to participate part-time in the program. They have separate classes created for those students. This practice causes more work for all involved, the faculty teaching load is increased, and the cohort model foundation is convoluted with this practice. The extra work would be reduced by having a part-time track for postsecondary students, and the cohorts would stay intact.

\section{Recommendation Four: Clear pathways for students to transition from high school to postsecondary status}

The transition from a high school student to a postsecondary student could be the disconnect that causes students to stop out of the KCKCC TEC cohort program. High school students have a designated time to attend classes with provided transportation to and from KCKCC. Additionally, students are held accountable for attendance by the KCKCC faculty, the high school, and their parents. Once they shift to the postsecondary level, that accountability subsides. The program should have a clear pathway for these students not to have a break that would allow other distractions to deter them from their educational goals. The path should include advising to discuss goal planning, program completion, financial aid, logistics, support, and career options. This advising session should take place before high school graduation. Having the students commit to enrolling in the next semester before they graduate could help them be dedicated to attending. If a student graduates in May, it would be best to have the student continue their enrollment in the summer rather than waiting until August to attend or they could participate in a summer internship opportunity. All these options would allow the students to remain engaged in the program. Students would not have a break in their 
momentum and could finish the program more quickly. This could apply the summer before $12^{\text {th }}$ grade for students who begin the KCKCC TEC cohort program in $11^{\text {th }}$ grade. Those students could participate in an internship or continue with the program course work. However, the option would need to be consistent for all students to keep the cohort model intact. If a part-time track is established, as mentioned in recommendation three, this pathway would be identified and established for the high school students, as well as the part-time postsecondary students.

\section{Recommendation Five: Support for minority students}

In addition to the former four recommendations, direct support for the minority students is also needed. KCKCC TEC cohort faculty should be aware that Black/African American and Hispanic students are not graduating as expected from the KCKCC TEC programs. The faculty should provide additional support to those students. This could be a simple as increasing their check-ins with these students. Additionally, minority groups on campus should be connected with the minority students in the KCKCC TEC program. Lastly, successful former minority students who graduated from a KCKCC TEC program should be invited to share their stories with the minorities in the program and provide advice to them.

\section{Summary}

The recommendations from this study focused on the structure of the cohort and how improving the structure could promote program completion. The recommendations could have the greatest impact on the program if they were all implemented. However, any one of the recommendations would help promote program completion. 


\section{SECTION TWO}

PRACTIONER SETTING FOR THE STUDY 


\section{Introduction}

This section is comprised of the history of the organization, the demographic area the organization serves, the overall student body demographics of the organization, the specific location of the cohort programs, and the dual concurrent enrollment program. The type of students who enroll in the KCKCC cohort programs are either dual concurrent students or postsecondary students. Dual concurrent students are high school students who meet a set of criteria and are allowed to enroll in college-level courses. Postsecondary students are students who graduated from high school and are enrolled in college courses. The remainder of the section discusses the organizational analysis, leadership analysis, and implication for research in the practitioner setting.

\section{History of the Organization}

The organization that serves as the focus of this research study is Kansas City Kansas Community College (KCKCC). This college was initially founded in 1923 in Kansas City, Kansas. The population that KCKCC serves is primarily from Wyandotte county, which has 163,227 residents. Wyandotte County has a median age of 33.7, with a median household income of $\$ 42,783$. The population is $41.6 \%$ White, $28.1 \%$ Hispanic or Latino, and 22.7\% Black or African American (datausa.io, 2020). The demographic of Wyandotte county contributes to the overall student body at KCKCC since many of the students reside in the county.

KCKCC has approximately 5,361 domestic and international students. A total of $60.4 \%$ of the total population is female. KCKCC offers five-degree types and multiple certificates. The TEC programs offer over 30 education certificates and associate degrees. KCKCC is fully accredited by the North Central Association of Colleges and 
Schools, a regional accrediting body. Students may live on-campus in one of the three residence halls or live off-campus and commute; this provides students a traditional learning experience or an opportunity to commute. KCKCC has over 40 student clubs and eight varsity teams.

KCKCC has two additional site locations, The Dr. Thomas R. Burke Technical Education Center (TEC) and the Pioneer Career Center (PCC). This study will focus on the cohort programs at the TEC due to the cohort programs offered at this location. Previously, the TEC programs were provided by the USD 500 high school district. The programs merged with KCKCC in 2008. Dr. Thomas R. Burke Technical Education Center offers over 20 programs with approximately 1,207 students, including 387 high school dual credit students and 820 postsecondary students for the 2019-2020 academic year. The certificates range from nail technology to welding to computer-aided drafting. For a full list of the certificate programs, see Appendix D1. All the programs at the TEC center are certificate programs. The students are either currently enrolled high school students taking college courses or postsecondary students who have already graduated from high school or earned a general educational development certificate (GED). The concurrent and dual enrollment program allows students who are still in high school to take college courses and earn college credit. The college credit earned also applies to the students' high school diploma.

Currently, KCKCC, including the TEC center, serves 17 high schools, including alternative high schools and the Kansas School for the Blind. The largest district served is the USD 500 district, which is comprised of five high schools. The USD 500 school district is in Wyandotte county. Typically, there are 2,000 dual and concurrent 
enrollments each fall and spring semester, which represents one of the largest populations at KCKCC. These students can enroll in TEC programs as well as traditional college courses. Some courses are offered at students' high schools, while others must travel to KCKCC to attend the class.

\section{KCKCC Technical Education Center cohort programs}

The Technical Education Center that houses the TEC cohort certificate programs was initially hosted by the local USD 500 school district. The program served both high school students as well as postsecondary students. In 2008, the state of Kansas passed legislation that required all technical education programs to be affiliated with a college or university. The TEC programs could no longer be governed by a unified school district. Therefore, the technical education program in Kansas City, Kansas, associated with USD 500, merged with Kansas City Kansas Community College in 2008. Many of the faculty and staff who were part of the original merger are still employed at KCKCC and still work with the TEC programs. The cohort model of the TEC programs is a continuation of the original program being in a high school. The culture of the TEC center still has more of a high school feel rather than a college feel. For instance, the faculty teach each day from 7:30 am until 2:45 pm with a lunch break from 10:30 am until 11:20 pm. For lunch, there is a cafeteria on-site for the faculty, students, and staff that serves a limited breakfast and lunch menu which changes daily. This set-up is similar to an American style cafeteria and less like a college food court. The facility has a bookstore that students can use to purchase textbooks, supplies, snacks, and other program necessities. There are staff offices, a student resource center, and a large meeting room. The TEC programs are located throughout the building. There are typically one to three faculty 
members per TEC certificate program. High school students attend one of two daily sessions. The morning session begins at 7:30 am each weekday and ends by 10:30 am, and the afternoon session starts at 11:20 am and ends by $2: 45 \mathrm{pm}$. The high school students take a bus from their high school to and from the TEC center. Occasionally, there are bussing issues when a bus is running late or if a student missed the bus. These issues are typically resolved between the KCKCC staff and the high school counselor or by contacting the bussing company directly. The busses also add to the high school feel of the location. The postsecondary students attend all day each weekday from 7:30 am 2:45 pm for the duration of their program. Their instruction overlaps with the high school sessions. A few TEC programs have evening sessions for postsecondary students only.

All TEC students must apply for admissions to KCKCCC. Some programs require placement testing for students. A high school student's initial enrollment occurs when the student submits an enrollment form. The enrollment form lists the student's demographic information and the student's desired TEC certificate program. Since the students are in high school, they are required to sign the form, along with the parent/guardian and the high school representative. The high school representative is typically the counselor or principal. Once the documents are received, the KCKCC TEC personnel organize the forms by the TEC program and then by the high school in which the student is currently attending. The students are enrolled in the program based on the total number of seats available and the total enrollment forms submitted from each high school. The staff work to have equal program enrollment representation for each of the high schools in KCKCC's service area. Once the students are enrolled in their respective programs, the students and the high schools are sent their enrollment schedules. The 
students, high schools, and KCKCC employees then make any necessary enrollment updates such as changing students' program enrollments or switching students between the morning or afternoon sessions.

Postsecondary students must apply for admissions, complete placement testing if necessary, and meet with the KCKCC personal as well. Postsecondary students are exempt from completing the enrollment form. Postsecondary students are required to meet with KCKCC personnel to enroll in a TEC cohort program. The students meet with an admissions specialist to ensure their application has been processed and to verify their personal contact information. While meeting with the admissions specialist, program availability is determined. Placement in a TEC program is strictly based on a first-come, first-served basis. The number of open seats in the programs is based on the remainder of seats after the high school students' enrollment has been allocated. If there is not an opening in a program, the student still is able to meet with an advisor to talk about other program options or have their name placed on a waitlist for the program. The waitlist is a manual waitlist managed by the admissions specialist. The student then meets with an advisor. After the advisor meeting, the student is enrolled in the first set of courses for the cohort program. Students are not allowed to self-enroll in TEC cohort courses. The cohort courses are prescheduled and grouped together based on the program and the semester of enrollment. Students meet with the registrar specialist to have their schedule and billing statement printed, then the financial aid specialist to discuss federal funding options and, finally, with a business office specialist to go over payment options.

Once the semester begins, all students attend orientation during the first week of classes. Orientation is hosted each semester for all TEC cohort students. The high 
school students' grades are sent to their high school midway through the semester. Before the next semester begins, the high school students must meet with a KCKCC personnel in order to continue enrollment in the TEC program. During the enrollment meeting, the high school students must visit with an admissions specialist to verify and update their demographic data. Next, the student meets with an advisor where they discuss future planning and the student's performance in the program. If the student decides to continue their enrollment in the program, the enrollment form is completed, signed by the student, and the student obtains the signatures of the parent/guardian and high school representative. The form is returned to the KCKCC, and the KCKCC registrar specialist enrolls the student in the next semester courses. If the student is projected to graduate from high school and has not yet completed the TEC certificate program, the student will still meet with the KCKCC personnel and the financial aid specialist. Students will update their level from a high school student to a postsecondary student and will be enrolled in the next set of courses.

Postsecondary students meet with the same KCKCC personnel as the high school students who are graduating. If they choose to continue their enrollment in the program, then they are enrolled in the next set of prescribed courses, pending there is not an enrollment hold on the account. If the students have a hold on their account, they are directed to someone who will help resolve the hold. Once the hold is resolved, enrollment takes place. This process continues until the student completes the program.

The TEC cohort programs are all part of the Excel in Career and Technical Education Program (CTE), formerly known as Kansas Senate Bill 155 or Tiered program, which was passed on July 1, 2012. The four aspects of the bill are (1) tuition 
reimbursement, (2) certification incentive, (3) transportation reimbursement, and (4) CTE marketing campaign. This program allows high school students to enroll in college-level CTE courses without a tuition cost to the student (Kansas State Department of Higher Education, 2020). Basically, the students enrolled in a CTE course(s) are only responsible for paying for any supplies or material needed for the TEC program at KCKCC. KCKCC and the high schools whose students are enrolled in the CTE courses receive reimbursement funds from the state of Kansas. The Excel in CTE program provides high school students with an opportunity to complete most of their TEC programs at little to no cost. If a high school student does not complete the TEC program while in high school, the student can continue the program and apply for federal financial aid to offset the remainder of the program cost. However, the student is now responsible for the tuition and fees of the program when they were not high school students. The education is still the same, but the student no longer qualifies for excel in CTE benefits. It is financially beneficial for high school students to complete the TEC program while still in high school. The students who complete a TEC certificate while in high school have invested their time and effort without much of a monetary cost.

\section{Organizational Analysis}

To help understand the colleges and universities as organizations, organizational theories have been reviewed and applied to higher education. For instance, Bolman and Deal (2017) identified four theoretical frames to help understand organizations and to instruct organizations to identify and solve problems. Structural, human resources, political, and symbolic are the four frames used to define organizations. Once the situation is determined using one or more of the frames, a proposed solution can be 
implemented using the same theoretical assumptions of the frame. Multiple perspectives allow recognition of problems on a deeper level leading to better solutions. By identifying the problem, a solution can be found within that frame. The alignment is critical to identify solutions and solve problems efficiently.

Organizations are composed of different styles, allocations of power, and cultures. Cohorts within a college environment can be compared to small organizations within a larger entity. For this study, established organizational theories will be applied to cohorts for analysis purposes.

\section{Structural frame}

Ensuring that people are in the right roles and relationships is the guiding principle of the structural frame (Bolman \& Deal, 2017). Essentially, the structural frame is a blueprint for officially sanctioned expectations and exchanges among internal players and external constituencies. Weick (1976) defined educational organizations as a loosely coupled system, meaning the actors, technology, and rewards combined to make up an organization. He promoted how it is essential to identify where coupling can occur since those properties are how they hold the organization together. Mintzberg (1994) discussed how organizations are composed of three dimensions: (1) the critical part, which are the strategic apex, operative core, middle line, technostructure, and support staff; (2) prime coordinating mechanism, which coordinates all activities, and decentralization; (3) vertical, horizontal, and selective. These different dimensions allow strategies to be structured and configured.

The structural frame emphasizes the importance of placement, placing the appropriate people in the correct roles and relationships (Bolman \& Deal, 2017). The 
structure of an organization is the underlying framework that maintains the operational function of the organization. A lack of structure could lead to apparent programmatic problems. At KCKCC, the cohort programs rely on structure and logistics to function smoothly, whereas non-cohort programs are not as rigid and allow students more freedom to select courses at will. Like many universities, KCKCC has been focused on data to make decisions regarding sparse allocations. Data are structural tools used to align information to present for comprehension. At KCKCC, the administration adopted the use of data to make decisions because it appeared to make a non-bias decision. To fully understand and apply the structural frame, the assumptions of that frame should be considered. Those assumptions include:

1. Organizations exist to achieve established goals and objectives and devise strategies to reach those goals.

2. Organizations increase efficiency to enhance performance through specialization and appropriate division of labor.

3. Suitable forms of coordination and control ensure that diverse efforts of individuals and units mesh.

4. Organizations work best when rationality prevails over personal agendas and extraneous pressures.

5. Effective structure fits an organization's current circumstances (including its strategy, technology, workforce, and environment).

6. When performance suffers from structural flaws, the remedy is problem solving and restructuring. (Bolman \& Deal, 2017, pp. 48) 
Kansas City Kansas Community College operates within the structural model. Their employees have a fixed division of labor, hierarchy, specific rules that govern performance, and separation from personal desires, concepts explained by Bolman and Deal (2017)

\section{Political frame}

The political frame is very challenging to navigate since there are various stakeholders. Those stakeholders have personal agendas and interest that must be accounted for, and the discovery of these dynamics are not always apparent. The guiding political frame assumption helps to explain the interconnections that form coalitions, the interests of the individuals and groups to struggle over scarce resources. Bolman and Deal (2017) described authority from the viewpoint of a power source. The authors discussed a variety of sources of power, position power, information and expertise, reputation, personal power, and so on. These types of power are based on the backgrounds and character of a person and would seem to be the most authentic. To maneuver through the political terrain, Bolman and Deal (2017) proposed a few beneficial skills such as setting the agenda, mapping the political terrain, networking, forming coalitions, and bargaining and negotiating. Levi (2014) discussed how social influence refers to attempts to affect people and how to influence groups to have norms that can equalize the power and help to control the communication flow. With an understanding of these aspects, motivations and actions are better understood when working with all the key stakeholders involved.

Politics are apparent in all organizations, and universities are no exception. The resources at $\mathrm{KCKCC}$ are pulled in multiple directions, and each program is angling for 
resources within the college. Resources at KCKCC might include finances, space, equipment, personnel, program spaces, etc. The political frame proposed by Bolman and Deal (2017) involves power, conflict, and ethics, which are all involved in the situation between the different operational units at KCKCC. Bolman and Deal (2017) outlined assumptions about the political frame:

1. Organizations are coalitions of different individuals and interest groups.

2. Coalition members have enduring difference in values, beliefs, information, interest, perceptions of reality.

3. Most important decisions involve allocating scarce resources-deciding who gets what.

4. Scarce resources and enduring differences put conflict at the center of day-today dynamics and make power the most important asset.

5. Goals and decision emerge from bargaining and negation among competing stake holders jockeying for their own interests. (Bolman \& Deal, 2017, pp. 184).

Coalitions and interest groups at KCKCC consist of different high school administrations that send students to participate in the TEC cohort programs. The students who enroll in the TEC cohort programs provide funding and support for the KCKCC TEC general operation. Additionally, other colleges are competing to secure the enrollments of the TEC cohort students. Enduring differences create challenges for leaders and organizations. Often each group is operating under their assumptions and needs, which may not coordinate or support the other constituents involved. This disconnect can lead to friction, misunderstanding, and confusion. 
Scarce resources are evident in colleges, as many universities have closed recently due to funding issues. Since 2016 over 50 colleges and higher educational institutions have closed with more anticipated closures in the future (Education Drive, 2020). Each program at KCKCC works diligently to show the value of the provided education and revenue generation. Naturally, this potential loss of funding due to anticipated low enrollments can lead to day-to-day conflict and power struggles. The focus of student service and employee satisfaction are also considered resources and are often overlooked, as the immediate value is intrinsic and not monetary. Many programs are competing over funding, resources, and students.

\section{Human resource frame}

The human resource frame focuses on the people of an organization, ensuring human needs are met, and the organization invests in the people (Bolman \& Deal 2017). To better understand the human resource frame, Bolman and Deal (2017) provided four assumptions that target the organization's people, how the organization serves the people and ensures the best fit for all hires. The assumptions are as follows:

1. Organizations exist to serve human needs rather than the converse.

2. People and organizations need each other. Organizations need ideas, energy, and talent: people need careers, salaries, and opportunities.

3. When the fit between individual any system is poor, on or both suffer. Individuals are exploited or exploit the organization—or both become victims.

4. A good fit benefits both. Individuals find meaningful and satisfying work, and organizations get the talent and energy they need to succeed. (Bolman \& Deal, 2017, pp. 118). 
Maslow's Hierarchy of Needs is a pyramid of individual needs for a person to thrive. Without meeting the basic needs of existence, a person cannot progress to the next level. According to Maslow (1954), we must ensure our basic needs are met before we can move forward; however, sometimes, the needs can overlap. The basic needs are (1) physiological, (2) safety, (3) social/belonging, (4) esteem, and (5) selfactualization. Maslow's Hierarchy of Needs relates to the Human Resource frame because a person cannot be effective if their basic needs are not met (Maslow, 1954). Organizations are comprised of people, and those people must have their needs met to contribute efficiently to the organization. When people cannot contribute to the organization, the organization starts to fail to thrive as well. When working with people, it is essential to be willing to understand their motivation. Not having their basic needs met could affect the overall productivity of the organization.

The main objective of the human resource frame is investing in people and ensuring a strong relationship between the people and the organization. Strong human resources should be evident from the beginning by hiring the right people, rewarding them well, promoting from within, empowering employees, and providing information, support, and diversity (Bolman \& Deal, 2017).

The Human Resource frame focuses on people and relationships (Bolman \& Deal, 2017). Both professional internal and external relationships are encouraged and supported at KCKCC. The administration and KCKCC Board of Trustees have promoted the relationship and partnership between KCKCC and the high schools within their service area. The students in the cohort programs are from local high schools within KCKCC's service area. KCKCC has memorandums of understanding (MOU) with the 
high schools. These relationships require constant communication and are often a challenge to maintain within the cohort program. Relationships within the cohort are also formed between high school students, postsecondary students, instructors, and the KCKCC TEC staff.

\section{Symbolic frame}

Symbolism is all around us, and many cultures utilize symbols for various rituals, celebrations, acknowledge an accomplishment, victory, or other ritualistic activities. The same happens in organizations and higher education. Convocation, new student orientation, and graduation are just a few symbolic rituals that are indicative of higher education. Bolman and Deal (2017) proposed five assumptions concerning the symbolic frame. These assumptions place specific attention on the value symbolism brings to individuals through events and actions. Bolman and Deal (2017) noted that ritual is also a type of symbolism that provides routine and structure that gives meaning to each day. This concept allows the symbolic frame to be viewed on a deeper level that could be applied in multiple settings.

Examining a problem from multiple perspectives allows for a greater realization of the problem and, by understanding the issue on various levels, a more reliable, more robust solution can be developed. Additionally, the four frames can be applied to individuals as well as situations. By determining how an individual operates, then communication and planning in that same frame can be critical to reaching the end goal. Leaders must manage conflict regularly. While we consider most conflict as unfavorable, conflict is natural, and there can be benefits when conflict is handled 
appropriately (Levi, 2014). To develop a mutually satisfying approach to managing conflict, open communication and respect are necessary.

The symbolic frame focuses on the tribal aspects of contemporary organizations (Bolman \& Deal, 2017). Within higher education and, more specifically, within the KCKCC TEC program, there are many symbolic references such as orientation, welcome on the first day of classes with fresh donuts, continued enrollment process, student activities events, commencement exercises, diplomas, etc. Cohort models are incorporated into KCKCC's current culture as the structure allows for specific timing of events and the use of artifacts.

\section{Implications for Research in the Practitioner Setting}

This research is valuable to higher educational organizations because the study will provide insight into cohort models. Specifically, information gained from the students within the cohort models and what attributes are associated with retention and completion within the KCKCC TEC programs will be useful to consider in other programs within higher education. The survey results will provide the student's perspective of what they find helpful to keep them in the program. Not only will the researcher examine the students, but the study will also investigate the relationships formed within the cohort between the students and the faculty. The information gained could be applied to other cohort programs and potentially impact those programs and hopefully promote retention and degree completion.

It is essential to understand that the information gathered from this research study cannot be generalized and applied to all programs. More research is needed before the investigation is generalized to other students, programs, etc. While the research is 
important and of value, the study would need to be repeated multiple times at different colleges with other students before the findings could be applied to all cohort programs.

\section{Leadership Analysis}

\section{Introduction}

Both the leader-member exchange theory and path-goal leadership are utilized in the TEC cohort programs at KCKCC. The KCKCC TEC cohort faculty regularly demonstrate leadership from each of these theories. The most predominant theory used in the TEC cohorts is the leader-member exchange theory, directly followed by the path-goal leadership theory.

\section{Leader-member exchange theory}

The Leader-member exchange (LMX) theory, according to Northouse (2019), is a leadership process that focuses on the relationship and communication between leaders and followers. Followers are broken down into two groups, the in-group and the outgroup (Northouse, 2019). The individuals who are in the in-group typically go above and beyond their standard responsibilities. Whereas the out-group only expands the minimum amount of effort and do not extend themselves to take on any added responsibilities. In exchange, the leader can rely on the in-group members to achieve goals. The in-group is afforded additional opportunities and benefits in exchange for their attention and contributions. On the other hand, the out-group members are treated fairly, but they do not receive any additional benefits or attention. This treatment is not a reduction in benefits for the out-group members.

The LMX theory has positive and negative aspects. Northouse (2019) outlined the following strengths (1) LMX provides a description of how leaders utilize some followers more than others to achieve goals, (2) LMX focuses on the importance of communication 
and relationships, (3) the theory calls attention to the leader to be mindful of how the leader relates to followers, and (4) high-quality leader-member exchange has correlated with positive outcomes. On the other hand, Northouse (2019) described some of the drawbacks to the LMX theory. Those drawbacks included (1) concerns about the fairness of treating one group differently than another group, (2) the theory does not explain how to create quality exchanges between the leader and the members, (3) the theory does not explain the factors that influence the relationships, and (4) it is unclear if the measurements of the theory are adequate to fully capture the complexities of the exchanges.

The LMX theory is apparent in the TEC cohort program at KCKCC because of the exchanges that take place between the groups. The TEC cohort professor serves as the leader and exchanges take place with the students in the program. The students make up the in-group and out-group members. There are two groups of students in the program, high school students and postsecondary students. The level does not designate if they are in or out-group members. Their presence, attention, and devotion, or lack thereof, influence the exchange membership. The in-group consists of students who attend classes regularly, actively participate while in class, submit their assignments on time, and assist other students. The out-group has students who disrupt class, attend periodically, and submit their assignments incomplete or late. Additionally, some students might dominate the class and overpower the voices of other students. These students could have positive or negative impacts on the class as a whole and their impact could influence if they are in the in- or out-group. The goal of the professor is to explain and share the curriculum with the students to meet the program's objectives. Each day 
the professor sets expectations about the material covered and the material sets the foundation for the next phase of learning. The professor can benefit from the in-group to help propel the entire class toward the goals. However, the students in the out-group might feel left out or that they are not receiving as much focus and attention as the students in the in-group, depending on how the instructor treats the in-group of students.

\section{Path-goal theory}

Path-goal theory is another leadership theory that applies to the TEC cohort program at KCKCC. This theory focuses on how leaders motivate followers to achieve goals and concentrate on the relationship between the leader and the characteristics of the followers (Northouse, 2019). Northouse went on to say the basic idea of path-goal leadership is for the leader to identify obstacles preventing goal attainment, then remove those obstacles or engage in behaviors that would motivate the follower to overcome the obstacle. The theory outlined specific behaviors to correlate with follower characteristics for optimal motivation. These leadership behaviors consist of (1) directive, (2) supportive, (3), participative, and (4) achievement oriented (Northouse, 2019). According to this theory, the leader selects and applies the leadership behavior that most appropriately fits the situation. TEC cohort professors use each of these styles in the classroom, depending on the situation. For example, directive leadership is used when guidance and structure are needed. TEC cohort professors often utilize this type of leadership for classroom management. The professors are very straightforward and explicit with students when they are not paying attention or are distracting the class from the subject. Supportive leadership provides the leader with an opportunity to nurture followers and give additional attention to ensure the followers are aligned with the goal. Professors recognize which students need attention and provide extra support to those students to work towards the program goal. Participative leadership 
provides involvement. The TEC cohort programs are very participative due to the design of the professors. The professors have constructed the TEC cohort curriculum with a hands-on approach for the students. The cosmetology and nail technology programs both allow community members to make appointments and receive services from the students, and the professor is responsible for this program. This provides the students with an opportunity to practice their skills with customers. The culinary arts program caters to several on-campus events and has a bakery at the TEC center that sells items baked by the students to KCKCC employees. This program is also overseen by the professor. The professor of the construction technology program regularly secures contracts to build various items for the college and the community for the students to participate with the professor to practice their skills. The automotive technology programs allow employees to bring in their vehicles to the students for oil changes. The professor of this program demonstrates the necessary skills to the students. Participation in these hands-on, real-life mock settings allows the professors to demonstrate skills for the students and to directly observe the students in action. For programs that are not able to have customer interactions, the professors still ensure tactile learning and skill application is present within the program. The welding program has welding stations that students use to practice their welding skills. The commercial, residential equipment technology professor built a mock kitchen for students to repair an appliance, so they get a feel of what it is like to work in a customer's home. These are just a few examples of how the TEC cohort program professors use participative leadership to motivate students. These settings facilitate leadership opportunities for the professors because they can participate with the students to demonstrate skills and provide immediate feedback.

Lastly, achievement oriented leadership is used to provide challenges when followers need to excel. The professors in the TEC cohort program teach the students skills that 
continue to progress in skill level. These skills progressively become more challenging. As the students achieve the skills with success, the professors praise them within the class and often recognize the students for their skills publicly during presentations. Ultimately, the progression of the curriculum leads to the completion of the program. Program completion is the final and ultimate goal. The exchanges between the professor and the students move the class toward the goal.

\section{Summary}

KCKCC's Technical Education Center hosts several TEC cohort model programs with enrollment from both high school students and postsecondary students. The programs operate on a cohort model and the students work toward the goal of program certificate completion. Bolman and Deal's (2017) four frame approach applies to the TEC cohort programs as the cohort has elements of each of the four frames (1) structure, (2) human resource, (3) political, and (4) symbolic. Additionally, the TEC program has roots in the leader-member exchange theory and the path-goal leadership theory. 


\section{SECTION THREE}

SCHOLARLY REVIEW FOR THE STUDY 


\section{Introduction}

Cohort models have been used in higher education for many years; this is evident in models in schools of law and medicine as they have an incoming class that completes the program and graduates at the same time. More recently, higher education has started to introduce cohort model programs. Cohort models have surged in popularity in the United States, the United Kingdom, Canada, and many other countries (Bista \& Cox, 2014). Since there has been an increase in cohort model programs in higher education, there has been more research conducted about the structures of cohorts, the relationships formed within cohorts, and the outcomes produced by cohorts. This section of the paper provides an in-depth review of the research conducted on cohort models of education.

\section{Research about cohort models}

\section{Cohort Description}

Cohort defined. To explore cohort models, we must first define a cohort model and understand the dynamics associated with cohorts. The cohort model allows students to start a program and progress through the curriculum together until completion (Bista \& Cox, 2014). Agreeing, Maher (2005) indicated cohort models are similar to learning communities, consisting of a group of students who start a program together, proceed through the program, and conclude at approximately the same time. Learning communities are used synonymously with cohort models. Like cohorts, learning communities have things in common such as shared knowledge and shared responsibility (Tinto, 2000). A cohort is comprised of students who pursue the same discipline who are grouped and complete a pre-determined set of courses (Lei, et. al., 2011). Much like 
primary or secondary education, students start their education together, at the same time, and progress through their classes together until they graduate.

Cohort structure and design. The structure of the model is not the same in all cohorts and many factors are taken into consideration when designing a cohort model. The cohort structure has an impact on students and faculty (Unzueta, Moores-Abdool, \& Donet, 2010). The specific structure of a cohort sets the foundation for the entire program. However, Lamb and Jacob (2009) caution that while the cohort structure does not necessarily provide or ensure coherence, the cohort model does provide opportunities. Still, individuals must be willing to take advantage of those opportunities. Overall, a better understanding of the cohort model will allow the administration to better understand how to make decisions about the design and implementation of a cohort model (Pemberton \& Akkary, 2010; Seifert \& Mandzuk, 2006).

Cohort students start the program at the same time by enrolling and completing specific courses together until the program is complete. This structure has been found to be a benefit of cohort models due to the efficient and expected schedule of courses and assured number of students (Barnett, Basom, Yerkes, \& Norris, 2000; Barnett \& Muse, 1993; Potthoff, et al., 2001). The courses in which students enroll together are not random, according to Tinto (2000); rather, they are connected and linked systematically. In support of course sequencing, Nimer (2009) identified a significant benefit of the cohort program is the systematic sequencing of courses, which saves time and reduces stress for students, especially students with additional commitments. These groupings of classes change the learning experience for the student (Tinto, 2000). Shared learning experiences in linked courses, group projects, and collaborative work all contribute 
to a communal learning experience. Block scheduling allows for ideal schedules that have a predisposed flow (Hess \& Mason, 2005).

The predictability of course and program schedule positively affected enrollment management (Barnett et al., 2000). For instance, when enrollment is more predictable, then course scheduling, professor assignments, budgets, and graduation are more properly planned. On the other hand, the challenge of a rigid program is the lack of flexibility to accommodate student needs (Barnett et al., 2000). Applying Bolman and Deal's (2017) organizational frames, Bentltey, Zhao, Reames, and Reed (2004) claimed that cohort models are rooted in the structural frame, as they are planned in specific detail in advance.

Research suggests the following approaches should be combined when building a cohort model: (1) supportive, (2) reflective, and (3) community (Choy, Delahaye, \& Saggers, 2015). To elaborate, cohort models should be developed to naturally provide support to students by providing students with opportunities to form relationships with other students and faculty. By reflecting on their experiencing and learning, students have a chance to learn more about themselves and others, and it also allows faculty and program administrators the possibility to made adaptations and changes based on the student reflections. Lastly, the sense of community allows students and faculty to feel as if they are a part of something, that they have a place and belong in the program. Additionally, the outcomes of learning should be considered when setting up the cohort schedule and formatting (Reynolds \& Sitharaman, 2000). A learningcentered cohort was an ideal structure, according to Potthoff, Dinsmore, and Moore (2001) because the structure allowed students to personalize their education and learn 
more about themselves. This allowed students to identify their own biases and determine how to overcome those biases. Not ignoring student activities, Rocconi (2011) concluded that students who participate in educational opportunities while in college are more developed and experience more significant growth. Therefore, cohorts should be designed to include activities that include student-faculty involvement along with student collaboration. Finally, it was suggested that existing programs could be remodeled into a cohort program. Mountford (2005) discussed the importance of program redesign to achieve a higher level of cognitive learning for students.

Not everything about the cohort structure is positive. The structure does have challenges. Faculty in a study noted drawbacks of the cohort structure, including rigid delivery structure, time demands, and financial burdens placed on students were disadvantages (Barnett et al., 2000). Those faculty claimed the lock-step process, completing classes in a specific order without deviation, forced students to take full course loads even if the students had full-time jobs. It is a challenge when students are out of sequential class order in the rigid, inflexible cohort design (Unzueta, MooresAbdool, \& Donet, 2010). Shifting to the student's perspective of a cohort structure, students prefer to have more course choices (Johnson \& Romanoff, 1999); however, students were accepting of the preselected courses if the instructor was wellprepared, and the class was found to be interesting. Students who participated in a cohort program said the design of the program provided an environment that allowed them to broaden their preconceived perspectives (Perez, Fegadel, \& Bromley, 2015). The cohort program allowed students to think differently about their experience and see other experiences from a different perspective. Moreover, the students claimed the 
program allowed them to experience emotional and psychological support with one another. Research conducted by Bista and Cox (2014) focused on the student's perspective and found that the doctoral cohort program met the students' needs. The study also found that students were highly satisfied with the class schedule, degree requirements, and manageability of courses. Students liked the size of the cohort and peer interaction because it felt like a supportive atmosphere. Students were in favor of the precise timeline, clearly defined pattern of the course schedule, and the coordination of the instruction that cohort models provide (Maher, 2005).

Cohort environment. Cohorts tend to create their own environment due to students taking classes together, including the same faculty members. The students and faculty spend a significant amount of time with each other. To lay the foundation for the cohort environment, Rausch and Crawford (2012) concluded that a sense of belonging at the beginning of a cohort program, paired with a face-to-face session, provides a setting for trust and a safe environment. More specifically, Perez, Fegadel, and Bromley (2015) discovered that over $28 \%$ of graduates shared qualitative praise about the cohort program without any prompt. This might seem like a low number, but this number represents those students who volunteered to share praise about the program without being asked. Additionally, students in the study were pleased by the effectiveness of the program and how it promoted group unity and a beneficial learning environment.

Cohort programs provide a setting for enhanced learning and development (Reynolds \& Sitharaman, 2000) and that effective cohorts create an atmosphere of learning that helps students who are challenged in handling complex ideas (Ross, Stafford, Church-Pupke, \& Bondy, 2006). Cohort models created a safe zone allowing 
students to interact with one another safely and promoted equal involvement of participants (Maher, 2005). Research by Engstrom, Santo, and Yost (2008) found that cohort members were able to capitalize on each other's strengths through the program to support their learning and each other. The cohort members also saw the group projects provided knowledge building. The students also understood the value of knowing cohort members before the assigned group projects, the familiarity made sharing ideas easier. The cohort provided students with a sense of safety, encouragement, and commitment to each other. Mello's (2003) research found that cohort model programs provided students with a sense of belonging, which allowed them to get to know their professors and classmates better. Mello went on to share $96 \%$ of the students felt that being in the cohort was beneficial. Possible contributions included knowing the other participants who made them feel more comfortable and supported. Students also noted they felt a rewarding experience that led to a deep and meaningful learning experience. Early in the cohort program, students meet outside of class to make their academic plans, connect, socialize, and support one another. This early meeting allowed the group to establish trust, which created a non-threatening environment allowing individuals to share ideas freely, according to Fahlman (2011).

The research was conducted on students who have completed a cohort program, Maher (2004) discussed the importance of alumni involvement as well as how alumni connect the past and present through shared experiences. Cohort models support shared experiences. For instance, Bentley, Zhao, Reames, and Reed (2004) found that symbols were used in cohort models; specifically, food was used to bring people together. Many potlucks, parties, dinners, etc., were hosted during cohorts to build a foundation of 
community. Having alumni involved in the program sets a tone for the students who are currently in the program and impacts the environment. Students can see individuals who have successfully completed the program, as well as hear their advice and tips. They also can provide networking and encouragement to the current students. Reynolds and Hebert (1998) concluded that cohorts might support learning; however, it is not just the cohort itself that supports the learning; it is a conglomeration of multiple entities, such as structure, support, cohort community, reflection, and trust.

Cohort curriculum. In addition to the design and structure of cohort models, the specific curriculum taught has also been examined. Research has provided many recommendations for cohort faculty to consider when designing their curriculum. It was recommended by Engstrom, Santo, and Yost (2008) that the faculty of a cohort work closely together to determine the curriculum and delivery of the curriculum.

Additionally, it was suggested that course design and grading be consistent across the program. This consistency allows students to have a frame of reference for all their courses and expectations before the class begins. Faculty should reform their curriculum and consider the curriculum from a holistic point of view obtained by the duration of the program (Browne-Ferrigno \& Muth, 2004). Considering the cohort program holistically provides an opportunity to connect the curriculum to create a smooth flow and transition between courses. The curriculum of a cohort model allows faculty and an opportunity to think about the program curriculum holistically and how the curriculum can build and intertwine to best support the students. A cohort or unified model of learning establishes an opportunity for a fresh and renewed emphasis on learning (Mohn \& Machel, 2005). 
Overall, Potthoff, et. al (2001) stated that "a cohort is a good place for learning" (p. 41). Therefore, it is ideal for faculty to utilize the structure of the cohort model to maximize the curriculum outcomes.

While researchers provide suggestions for the cohorts' overall curriculum, they have also provided recommendations for classroom assignments and interactions. Tinto (2000) claimed that faculty should modify their syllabi for learning communities to promote collaborative learning. Faculty should ask students to share their experiences based on the curriculum and to reflect on their learning experience. Curriculum with short activities that lead to a long-term goal is not always well received by students even when the long-term goal is meaningful (Lieberman, 1996). Therefore, the researchers went on to suggest classroom activities be enticing to keep students engaged and interested. Another suggestion for cohort faculty proposed by Maher (2005) suggested faculty provide meaningful activities and designate time to focus on relationships so that the idea of superficial relationships is avoided. Similarly, Lichtenstein (2005) reported that faculty who utilize a group and peer work in class allows students to have more interactions and create friendships among one another.

The cohort model allowed for collaborative learning by sharing information and connecting thoughts (McPhail, Robinson, \& Scott, 2008). Students believed that this was a beneficial and meaningful learning method. Faculty could help benefit students by allowing them the opportunity to work collaboratively, rather than independently, as cohort learning is cooperative and social (Hess \& Mason, 2005). This collaborative learning also allows students to experience various points of view and perspectives. Interaction with faculty is still promoted and valued. Faculty also learn from their 
students and can creatively deliver the curriculum and expand their ideas regarding their discipline. Students that participate in activities promoted by the cohort program were linked to the instruction quality (Mather \& Hanley, 1999).

Having a curriculum that students respond well to is essential and has the potential to support more enriched classroom discussions. Curriculum that goes beyond the information provided by the faculty is found to provide an intellectual richness to students (Tinto, 1997). Classroom activities in cohort models were examined independently of the curriculum, and research suggests that students in learning communities were more participative in class compared to students who were not part of a learning community (Baker \& Pomerantz, 2001). The faculty also noted that students in learning communities were also noisier than the students who were not in learning communities. The study did not go into detail about the noise generated from the cohort students.

Focusing on student and faculty relationships has also been relevant when considering curriculum and assignments. Relationships formed within the cohort were valued at a higher level. Advised by Robinson, Beachboard, Li, and Adkison (2011), learning community designs should be inclusive of students' feelings of relatedness as they found that students who related to each other and faculty were able to engage in higher order thinking assignments. In addition to considering relationships when building a curriculum, student cultures should also be a focus point. Faculty should focus on cultural methods to benefit the student and their academic experience (Reed, Archer, \& Leathwood, 2003). 
Cohort funding consideration. With any new program, the cost associated with the program is typically taken into consideration. This is no exception with the cohort program. Neir, Toledo, Baptiste, Maliszewski, and Borries (2016) concluded that a cohort model is not only practical but also a cost-saving educational approach to education. Mountford (2005) went on to explain the process of redesigning the curriculum does not cost the university any additional funds, only faculty and staff time since faculty and staff salaries are already budgeted and additional employees would not necessarily be required. Delahaye and Saggers (2015) continued to note that academics are expected to develop excellent researchers with limited resources; therefore, they are in continual search of effective models, and cohort models of supervision seem to elicit many such efficiencies. Ultimately, Johnson (2000) discovered that investing in learning communities is worth the time, funds, and effort as at-risk students are more likely to experience successful completion of their degrees than if they were not in a learning community. To that end, Choy, Delahaye, and Saggers (2015) stated universities should still invest the time and resources for cohort development to be studied further. Lastly, Barnett, Basom, Yerkes, and Norris (2000) discovered that overall cohort users find the organizational effectiveness and benefits justify the use of cohort models.

\section{Student and faculty characteristics}

Cohort demographics. Some research has been directed toward race, ethnicity, and gender of cohort students. Case and Hernandez (2013) found in their study that international ethnic identity exploration was an essential part of the cohort. They also noted ethnically and racially diverse cohort programs could provide students with the support necessary to reach their educational goals. However, this study did not focus on 
any particular groups or types of students, just that diversity should be an integral part of the cohort program. Examining a specific ethnicity, Huerta and Bray (2013) studied Latino students in learning communities. Their research found the community classroom experiences and collaborative learning were beneficial to Latinos. They concluded students had academic and social success because they formed connections and received support.

Studying gender within cohorts, Reynolds and Sitharaman (2000) found that males and students under age 30 in cohorts had more educational advancement than those comparable in non-cohort groups. Considering gender concerning relationship building within a cohort, women were more likely to seek out opportunities to bond and men tended to lean toward the structure in place to build relationships (Reynolds \& Hebert, 1998). Cohort programs are not only intended for traditional college age students. Cohorts are used in higher education mainly targeting nontraditional students (Maher, 2004). Research indicated a growing number of students on a college campus are nontraditional students (Wyatt, 2011) and colleges are urged to become more effective when working with nontraditional students. It was suggested that colleges create programs that appeal to nontraditional students, which include their families. To support the nontraditional students, faculty should tailor their teaching styles and delivery methods to meet the nontraditional students' learning styles. For adult learners who have multiple responsibilities, having a program with all the courses selected and a clear timeline to completion could be advantageous. The level of support was exceptionally beneficial to those who worked full-time, had a family, or had many outside commitments (Perez, Fegadel, \& Bromley, 2015). However, if an adult learner 
would need to take time off, there could be challenges getting back on track.

Student characteristics. Just as the structure and design of cohorts have been studied, so have the students who enroll in cohort programs, specifically student attributes and characteristics. Researchers studied the characteristics of students who appear to thrive well in cohort settings. Maher (2005) identified two types of students that enroll in cohort programs: the pioneers and the accidental tourist. The pioneers were excited to be involved in a cohort program. In contrast, the accidental tourists unintentionally fell into the program and were not as concerned about the structure of the program. For students, the program was merely a means to an end. Thinking about the attributes needed for a student to complete a cohort program, Santicola and Morris (2013) identified four characteristics that lead to continued persistence in their doctoral cohort program: "commitment/discipline, putting the doctorate first, prefer to work independently and research alone, and full-time employment" (p. 262). These attributes might not necessarily be indicative of a person who is likely to complete a cohort program. Still, they could probably be successful in any program regardless of if the program is in a cohort format or not. Individual traits of students in the cohort program mirrored those of effective collaborative groups (Ross et al., 2006). With this understanding, educators can help students to further develop those necessary skills for collaboration. Cohort groups are more than a group of classmates (Nimmer, 2009); instead, they are a set of individuals with similar interests, lifestyles, backgrounds, and strengths who take courses cooperatively.

Not only have the characteristics of students in cohorts been studied, but researchers have also shared recommendations about what incoming cohort students 
should expect before entering a cohort program. It was recommended by Scribner and Donaldson (2001) that cohort students should be prepared for the intense learning that is indicative of working with groups and the same individuals over a long period. Research suggested students planning to enter a cohort should be aware of the cohort format and educational experience expectations prior to applying to the program so they can determine if the program is the right fit for them and research concluded that students should be aware that cohort programs are designed for self-directed students before applying to the program (Maher, 2005; McCarthy, Trenga, \& Weiner, 2005). Cohorts provide an opportunity for students who can accommodate the structure (Pemberton \& Akkary, 2010). On the other hand, active students with external responsibilities are not as likely to find the cohort structure accommodating. Students who are not comfortable with these expectations might find cohort learning challenging or less effective.

Shifting to the cohort student's perspective, studies explored how students perceive themselves, other cohort students, and students outside the cohort. According to Tinto (1997), students in learning communities perceived themselves to have higher intelligence than those who were not in learning communities. Students in learning communities thought they had more opportunities compared to students who were not in learning communities (Rocconi, 2011). Students in a learning community were compared to traditional learning and found that those in learning communities considered themselves to have gained greater intellectual knowledge than those of traditional learners (Tinto, 2000). In a study by Baker and Pomerantz (2001), students in learning communities felt their non-learning community friends were envious of the learning community's experiences and successes. Their friends also felt more stressed. Agnew, 
Metzman, Longwell-Grice, and Saffold (2008) stated, "Benefits of the cohort model include increased student affiliation, increased emotional and social support, reduced attrition, increased active participants among students, support through transition to college and social inclusion" (p. 21). On the other hand, cohort models have promoted social exclusion toward individuals who do not fit the stereotypical social norms of the cohort group (Agnew, Metzman, Longwell-Grice \& Saffold, 2008).

Cohort faculty. Faculty are critical in any program as they are the individuals who deliver the information to the students and provide the education. Since faculty members are so vital to education, research has been conducted to specifically consider the attributes of the faculty in cohort models. The role faculty play in cohort models is different than that of traditional college courses. Cohort models are not formatted in a traditional college structure; therefore, the faculty must adapt to the cohort structure. Research has examined what faculty characteristics are beneficial. It was recommended by Jaffee (2010) that faculty be carefully screened before being selected to teach in a cohort to avoid a possible mismatch between the cohort dynamics and teaching styles. Additionally, faculty should consider the unique cohort nature and tailor their interpersonal and pedagogical teaching to each cohort. Cohort faculty must be prepared to teach in a cohort because they help to foster a learning community (Potthoff, Dinsmore, \& Moore, 2001). Given the students take their courses together with the same faculty, it is important to understand the challenges that may arise for faculty and what attributes faculty need to handle these challenges. In addition, Potthoff, Dinsmore, and Moore found that cohorts tend to develop a unified voice and challenge faculty. This appears to be more powerful than individual voices. To empower students positively, 
faculty should allow students an opportunity to decide on parts of the curriculum to cover and give students a variety of choices. Potthoff, Dinsmore, and Moore also concluded that since cohorts create a safe space for students, they are more comfortable in challenging perspectives and taking risks. Cohort leaders should be prepared to deal with complicated group dynamics (Browne-Ferrigno \& Muth, 2004). To combat possible difficult dynamics, group activities to enhance cohesion and learning could help deal with potential conflict. According to Maher (2004), some students might not be willing to participate in all events. If this is the case, it is recommended to address the concern immediately. Cohort instructors are valuable and have a tremendous responsibility for cohort programs as they necessitate activities outside the classroom (Maher, 2004). The concept of community should be considered since the students have all their coursework together. Faculty should also be cognizant of the possibility of groupthink occurring if pressure is placed on students. Moreover, Preis, Grogan, Sherman, and Beaty (2007) stated a cohort model could impose on a faculty member's opportunity to engage in academic freedom due to the rigid structure of the program.

Cohorts do not only provide challenges for faculty. Research has also reflected on positive outcomes and experiences for faculty. Faculty felt that by instituting a cohort program, during the planning and implementation stages, they had an opportunity to work closely with their colleagues and grow professionally and personally (Lamb \& Jacobs, 2009). Learning communities allow faculty to work in cooperation and, by collaborating, the teaching should be improved (Huerta, 2004). Hasinoff and Mandzuk (2005) found that in cohort education, faculty, social capital, and relationships do impact the overall 
development of a cohort professor's identity. Cohorts provide benefits for faculty. For instance, cohort students tended to be more appreciative, have greater participation, and are more collaborative than their non-cohort counterparts, which were considered advantageous for the faculty (Beck \& Cosnik, 2001). These results lend themselves to allow for a more robust and satisfying teaching experience for faculty. Cohort programs: (1) change interpersonal relationships, (2) cause shifts with faculty, (3) set a platform for bonding, (4) allow for a more in-depth review of issues, and (5) create an increased sense of student cohesiveness (Teitel, 1997). Faculty members who plan and facilitate a cohort model together grow personally and professionally through the collaboration, experiencing many of the same benefits as their students (Lamb \& Jacob, 2009). Research conducted by Barnett, Basom, Yerkes, and Norris (2000) found that $72 \%$ of faculty teaching in a cohort model felt the impact on students during their program. Furthermore, $52 \%$ of the faculty viewed the cohort model as an efficient delivery method. Perez, Fegadel, and Bromley's (2015) study revealed that faculty found the cohort program to enhance faculty collaboration, planning, and development of a cohesive curriculum.

\section{Connectedness and relationships}

Student connectedness. Cohorts could be viewed similarly to small families that provide support and encouragement to one another. Research has examined relationships of connectedness among students. The family-type atmosphere of the cohort model can provide a positive learning environment that allows everyone to work toward a common goal (Unzueta, Moores-Abdool, \& Donett, 2010). Looking more in-depth at the relationship, Dinsmore and Wenger (2006) identified the power of relationships as an 
essential factor that influenced the learning cohort from the participants' perspective. Additionally, they noted that learning is enriched when relationships are positive. The cohort model could produce feelings of support, respect, and inclusion between faculty, students, and members of various cohorts (Nimmer, 2009). Even though most of the students do not know each other when they begin the program, the model is structured in a way that allows the students to collaborate and build a community (Rausch \& Crawford, 2012). Stearns, Margulus, and Shinsky's (2012) study found the student network established from the cohort lasted for many years after the conclusion of the program. It was noted by Killingsworth, Cabezas, Kensler, and Brooks (2010) that the cohort experience provides networking opportunities for individuals. It also stablishes a platform where people can surround themselves with others who have different strengths, values, and beliefs. This setting allows the group to share sensitive topics, overcome group tensions, and to form a community. Nevertheless, it is important to remember a cooperative cohort agenda cannot eliminate the competitive and individualist tendencies of students (Sathe, 2009).

Faculty-student relationship. Studies have examined the relationship between the students and the faculty members within cohorts. Many cohort models often have the same faculty through the program's duration; therefore, the relationship between faculty and students has been of interest. A study by Teitel (1997) surveyed students and faculty and found that both groups thought the cohort model was very positive. One study found instructors set the foundation for a sense of belonging that established a community with a common purpose. Students were so impacted by these faculty relationships that they 
attributed this connection as helping or hindering their overall learning (Dinsmore \& Wener, 2006). In a learning community, the instructor is vital. According to Lichtenstein (2005), the instructor creates a sense of community, promotes classroom cooperation, and students developed strong relationships with their instructors. Getting to know faculty beyond the classroom and their commitment to the students was considered one of the major benefits of the cohort program. When students had concerns, those concerns were focused on the geographical location of the program from the campus and faculty, providing more focus on education, best practices, and experience requirements (Seed, 2008). The categories surrounding the concerns are all tied to the program faculty.

Research has also reviewed the contribution of cohort faculty and what services they are able to provide to the cohort students outside of classroom pedagogy. Several positive effects that resulted from student-professor participation in a cohort were identified by Beck and Kosnik (2001), which included: (1) loyalty, (2) willingness to help, (3) care, (4) social and personal growth, (5) awareness, (6) high participation, (7) quality discussions, (8) willingness to take risks, (9) expressiveness, and (10) collaboration. Cohort students enjoyed interacting with instructors from a variety of disciplines and diversity (Potthoff, Dinsmore, \& Moore, 2001). This allowed students to form new relationships. Maher (2005) discovered that faculty conversations in cohort models were more passionate and focused. The faculty and students also had a high level of information disclosure as a sense of trust increased. Seed (2008) found that faculty perceived cohort students have deeper connections, which allows the students to work better together than they had experienced in previous non-cohort students. Focusing on 
learning communities, Melnychuk (2001) found that the learning environment contributed to trust, respect, and openness, all of which allowed growth to take place. The entire cohort, including instructors, evolved in this environment to form a group of colleagues rather than the traditional teacher-student models. Research conducted by Lamb and Jacobs (2009) concluded the cohort model did not ensure coherence. Instead, the cohort model creates a framework for faculty to collaborate and instill opportunities, benefits, and services for students. A total of $66 \%$ of cohort student statements were coded under the theme of the importance of relationship and learning from their instructor. Moreover, $80 \%$ of the statements described the positive relationship students shared with the instructor, which led to unity in how these relationships fostered learning and connections.

Faculty mentor relationship. It is no surprise that, like other academic programs, cohort faculty members become mentors to the student as their relationship deepens over time. Since cohort programs have the same group of students and faculty for the duration of the program, the opportunity for mentorship deepens. According to Seed (2008) confirmed faculty mentorship happens in cohorts. This study found faculty participation in the cohort allowed students to have a different relationship with faculty, more of a mentoring relationship. The faculty mentorship was found to be exceptionally important, so important it was recommended that time be devoted to the mentor-mentee relationship development in cohorts (Mukeredzi, 2017). In comparison to non-cohort models, Maher (2004) concluded that cohort faculty provide a more intensive level of teaching, mentorship, and collaboration than in non-cohort teaching. A cohort tends to maximize the faculty's opportunities to provide support and mentorship (Nimmer, 2009). 


\section{Cohorts as groups}

Cohort group dynamics. Group dynamics are a part of all classrooms, as classrooms are made up of a group of students. Since students in a cohort take all their classes together over the duration of the program, they have an opportunity for different dynamics due to the amount of time they spend together. Each cohort is a distinct group with unique characteristics (McCarthy, Trenga, \& Weiner, 2005). Scribner and Donaldson (2001) (1) group dynamics are important in cohort models, (2) group cohesiveness is necessary for cohort learning, and (3) cohort programs should include group dynamic information early in the program and circle back to group dynamics to promote group cohesiveness. The study focused on the individual student's experiences, beliefs, and background effects on group dynamic. Scribner and Donaldson (2001) concluded that the cohort students' past experiences and biases affected the cohort group dynamics. These preconceived notions about members pigeonholed many students, which detracted from their learning and experience.

Focusing on social interactions within the classroom, McCarthy, Trenga, and Wainer (2005) found cohorts have the importance of shared culture to enhance social, personal, and educational outcomes. Social capital was identified as a major benefit of cohort models as the cohort creates networks that lead to enhanced opportunities (Umekubo, Chrispeels, \& Dalay, 2015). Supporting social capital within cohorts, small classroom size had a strong socializing effect of students allowing students to become friends and faculty to feel more comfortable (Mather \& Hanley, 1999). Cohorts' affinity to create a shared sense of identity lead to the realization that students in cohorts are not only concerned about their learning but that of their classmates' learning as well (Fedor, 
2017). Additionally, the cohort students believed they had a more positive experience of learning than they would have in a non-cohort setting. The absence of collaboration and collegiality creates conflict and frustration, and the opportunities the cohort provides are then lost (Govender \& Dhunpath, 2011).

Cohort community. Cohort models are thought to provide students with a community of support and connections since the cohorts of students learn together over time. Extensive research has been conducted studying the relationship between students and the support or lack thereof. For instance, cohort programs at the university level can create learning communities that provide students with a rich locus of study (Sathe, 2009).

Moreover, according to Tinto (2000), most students experience isolation and individualization that does not consist of involved learning. This has led educators to consider the possible impacts of learning communities that focus on community learning. Students in a cohort developed a community system rather than a hierarchical system (Cuddapah \& Clayton, 2011) and continual curricular overlap, collective teaching, and consistent group activities created a community for cohort students (Mather \& Hanley, 1999). Doolen (2014) studied a learning community test cohort and found that the cohort did not improve student success. However, they did find the students had higher levels of satisfaction with techniques used in the cohort course and a more positive attitude toward the discipline. The study suggested that collaborative learning or learning communities could be influential for student success. Engstrom, Santo, and Yost (2008) found the student discussions, group assignments, instructor facilitation, and feedback allowed the 
cohort members to feel a sense of community. Cohorts create communities among students, and the students are better equipped to work with each other in and out of the classroom (Hess \& Mason, 2005). They can be connected and make friends at the same time. Focusing on friendship within the cohort, Nimer (2009) found that cohort groups become familiar with one another, the students tend to be friends providing support with personal and educational challenges as well as celebrating their successes. Considering how cohort friendships build to form deeper relationships with the importance of trust, Sapon-Shevin and Chandler-Olcott (2001) found that cohort students were split about the necessity of friendship as a requirement for the community within the cohort. They determined trust was a common requirement of community and when the trust was absent, students felt less comfortable sharing. When trust is gained between cohort students, it allows them to provide honest feedback and disagree with each other (Bentley et al., 2004). Continuing to focus on trust, Greenlee and Karanxha (2010) found that students in the cohort felt they experienced a strong bond of trust and cohesiveness. Open communication, collaboration, and empowerment were all found to be positive effects of the cohort.

Not only has the research focused on friendship within cohort models among students, but research has also compared cohort groups to family units. Moving beyond friendship, Maher (2004) noted that cohorts provide strong interpersonal relationships for students that are similar to family relationships. Relationships within the cohort evolved, and students were like a family or a team, responsible for emotional support and care of the other cohort members (Maher, 2005). Small groups continue to provide a significant 
amount of human social experience, as noted by McGrath, Arrow, and Berdahl (2000), and cohorts are made of small groups of students. Shifting to consider Bolman and Deal's (2017) organizational frames, the human resource frame is directly correlated with the cohort model. Fellow students are like siblings, and the same group of students goes through the entire program together as a family. Moreover, families learn about each other just as cohort members learn one another's strengths and weaknesses.

To determine how these communities and relationships form, Fedor's (2017) study found that students realized that they would have classes with the same individuals for the entire duration of the program, so there was a mutual desire to get to know their classmates. As students learned each other's strengths and weaknesses, they were able to utilize those abilities to complete projects more quickly and work more efficiently (Fedor, 2017). When comparing cohorts to non-cohort groups, Maher (2004) noted that cohort students feel so strongly about their group bond that they view students who are in the same courses but are not in the cohort as outsiders. In comparison to competencybased programs, Bell and Michell (2000) found that cohort models are more advantageous when it comes to efficiencies and social/group interactions. However, they did note that competency-based education provides more advantages for students to take ownership of their education and to comprehend theory and practice. Bell and Michelle compared competency-based programs to cohort programs and found that cohort-based programs offer more social support and companionship than competency-based programs. Additionally, they found that the cohort model allows students to collaborate when studying and solving problems informally. 
Students in cohort programs not only spend classroom time together, but research has found that they tend to spend time outside of the classroom together. Students who participate actively in the classroom community are likely to meet with their classmates outside of the classroom (Tinto, 1997). The time students spend together helps them to form relationships and support units. Students in learning communities form their groups to support one another outside of the classroom and they tend to spend more time together outside of class than students in traditional programs (Tinto, 2000); many students found these groups to be critical to their continuation in college and allowed them to have more involvement and participation in the classroom. Students in Cushman's (2007) study found that they were able to overcome barriers by developing strong social and academic relationships. Many of the relationships in the study started when students joined campus organizations. Students in learning communities developed their support groups. They spend additional time together outside of class and are more active in class than those who were not in learning communities (Tinto, 2000). The time students spend together is not completely academic. They join campus organizations and attend campus events together. Cohort students in Johnson and Romanoff's (1999) study were found to spend more of their free time attending campus events compared to noncohort members. Ultimately, Sathe (2009) found that a cohort model provided a higher group commitment.

Group learning and support. Group learning, how groups learn together and provide support to encourage learning, has been studied. As the previous section mentioned, groups can shape the dynamics of the classroom. As these dynamics unfold, the impacts on learning are also considered. Students affirmed group learning within the 
cohort program. Students felt that the structure of the cohort created a natural environment for peer learning (Dinsmore \& Wener, 2006). Additionally, Tisdell, Strohschen, Carver, Corrigan, Nash, Nelson, Royer, Storm-Mackey, and O'Connor (2004) found that cohort students were able to learn from one another and did not rely only on textbook information. Additionally, it was found that members of the cohort felt that the other members were affirming and helpful during their learning experiences (Choy, Delahaye, \& Saggers, 2015). Research by Huerta (2004) concluded group learning takes place in cohort models. This allows students to talk about what they learned in class with their classmates, who are their friends. Overall, this engagement increases student learning. Rather than seeking clarification from instructors, students in cohorts will seek out information from their smaller support groups to better understand the information before asking faculty. Students exchange their questions, thoughts, and plans in order to support each other, creating a social dynamic. Agreeing, Wisker, Robinson, and Shacham (2007) claimed that the use of cohorts allows for group work to share thoughts and ideas to support development. They also stated these smaller groups are established based on friendships and proximity and Hanushek, Kain, Markman, and Rivkin (2003) discovered that groups of peer's overall achievement impact learning and overall test scores.

Research has found that cohort students tend to create an environment of support and encouragement. This environment of support bleeds into the students learning, students are connected, and they rely on each other. A study by Neir, Toledo, Baptiste, Maliszewski, and Borries (2016) found peer support was critical for cohort participation. Additionally, students support one another by providing encouragement and support 
during difficult situations and sharing exam preparation materials. The research found similar results affirming student support in cohorts. Moreover, Unzueta, Moores-Abdool, and Donet (2010) discovered that the cohort helped motivate students when they felt overwhelmed. They did not want to let the rest of the group down. All students were working toward the same goal. Students can develop a network of support when they are involved with a shared learning group, allowing students to bond socially and engage more academically. Participation in these groups encourages attendance and active participation in the classroom. Cohort students were considered part of a community that developed around common learning, cognitively and at an emotionally supportive level (Drago-Severson, Helsing, Kegan, Popp, Broderick, \& Portnow, 2001). Cohort students studied in Dinsmore and Wener's (2006) research were found to share an intense bond with their fellow students as they relied on others' feedback and collaboration to contribute to their overall learning. Cohort models create group collaboration among administrators, faculty, cohort alumni, and current cohort students, according to Nimer (2009). As well as positive peer relationships formed familial and emotional ties, team-views, and responsibilities, according to Seed (2008). Recommended by Nimer (2009) to ensure cohesiveness, students should meet with various members of the cohort rather than the same people repeatedly. Scribner and Donaldson (2001) found that social relationships of the studied cohort were so powerful they needed to be accounted for in relation to education and learning. They also determined that learning and performance were not deemed to be the same, meaning, learning was not indicative of a student's performance to demonstrate what was learned. Overall, the cohort students found the cohort model to help them deal with isolation and feeling like they were a part of a 
community (Slater \& Trowbridge, 2000). Research by Tinto (2000) concluded that learning communities bridged the gap between academic and social life. Students in learning communities learn and make friends at the same time. After focusing more deeply on group relationships, Potthoff, et. al (2001) described the personal and professional respect for cohort members as striking. Students are committed to learning about one another's personal and professional lives and that cohort groups provide a setting for bonding of students and faculty. Once the program ended, the relationships did not end. The students continued to use social media and students remain connected well after the conclusion of the program (Fedor, 2017). One consideration for these continued relationships could be intense connections between the students.

Online learning. Cohorts are not limited to a face-to-face format. Many cohorts are online. The online format compared to the face-to-face format is of interest as students might not feel as comfortable in both learning environments and could prefer one format over the other or feel indifferent. Online community groups and support have been studied in comparison with face-to-face cohorts. Additionally, how students form relationships in an online cohort program is relevant to consider. If students can still form valuable relationships regardless of the format, then the relationship-building might be attributed more to the cohort. Online cohort groups reflected the same sense of presence and intimacy that fosters a familial experience as that of a face-to-face cohort (Conrad, 2005). In an online cohort program with a mandatory residential orientation before the start of the study, Tisdell et al. (2004) discovered the relationships that formed during the face-to-face orientation continued to develop and members continued to learn about one another as the program progressed and engage in mutual respect. 


\section{Challenges}

No program is without challenges and cohort models are no exception. Past research has identified numerous challenges related to cohort models. It is important to realize that cohorts are not perfect. There are challenges and drawbacks when groups of people interact over time. Cohort models are not the only or ideal solution to student learning (Tinto, 2000). It is crucial to keep in mind that not all students enjoy learning with others and not all faculty like to participate in the collaborative curriculum. Agreeing, Zhao and Kuh (2004) concluded that learning communities are not silver bullets. They have limits and complications. Rather, the learning communities do not produce immediate positive results. The effects are more likely indirect. Tinto (2000) stated learning cities are not 'magic bullets' to enhance student learning and they, too, have constraints on effectiveness. Ultimately, a balance between the challenges, positive experiences, and outcomes must be created. Research by Nimer (2009) concluded that being part of a cohort group is a considerable task and, at times, very demanding. However, Nimer claimed, the rewards are great and well worth the hard work.

Considering the challenges of relationships, Maher (2005) determined that some students view peer interactions as tasks, whereas others considered their interactions to be more family oriented. Peer relationships in cohort programs were found to be a doubleedged sword (Dinsmore \& Wener, 2006). For instance, 63\% of reported statements by students promoted the cohesiveness of the cohort, whereas $37 \%$ found the relationships within the cohort inhibited their learning. A cohort program created a community with students working well together, but they were not all friends, and the students did have tension among themselves (Ross et al., 2006). Supporting the challenges of cohort 
relationships, Unzueta, Moores-Abdool, and Donet (2010) found the studied cohort group had an adjustment period at the start of the program when everyone was getting to know each other. After the initial acquaintance period, some of the students formed cliques. Additionally, Barnett, Basom, Yerkes, and Norris (2000) claimed the cohort structure could lead to cliques or factions that would destroy the cohesiveness of the overall morale of the group. Moreover, the faculty was concerned about their relationship with students of cohort models due to the strong personalities of students and how the students in groups can become difficult to handle. Faculty noted the cohort group was supportive and relational; however, the faculty did face some challenges with the cohort in relation to (1) racial and cultural issues, (2) development of cliques, and (3) general differences between faculty and students. Faculty found it especially challenging to come into an established cohort after it had already been formed with existing norms and relationships (Unzueta, Moores-Abdool, \& Donet, 2010). It is also important to note that students have barriers to the community (Sapon-Shevin \& Chandler-Olcott, 2001). They may be hidden under the surface of interactions and not apparent to faculty.

Looking further into the relationship dynamics among cohort students, Mandzuk, Hasinoff, and Seifert (2003) found that a challenge of the cohort model is that too much focus is placed on bonding rather than bridging relationships. Additionally, when strong group identities emerged, they tended to stifle diverse voices which creates a culture of conformity. The students with leadership and social skills benefited from the cohort model whereas who are lacking those skills are not as well served by a cohort model. Cuddapah, and Clayton (2011) mentioned that groupthink was an issue that occasionally happened with the cohort. Groupthink occurs when everyone agrees without really 
considering the topic or students might not feel comfortable going against the majority of the group responses. At any rate, caution should be exercised to prevent groupthink in cohort learning. Some students in the cohort would dominate the class and create a single voice for the group, according to a study conducted by Mather and Hanley (1999), although the voice was not necessarily representative of the entire class. It was concluded that students did not speak up as a result of those dynamics.

Not only were some challenges revealed for students within the cohort, but challenges were also apparent based on the cohort student's perception of other students who were in the cohort. Carrell, Fullerton, and West (2009) found that students in learning communities have limited interactions with students outside their cohort group. Students in the cohort program seemed to think of the students in other cohort groups as distinct 'others'; therefore, Ross, Stafford, Church-Pupke, and Bondy (2006) concluded that it is important for a cohort to create a solid community. Still, it is just as important to show respect for individuals outside of their cohort group. A study conducted by Unzueta, Moores-Abdool, and Donet (2010) received feedback that the cohort limited student interaction with other students since they only work with students who are in the cohort. Students felt this limited their opportunity to be exposed to ideas and interests outside the cohort.

Research has also identified some challenges that students face. These challenges could be self-inflicted and not necessarily a result of the cohort. Many students' focus was on productivity and this focus, at times, impeded learning as students (Scribner \& Donaldson, 2001). The cohort students were so focused on producing work that they were not able to fully digest and comprehend the topics on a deeper level. Agreeing, 
Bernauer, Semich, Kletzin, and Holden (2013) discovered a concern about accelerated cohort programs at the doctoral level. Students do not have as much time to fully engage and develop the skills necessary to complete their degree requirements as they would in a traditional program. The program was so packed with information students did not have the opportunity to fully engage in discussions or have opportunities for applied learning. Outlining a few positive and negative effects of the cohort program, Mather and Hanley (1999) found the outcomes included (1) emotional and academic support, (2) friendship, and (3) work ethic establishment. On the other hand, students were competitive with one another. Lei et al. (2011) specified that cohort programs facilitate the competitive nature of students and may create unnecessary pressure for students.

Cohorts are not without challenges, and the cohort should attempt to minimize the challenges as much as possible. Ultimately, the benefits of the program should outweigh the challenges. McPhail, Robinson, and Scott (2008) determined there are positive aspects to cohort models as well as some drawbacks, therefore it is understandable why Maher (2005) suggested educators use caution before implementing cohort models.

Overcoming challenges. Not only do students have academic challenges that impede degree completion, they also must overcome personal challenges that could interfere with their educational goals. Cohort models have attempted to account for those challenges. Students in learning communities form their groups to support one another outside of the classroom and they tend to spend more time outside of class together than do students in traditional programs (Tinto, 2000). Many students found these groups to be critical to their continuation in college and allowed them to have more involvement 
and participation in the classroom. Learning communities were beneficial when dealing with isolation, because that leads to withdrawing from the program (Johnson, 2000). To combat isolation, students were able to overcome barriers by developing strong social and academic relationships within cohorts (Cushman, 2007). Many of the relationships in the study began when students joined campus groups or organizations. Additionally, the cohort helped to motivate students when they felt overwhelmed. Students did not want to let the rest of the group down as they were all working toward the same goal. Students develop a network of support when they are involved with a shared learning group, allowing students to bond socially and engage more academically. Participation in these groups encourages attendance and active participation in the classroom (Unzueta, Moores-Abdool, \& Donet, 2010).

\section{Cohort Program Outcomes}

Leadership. Leadership has traditionally been a focus of group dynamics and has been studied extensively. Leadership and how individuals handle situations have been studied throughout history. Persons in leadership positions are continuously analyzed; therefore, it is not surprising that leadership within cohort groups is a research focus. Students who participated in cohort models were more confident and demonstrated increased leadership skills (Fedor, 2017). Cohort students possess leadership and professional skills that contribute to the academic program just as much as the prescribed curriculum (Butterwick, Cockell, McArthur-Blair, MacIver, \& Rodrigues, 2012).

The cohort program has found that, in some cases, confidence is a program outcome. Cohort education provided students with high levels of confidence (Govender 
\& Dhunpath, 2011). Students were able to find confidence because they were able to provide support to each other and receive support when needed. However, students who enter the program could be confident prior to entry, and confidence could have just been affirmed but not necessarily developed (Fedor, 2017).

Academic outcomes. Research has examined cohort programs for outcomes that the students and faculty experience. Academic outcomes are a top priority for cohorts as the program is designed with a specific structure to produce results. Students who participated in learning communities had enhanced academic and social experiences and gained competence, skills, and knowledge during their college experience (Zhao \& Kuh, 2004). Researchers Reynolds and Sitharaman (2000) compared cohort student and noncohort student GPAs and found that cohort students had higher GPAs; however, the results were not significant. Students in learning communities felt that their writing ability improved, speaking in class was more comfortable, and they felt their instructors were accessible and caring (Lichtenstein, 2005). Cohort students have a greater opportunity to examine various topics at a deeper level by reflecting on the material, situations, and sharing past relatable experiences (Teitel, 1997). Students in a learning community benefited from engagement which is related to educational gains (Rocconi, 2011). Learning communities have a positive impact on student achievement and retention (Zobac, Spears, \& Barker, 2014). A research study by Maher (2005) stated that before the cohort began, students did not think the cohort model of education would have an impact on their learning; however, they quickly realized that they had underestimated the impact of the cohort model effects as they were able to directly experience the contributions of their classmates. Student teachers placed in a cohort found their 
education was directly relatable (Beck \& Cosnik, 2001). Regardless of the students' major, Johnson and Romanoff (1999) concluded that students in the studied learning community were academically satisfied with their educational experience. In addition to academic outcomes, some general outcomes were also acknowledged from the research. Cohort program advantages and drawbacks were identified by Barnett, Basom, Yerkes, and Norris (2000); the advantages of cohort models included: (1) support positive interpersonal relationships, (2) collegiality, (3) cooperation, (4) a sense of belonging, (5) networking, (6) cohesiveness, (7) trust, (8) mutual support, (9) efficient program delivery in relation to enrollment management, (10) precisely predictable enrollment and scheduling, (11) positive faculty advisement, (12) faculty-student relationships, and (13) the promotion of lasting professional relationships. On the other hand, the drawbacks identified were: (1) the costs due to the sequencing for faculty resources, (2) negative impact on students regarding cliques, (3) unrealistic course loads for students who have responsibilities outside the classroom, and (4) potential negative relationships between students and faculty. Cohort models offer students a wide range of opportunities and skills according to Lawrence (2002). These attributes consist of communication skills, conflict resolution, and accountability. The cohort also fosters a shared space to share knowledge and information. Researchers Drago-Severson, Helsing, Kegan, Popp, Broderick, and Portnow (2001) studied three different cohort designs and found students from all three cohort designs felt a sense of belonging and believed their cohort experiences were beneficial. The students thought the cohort experiences lead to academic learning, belongingness, and broadened perspectives. According to Swayze and Jakeman (2014), technology strongly influenced cohort communication and 
accelerated students' communication patterns. Santicola and Morris (2013) examined a cohort and non-cohort group. They found the cohort group had higher satisfaction than non-cohort members. In support of cohort models, Engstrom, Santo, and Yost (2008) concluded that the members of the cohort studied would not only be in a cohort program again, but they would also participate in the same cohort they just completed again.

Persistence, retention, program completion. Not every student who starts a college program is able to complete the program. Cohort programs work to account for many of the causes that could lead to student dropout. According to Moller-Wong, Shelley, and Ebbers (1999), the persistence of college students is important not only to educators but to professionals and the public. Therefore, academic intuitions should identify a system to monitor and track attrition and then share factors that support increased attrition rates. Many students find obstacles they are challenged to overcome in order to complete their academic programs. Motivation to complete a degree can be difficult, especially for students who have full-time jobs and commitments to not only themselves, but their families as well (Unzueta, Moores-Adbool, \& Donet, 2010; Nimmer, 2009). Students' challenges to deal with family obligations, financial responsibilities, and academic requirements should be considered in the development and implementation of a cohort model (Nimmer, 2009). Many of the students have numerous responsibilities and are not necessarily equipped to focus on education since they typically have full-time jobs and family responsibilities. Frequently, students will take a semester off to manage personal responsibilities and will never re-enroll in courses or complete their degrees. This results in higher education facing challenges with retention rates. 
Within higher education, the quest to find tools, resources, programs, systems, etc., to help with retention are countless. Cohort models could be a possible way to assist universities with their program retention. To help increase retention rates for students, it would be beneficial to consider the implementation of cohort-based curriculum programs as cohort models have been associated with retention (Bista, \& Cox, 2014; Lamb \& Jacobs, 2009; Maher, 2003; McCarthy, Trenga, \& Weiner, 2005; Nimmer, 2009). A common factor of cohorts is to promote retention, graduation, and overall student success (Lei et al., 2011). The Potthoff, et. al (2001) study found students in a cohort group had a higher retention rate with $90 \%$ of students completing the program. However, this rate could be due to other factors besides the cohort model. Yet, Case and Hernandez (2013) found the cohort model retained students at higher rates, $50 \%$ for the first cohort, $82 \%$ for the second cohort, and the students in the program graduate at a rate higher than the national average.

When cohort programs are compared to non-cohort programs, there have been some positive findings to support greater retention. Based on a study conducted by Johnson (2000), students in a learning community were retained at a higher rate than students who were exposed to less structured retention efforts. Additionally, students in learning communities were retained at a higher rate than other students at the university. Baker and Pomerantz (2001) found students in learning communities were more likely to have (1) achieved higher grade point averages, (2) better fall to spring retention, (3) more credit hours earned, (4) fewer on probation, (5) more students in honors programs, and (6) fewer course drops than students enrolled who were not enrolled in learning communities. It was determined that students were more likely to continue enrollment in 
their classes when they were a part of the learning community than those who were not. The learning community students were more engaged in student activities and had greater satisfaction with the university than those not enrolled in the learning community. Students who participated in a learning community experienced a higher grade point average, and retention for these students was increased (Hotchkiss, Moore, \& Pitts, 2006). Participation in a cohort program at the doctoral level increased the chances of program completion for all students within the cohort (Nimer, 2009).

With the findings of retention and persistence associated with cohorts, researchers have worked to identify some of the contributing factors of cohorts that lead to retention. Specific characteristics that contributed to persistence in the doctoral program were identified by Santicola and Morris (2013). These included (1) commitment/discipline, (2) putting the program first, (3) preference to work independently and research alone, and (4) full-time employment. Learning communities were beneficial when dealing with isolation, which is a cause that leads to withdrawing (Johnson, 2000). The learning community helped students create goals and be more committed to completing their degree. Many students profess that successful degree completion is a top goal of their college education experience. Consequently, it is then essential to review the retention and persistence of cohort models and how they contribute to an educational outcome or lack thereof. Researchers also studied how students in cohorts form relationships to support each other and how those relationships supported retention. Students in cohort groups motivate each other to complete tasks and provide a family atmosphere that keeps students from quitting (Unzueta, Moores-Abdool, \& Donet, 2010). The student experience was identified as a contributing factor to doctoral cohort success (Brill, 
Balcanoff, Land, Gogarty, \& Turner, 2014). The program relationships, networks, and mentorship all provide students with academic support, which leads to success and graduation. Not only were the student relationships studied, but the faculty-student relationship's possible effects on retention have been considered. The faculty-student relationship was considered a possible factor of retention within cohorts. Faculty mentorship also influences doctoral student retention (Brill et al., 2014).

Past retention research was applied to cohort models to see how the theory of retention and persistence is evident in cohort models. The combination and balance of social experience and academic involvement has been found to promote persistence and retention. Persistence is influenced by social and academic involvement (Tinto, 1997). Learning communities create a bridge between the academic and social worlds (Tinto, 1997). The bridge is forged when social dynamics and relationships are intentionally built into the cohort curriculum. Tinto (2000) found that students in learning communities were more socially and academically engaged and persisted at a higher rate than traditional students.

Not only do students have retention challenges, but high-risk students are even more prone to retention risks. Cohorts have also attempted to create opportunities for high-risk students and facilitate a learning platform that allows them to persist through a program. Looking at students who were considered high-risk, Hess and Mason (2005) found that high-risk students in a learning community at a community college had a higher retention rate than that of a regular non-risk population. Additionally, high-risk students in the cohort had a higher grade point average than those considered high risk and not cohort participants. Ultimately, investing in learning communities is worth 
the time, funds, and effort as at risk-students are more likely to experience successful completion of their degrees than if they were not in a learning community (Johnson, 2000).

Employment outcomes. In theory, education often leads to employment; therefore, it is important to focus on cohort models in relation to the work setting and employability. Cohort models created an environment that represented the workplace (Sathe, 2009). Students realized that their reputations within the cohort could be affected positively or negatively, just as in the workplace. Students also disclosed that gossip, politics, competition, and no new people were considered drawbacks to the cohort model, similar to the workplace.

Education is considered preparation for a career or specific employment. Similarly, cohorts have been studied to determine students' preparedness for employment. Sathe (2009) found cohort students realized the importance of socially learned dimensions of their discipline's profession, specifically through the interpersonal and group-work skills. The study did uncover individualistic and competitive tendencies. After students experienced those tendencies, they felt prepared for workplace situations, should they arise. Robinson, Beachboard, and Adkison (2011) found participation in a cohort was statically insignificant concerning academic development. However, they did find that cohort participation was statistically significant for employment preparation. Interpersonal skill development was one of the most successful and valuable aspects of the cohort model, and employers affirmed the development of the interpersonal skills of the cohort members (Sathe, 2009). Semich, Kletzin, and Holden (2013) found cohortbased programs target working professionals due to their 'executive-style.' In this 
structure, students do not have to spend as much time on campus and the relationships formed are mainly in the classroom only. Engstrom, Santo, and Yost (2008) found the biggest challenge was the maintenance of relationships since the members of the cohort were also working professionals in the same school district. Since the cohort students also worked together, their attitudes, biases, and workplace relationships were a factor that had to be considered in the relationship dynamics.

\section{Summary}

From the research review it is evident that cohorts have been studied extensively in higher education including the structure, the relationships, student and faculty characteristics, benefits, and overall program outcomes. After reviewing the past research conducted on cohort models, there appears to be a gap in research focusing on specific student demographics. There has been some research in this area, but not extensive. The race, ethnicity, and gender of students in cohorts are not overly represented in the current research on cohort programs. While there has been some past research on these areas, it is not extensive.

While cohort programs have been formed at the undergraduate, graduate, and professional educational levels, there were not any studies that reviewed cohort programs with high school students taking college-level courses or programs that combined both high school and postsecondary students in a college program. With these groups in mind, there did not appear to be any research on the retention and program completion of high school students enrolled in college courses or students based on race or ethnicity. Most of the retention and program completion rates found in past studies were based on the outcome of the studied cohort or the cohort compared to a non-cohort group. This lack of 
research could be due to there not being many programs of this nature with a cohort structure in place. This study hopes to contribute to the body of research on cohort models by conducting a study to address these specific gaps. 
SECTION FOUR

CONTRIBUTION TO PRACTICE 


\section{Introduction}

This study reviewed the current TEC cohort programs at KCKCC with a goal to learn more about TEC cohort models and determine how they influence persistence, retention, program completion rates, and student connectedness. Cohort models provide many of the outcomes necessary for retention and persistence to graduation in alignment with Tinto's (1993) retention theory. Cohort models offer stability, which is reassuring in the current climate of reduced governmental funding. The TEC programs are comprised of high school students and postsecondary students. These two groups of students were studied and compared to determine the cohort effects on each group. The findings contribute to the body of knowledge regarding technical education, cohort models, and high school students enrolled in TEC programs. Additionally, this study explored minorities in cohort models and their retention. This knowledge will provide other community colleges additional information that can be used to make more informed decisions about how to leverage resources to promote retention, as well as certificate completion and connectedness with students and faculty.

The remainder of this section includes the presentation slides that will be shared with KCKCC dean's council. The dean's council membership is comprised of the academic and non-academic deans, the vice president of academic affairs, the vice president of student affairs, and the KCKCC president. 
Kansas City Kansas Community College Dean's Council slide presentation

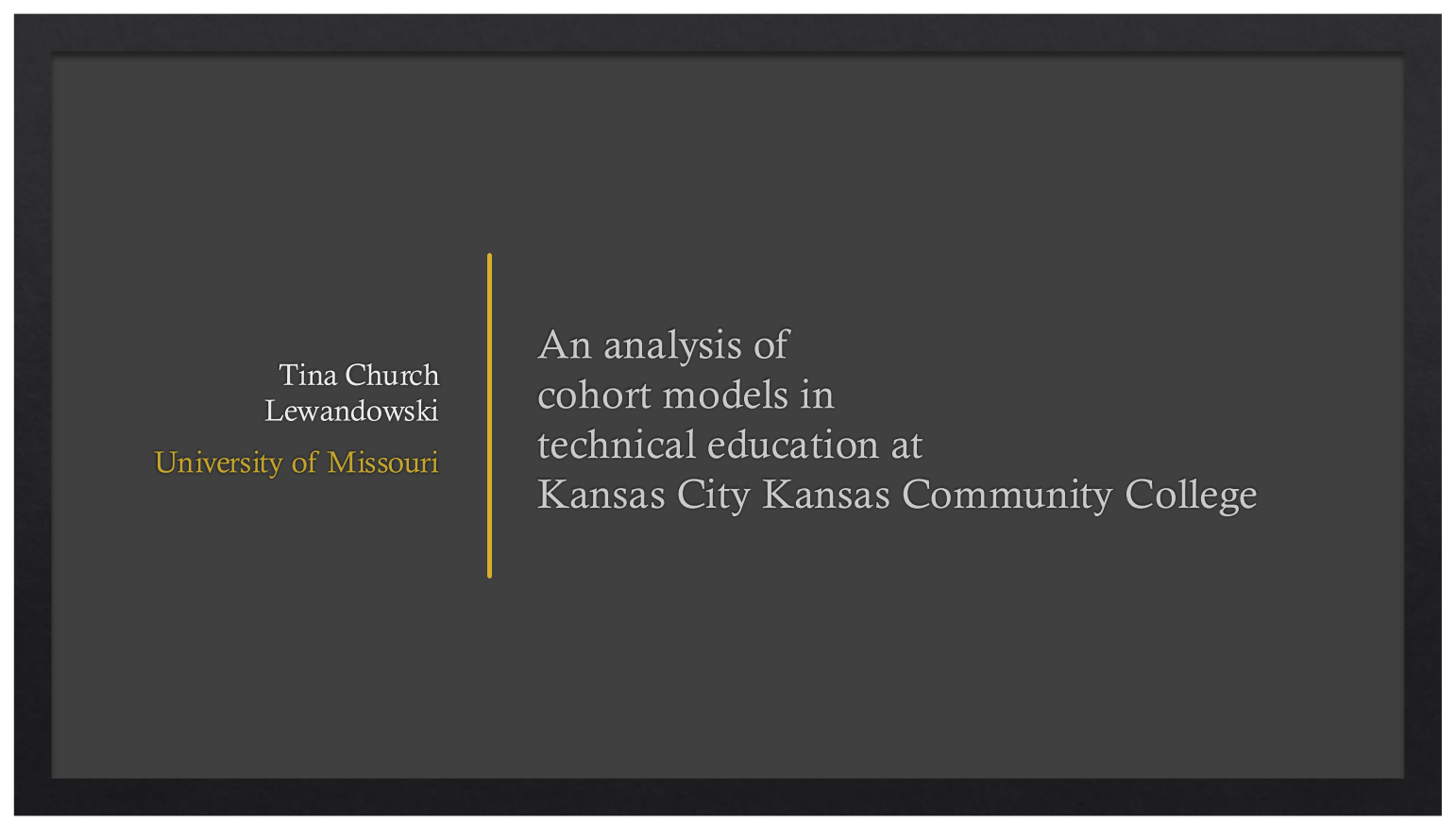




\section{Statement of the Problem and Purpose}

- Gap in research

๑ TEC cohort model retention

student types (high school and postsecondary)

$\diamond$ student demographics

completion rates

$\diamond$ relationship dynamics

- Results from the study

$\diamond$ promote TEC program completion for students

$\diamond$ reframe organization and structure of the TEC cohort programs 


\section{Literature Review}

$\diamond$ Gap

$\diamond$ TEC programs

$\diamond$ High school and postsecondary

$\diamond$ Race, Ethnicity, and Gender

- Cohort Structure

- Cohort Relationships/Groups

- Cohort Outcomes

*References available at the end of the presentation 


\section{Research Questions}

\section{Quantitative}

1. Is graduation of a TEC cohort program independent of a student's level (high school and postsecondary)?

2. Is graduation of a TEC cohort program independent of a student's race/ethnicity?

3. Is graduation of a TEC cohort program independent of a student's age at the start of the program?

4. Is graduation of a TEC cohort program independent of a student's gender?

\section{Qualitative}

5. What are the reasons for students' continued enrollment in the TEC cohort program?

6. What forms of support within the TEC cohort program encouraged students' program completion?

7. According to students, why do TEC cohort models support program completion?

8. What supportive contributions do TEC cohort faculty perceive should be provided to students? 


\section{Method/Participants}

Data Collection

๑ Student survey

- 42 high school and postsecondary TEC students participated

- Faculty and student individual virtual interviews

- $10 \mathrm{TEC}$ faculty and three high school and postsecondary students

- KCKCC TEC cohort program data

- 3308 student records from fall 2009 - fall 2020 


\section{Data Analysis}

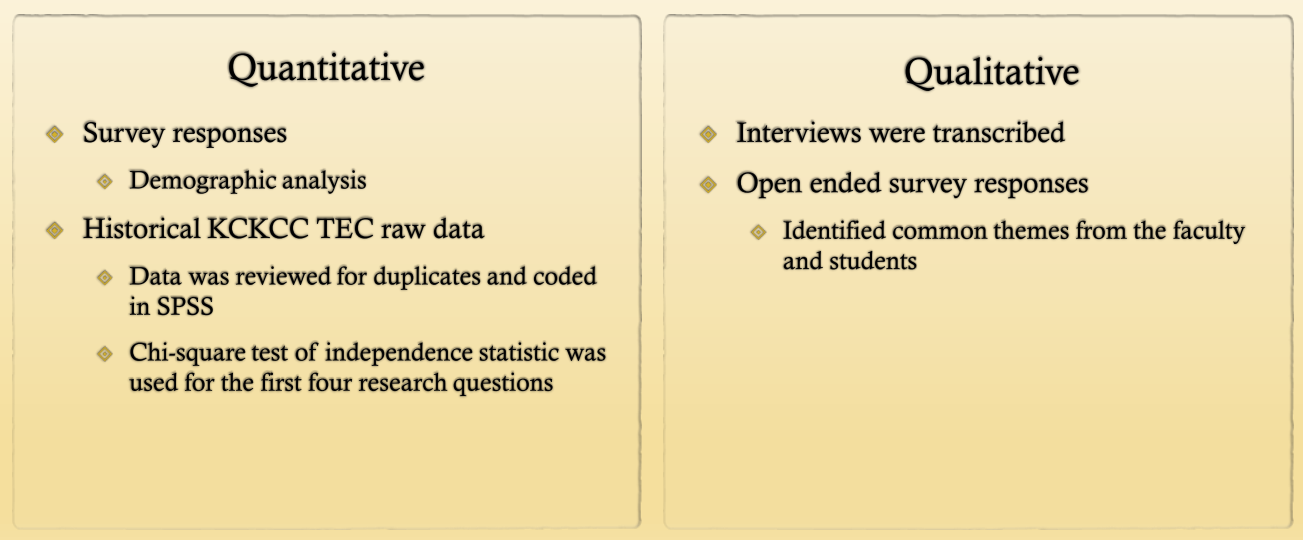




\section{KCKCC Data Demographics}

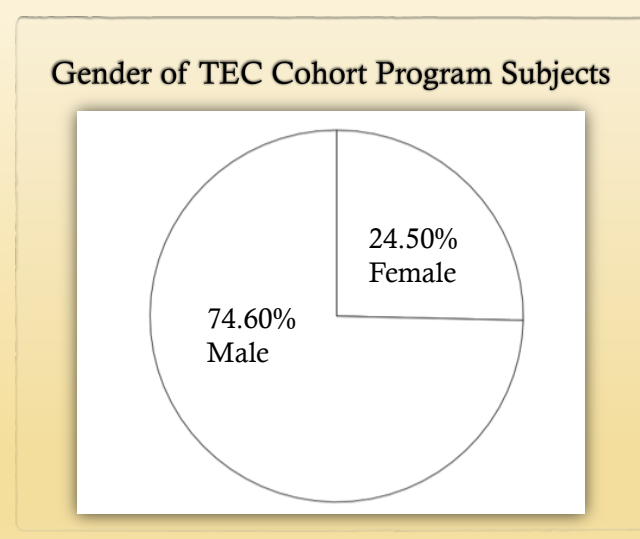

High School or Postsecondary TEC Cohort Program Student Levels of Participants

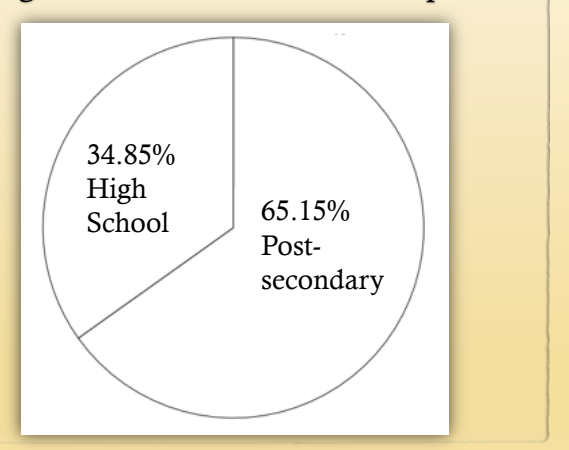




\section{Question 1: Is graduation of a TEC cohort program independent of a student's level (high school and postsecondary)?}

The number of students who graduated from a TEC cohort program differed by high school and postsecondary levels, $\chi^{2}(1, \mathrm{~N}=3308)=114.27, \mathrm{p}<.001$.

จ Reject the null hypothesis and conclude that there is an association between high school and postsecondary student level and whether or not they graduated from a TEC cohort program.

- Basically, postsecondary students graduate from the KCKCC TEC cohort programs at a higher rate than high school students. 


\section{Question 2: Is graduation of a TEC cohort program independent of a student's race/ethnicity?}

The relationship between these variables was significant, $\chi^{2}(6, \mathrm{~N}=3308)=51.91$, $\mathrm{p}<.001$.

$\diamond$ Reject the null hypothesis and conclude that there is an association between students' race/ethnicity and whether they graduated from a TEC cohort program.

White and Asian students graduated more than expected

- Multiracial students graduated as expected

Black/African American, Hispanic, and unknown race/ethnicity graduated less than expected 


\section{Question 3: Is graduation of a TEC cohort program independent of a student's age at the start of the program?}

- To determine if a significant relationship existed between students' age when they started a TEC cohort program and whether or not they graduated from a TEC cohort program, $\chi^{2}(12, \mathrm{~N}=3305)=124.12, \mathrm{p}<.001$.

$\diamond$ Reject the null hypothesis and conclude there is an association between students' age and whether they graduated from a TEC cohort program.

- Students who were 19 and younger did not graduate as expected

- Students between ages 20-59 graduated at a higher rate than expected

$\diamond$ Students who were 60 and older graduated at a level that was relatively close to expected 


\section{Question 4: Is graduation of a TEC cohort program independent of a student's gender?}

- To examine the relation between students' gender and whether or not the students graduated from a TEC cohort program. The relation between these variables was not significant, $\chi^{2}(1, \mathrm{~N}=3308)=3.17, \mathrm{p}=.075$.

$\diamond$ Fail to reject the null hypothesis as the results do not provide support for a relationship between gender and graduation. 


\section{Question 5: What are the reasons for students' continued enrollment in the TEC cohort program?}

\begin{tabular}{l}
\multicolumn{1}{|c|}{ Student Themes } \\
Relationships \\
- Hands-on learning experiences \\
- Career options \\
- Starting their college education earlier before \\
they graduate High School \\
Student attitude/determination
\end{tabular}

\section{Students' Survey Comments}

- "I wanted to make a dream a reality."

- "I've always wanted to do more for myself."

- "I'm self-driven." 


\section{Question 5: What are the reasons for students' continued enrollment in the TEC cohort program?}

\section{Faculty Themes}

\section{- Cohort structure}

$\diamond$ Some self-pacing opportunities

- Relationships

- Hands-on learning experiences

- Career options

- Starting their college education earlier before they graduate High School

- Student attitude/determination

\section{Faculty Interview Comments}

- "The cohort's concentrated structure actually saved students, because students are aware of the duration upfront, they are focused and motivated to continue."

- "I've seen students overcome repeated challenges to complete the program while other students are just looking for a reason to drop out of the program, even if that student is outstanding." 


\section{Question 6: What forms of support within the TEC cohort program encouraged students' program completion?}

\author{
Student Themes \\ Real-life experiences and workplace \\ simulations \\ Checking-in on the students \\ - Cohort structure and curriculum \\ Relationships with professors and classmates \\ provided support
}

\section{Student Survey Comments}

- "My classmates and teachers lift me up." 


\section{Question 6: What forms of support within the TEC cohort program encouraged students' program completion?}

\author{
Faculty Themes \\ Faculty shared KCKCC and external \\ resources \\ Real-life experiences and workplace \\ simulations \\ - Checking-in on the students/side \\ conversations \\ - High School facilitators/parents \\ - Cohort structure and curriculum \\ - Relationships with classmates provided \\ support
}

\section{Faculty Interview Comments}

- "Without trying to sound like a parent, I try to use classroom situations and draw parallels to real-life scenarios and try to talk about how to make good choices."

- "I look at their faces when they walk in the classroom and how they are walking, and I can tell if something is up with a student because I have really gotten to know the students." 


\section{Question 7: According to students, why do TEC cohort models support program completion?}

Student Themes
Relationships
Supportive faculty
Hands-on experience

\section{Students Survey/Interview Comments}

- "Classmates made it fun," and they "created bonds with each other."

- "Working with the same group of students encouraged me to continue in the TEC program. I loved working with all of my peers and being able to learn from all of them and created a bond."

- "The teachers were the ones that I always wanted to come back and learn more from."

- "I would have even liked more opportunities for workplace situations, like working outside in the rain, snow, hot days, just to have more work-like experiences." 


\section{Question 8: According to the TEC cohort faculty, what supportive contributions do they perceive should be provided to students?}

\begin{tabular}{|l|l|}
\hline \multicolumn{1}{|c|}{ Faculty Themes } & Faculty Interview Comments \\
- Enhanced cohort structure & "Structure could be enhanced to serve \\
students better." \\
Academic support for students \\
Formalized job placement \\
"We are creating a workforce for tomorrow, \\
so I always want to make sure we're doing \\
things to help them get a job." \\
\hline
\end{tabular}




\section{Overview}

\section{Quantitative Analysis}

More likely to complete

1. white or Asian race

2. ages ranging from $20-59$

3. postsecondary level

\section{Qualitative Analysis}

Reasons for completion

1. relationships with classmates and faculty

2. student attitude/desire to meet goals

3. academic preparedness/personal challenges

4. cohort structure 


\section{Recommendation 1: Prior enrollment academic testing and program interest}

- Provide students with more information about the program prior to enrollment

- Require placement testing or minimum earned grades prior to enrollment 


\section{Recommendation 2: Career and internship placement}

- Direct employment placement upon program completion

$\diamond$ Develop relationships with local industries/companies to create employment pipelines

Host career fairs and company interview days

$\diamond$ Create industry related internship programs 


\section{Recommendation 3: Part-time enrollment options for postsecondary students}

- Create a part-time postsecondary track

Each program would have three tracks:

- a full-time track of postsecondary students

- part-time morning track for postsecondary and high school students

- part-time afternoon track for postsecondary and high school students 


\section{Recommendation 4: Clear pathways for students to} transition from high school to postsecondary status

- Create a clear transition pathway from high school status to postsecondary status

$\diamond$ Advising

- Goal planning, program completion, financial aid, logistics, support, and career options

- Advising and enrollment must take place before high school graduation

- Create summer enrollment opportunities or internships 


\section{Recommendation 5: Support for minority students}

- Educate faculty about the needs of minority students, specifically, Black/African American students

Encourage faculty to provide more support to those students

$\diamond$ More check-ins

- Connect existing minority groups on campus with the KCKCC TEC programs

- Encourage successful minority graduates to connect with current KCKCC TEC students to share their experiences and provide advise 


\section{References}

Baker, S., \& Pomerantz, N. (2001). Impact of learning communities on retention at a metropolitan university. Journal of College Student Retention, 2(2), 115-126. Barnett, B. G., Basom, M. R., Yerkes, D. M., \& Norris, C. J. (2000). Cohorts in educational programs: Benefits, difficulties, and the potential for developing school leaders. Educational Administration Quarterly, 36(2), 255-282.

Bentley, T., Zhao, F., Reames, E., \& Reed, C. (2004). Frames we live by: Metaphors for the cohort. The Professional Educator, 5, (2), $39-44$.

Bista, K. \& Cox, D. W. (2014). Cohort-based doctoral programs: What we have learned over the last 18 years. International Journal of Doctoral Studies, 9, 1-20.

Bolman, L. G., \& Deal, T. E. (2017). Reframing organizations: Artistry, choice and leadership (6 $6^{\text {th }}$ ed.). Hoboken, NJ: Jossey-Bass

Case, K. F., \& Hernandez, R. (2013). But still, I'm Latino and I'm proud: Ethnic identity exploration in the context of a collegiate cohort program. Christian Higher Education, $12(1 / 2), 74-92$. Fedor, J. (2017). Cohort models of learning: Adapting content to women's learning styles. Journal of Leadership, Accountability and Ethics, 14(4), 31-44.

Kansas US Department of Education. (2020). Excel in CTE (formerly Senate Bill 155). Retrieved from https://www.ksde.org/Agency/Division-of-Learning-Services/Career-Standards-andAssessment-Services/CSAS-Home/Career-Technical-Education-CTE/Initiatives/Senate-Bill-155 Lei. S., Gorelick, D., Short, K., Smallwood, L., \& Wright-Porter, K. (2011). Academic cohorts: Benefits and drawbacks of being a member of a community of learners. Education, 131(3), 497504.

Lichtenstein, M. (2005). The importance of classroom environments in the assessment of learning community outcomes. Journal of College Student Development. 46(4), 341-356. Mather, D. \& Hanley, B. (1999). Cohort grouping and preservice teacher education: Effects on pedagogical development. Canadian Journal of Education, 24(3), 235-250.

Mello, R. (2003). The integrated cohort program: An elevation of a preprofessional course of study. The Educational Forum, 67(4), 354-362.

Nimer, M. (2009). The doctoral cohort model: Increasing opportunities for success. College Student Journal. 43(4), 1373-1379.

Reynolds, K. C. \& Hebert, F. T. (1998). Learning achievements of students in cohort groups. The Journal of Continuing Higher Education, 46(3), 34-42.

Reynolds, K. C. \& Sirharaman, S. (2000). Business education in cohorts: does familiarity breed learning? The Journal of Continuing Higher Education, 46(3), 34-42.

Ross, D. D., Stafford, L., Church-Pupke, P., \& Bondy, E. (2006). Practicing collaboration: What we learn from a cohort that functions well. Teacher Education and Special Education, 29(1), 32-43.Journal of Business and Training Education, 9, 29-44.

Tinto, V (1993). Leaving College: Rethinking the Causes and Cures of Student Attrition. Chicago, IL: University of Chicago Press.

Unzueta, C. H., Moores-Abdool, W., \& Donet, D. V. (2010). Perceptions of special education professors and culturally linguistically diverse doctoral students on cohorts. Teacher Educator and Special Education, 33(2), 169-182.

Zobac, S., Spears, J., \& Barker, G. (2014). Identical profiles, different paths: Addressing self-selection bias in learning community cohorts. Learning Communities Research and Practice, $2(1 / 3), 1-13$. 


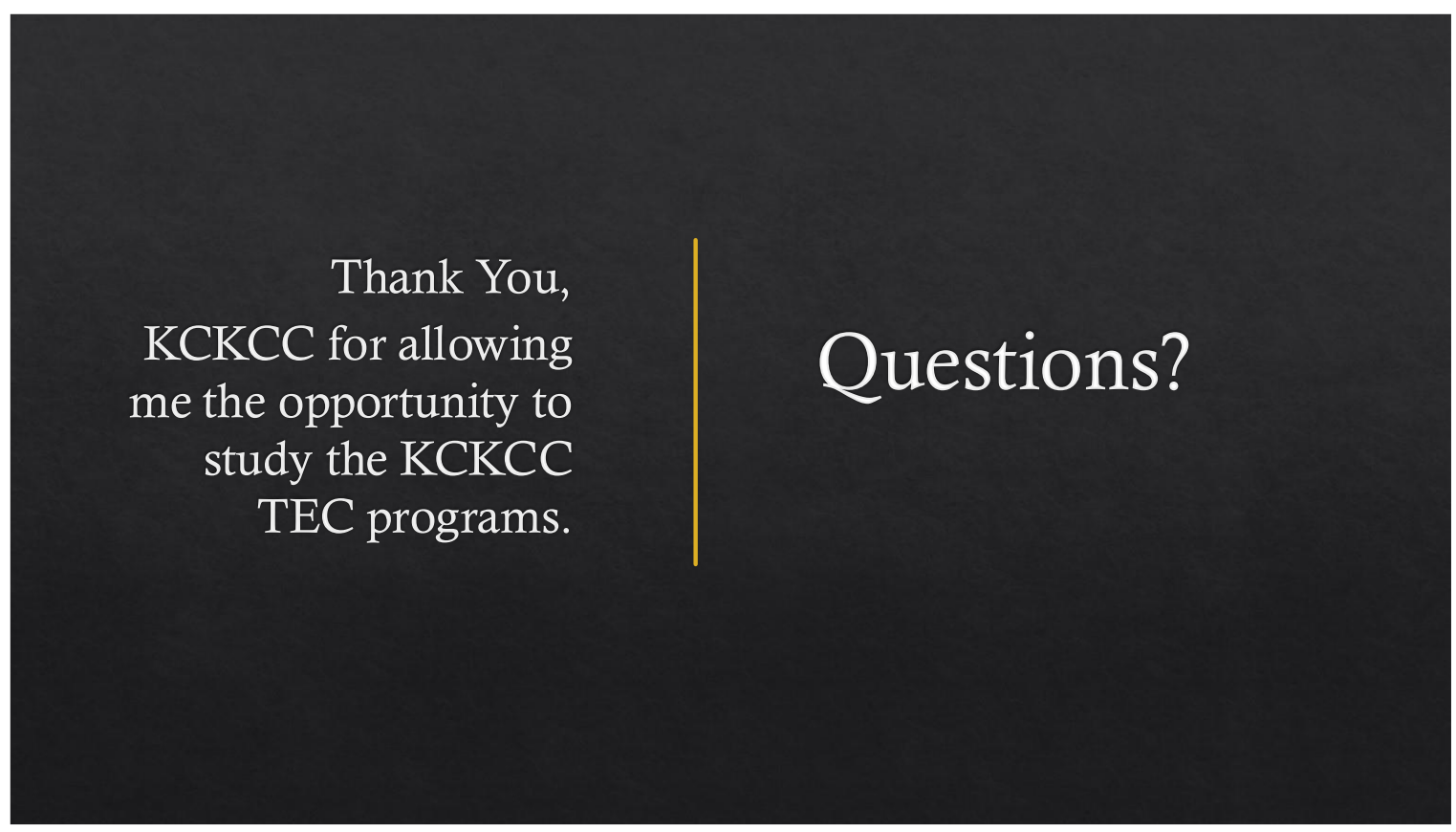




\section{SECTION FIVE}

CONTRIBUTION TO SCHOLARSHIP 


\section{Journal article submission statement}

The following manuscript is for submission to the Community College Journal of Research and Practice. All submissions are submitted through their online portal found at https://mc.manuscriptcentral.com/ucjc. 
An analysis of technical education cohort models of concurrent enrollment and postsecondary students

Tina Church Lewandowski 


\begin{abstract}
This mixed method study was conducted to gain a better understanding of technical education center (TEC) cohort programs at a midwestern urban community college. In a cohort model, the students start a program and progress through the curriculum together until completion (Bista \& Cox, 2014). Specifically, the study focused on two student types, high school students who were taking college courses and postsecondary students as well as the TEC cohort faculty. The TEC cohort model was examined to learn more about the graduation rates, continued program enrollment, and student support systems. Additionally, there was a to a gap in the literature about cohort models with high school and postsecondary students combined in programs.

The results of the study found that postsecondary students graduated at a higher rate than high school students. Relationships developed throughout the cohort among classmates and with the faculty were indicated as a contributing factor to program completion. Other themes included cohort model structure, hands-on learning, career opportunities, and student attitudes. The study concluded with a set of four recommendations.

Keywords: Cohort/cohort model/cohort program, high school student, learning community, non-cohort program, postsecondary student, retention, and technical education.
\end{abstract}

\title{
Introduction
}

Most students start college with the expectation of completing a program that will help them obtain the skills necessary for a job. For many students, this academic 
journey is not easy, and many roadblocks prevent them from achieving their goals (Pfund, Bono, \& Hill, 2020). This study focused specifically on the continuation of enrollment, meaning retention and program completion. In addition, this research examined the relationships formed, faculty mentorship, and community learning for specific demographics of the students in technical education programs at a community college.

The problem surrounding this research project was based primarily on the gaps within research on cohort models. Much of the cohort research focused on newly created cohorts, cohort programs compared to non-cohort programs, cohort structure, and faculty and student relationships (Barnett, Basom, Yerkes, \& Norris, 2000; Barnett \& Muse, 1993; Maher 2005; Nimer, 2009; Potthoff, Dinsmore, \& Moore, 2001; Potthoff, et al., 2001, Unzueta, Moores-Abdool, \& Donet, 2010). However, there was a gap in research about cohort models based on student types. Research conducted on high school students enrolled alongside postsecondary students in college cohort programs is nonexistent. Additionally, there was not a substantial amount of research devoted to the race, ethnicity, or gender of students in cohort programs. Due to this gap, there has not been any focus on their program retention and completion rates, nor has research been conducted about their formed relationships of support, community learning, or faculty mentoring that all are capstones of cohort programs.

Retention can be a challenge since students face many life decisions and have responsibilities outside of college (Hadfield, 2003). Adult learners have external obligations to overcome to remain in college. For instance, many of the students at KCKCC have full-time jobs and family responsibilities. These students commonly take a 
semester off to manage their personal responsibilities and fail to re-enroll in courses or complete their program. Retention is critical for overall student success and higher education institutional goal assessment. For students to have opportunities to start or advance within their career, a completed certificate or degree is often necessary. A partially completed credential or completion of a few college courses is not as valuable as a completed credential (Matheny, Chan, \& Wang, 2015). Therefore, it is essential for institutions to have a clear understanding of what factors lead to student success so they can help support students to complete their programs.

\section{Materials and method}

\section{Method}

A mixed-methods design was formulated to address the research questions for this study. The mixed-method design consisted of a quantitative analysis that explored the past data of high school and postsecondary students within the TEC (technical education center) cohort programs. A qualitative analysis examined the student survey, which consisted primarily of open-ended questions, faculty virtual interviews, and student virtual interviews.

\section{Research Questions}

1. Is graduation of a TEC cohort program independent of a student's level (high school and postsecondary)?

2. What are the reasons for students' continued enrollment in the TEC cohort program?

3. What forms of support within the TEC cohort program encouraged students' program completion? 
4. According to students, why do TEC cohort models support program completion?

5. According to the TEC cohort faculty, what supportive contributions do they perceive should be provided to students?

\section{Participants and data collection}

One set of participants in this study of TEC cohort programs were faculty members of the college TEC program. The college TEC programs have 29 faculty, and ten of the 29 participated in the study. The ten faculty members represented the following TEC programs: automotive technology, building and property maintenance, commercial and residential equipment technology, culinary arts, machine technology, welding technology, and computer information systems technology. Unfortunately, not all the TEC programs were represented by the faculty. Two of the programs, automotive technology, and culinary arts, had multiple faculty members participate in the study.

The other set of participants in this study were students enrolled in the college TEC program between the fall of 2009 and the fall of 2020. The students were invited to participate in an interview and survey. A total of 42 students participated in the student survey. Of the 42 participants, one was under the age of 18; there were 19 females, 21 males, and one participant listed "other" for gender. For race, 16 participants were Black or African American, 14 were white, one was Asian, one was multi-racial, and nine listed “other" for race. For ethnicity, five participants were Hispanic/Latino and 34 were NonHispanic. Three (3) students participated in a virtual one-on-on interview. Two of the students completed two TEC programs. Two students started TEC programs as high school students. 
The college provided a data set of students enrolled in TEC programs from the fall of 2009 until fall 2020. The report included student gender, race/ethnicity, birthdate, and graduation status as well as if the students were high school or postsecondary. Of the subjects represented in the data set, $25.4 \%$ were female and $74.6 \%$ were male, as represented in Figure 1.

\section{[Insert Figure 1]}

Figure 2 represented the student level when the student started the program, $34.85 \%$ were high school students, whereas $65.15 \%$ were postsecondary students.

\section{[Insert Figure 2]}

Participants ranged in age from 14 years old to over 70 years old, see Table 1.

\section{[Insert Table 1]}

The data were first reviewed for duplicate entries based on the semester of enrollment. Ultimately, the subject's first semester of enrollment was recorded along with the high school or postsecondary student type, gender, race/ethnicity, birthdate, program enrollment, graduation status. Records of 27 subjects who stopped enrollment and later re-enrolled in a TEC program after one year of non-attendance remained in the dataset. Students who had not enrolled in one year were considered inactive at KCKCC. Participants whose last record of enrollment was within one year of the analysis (fall 2020 , spring 2020 , or summer 2020) were excluded from the study. These students were considered active and had not yet had a chance to graduate from a TEC program or go more than one year without enrollment. A total of 123 records of participants were enrolled in more than one TEC program and remained in the data set. 
Upon review of the participants' student level, high school or postsecondary, six records were corrected. Those records started with an initial entry of postsecondary student status for the participant and then switched to a high school student status for the subsequent semesters of enrollment in the same program. It is impossible for a student status to shift from postsecondary then to high school student status. However, it is standard for student status to change from high school to postsecondary when the student graduates from high school and continues enrollment.

\section{Data analysis}

The results of this study included both quantitative and qualitative analysis. The quantitative research question was analyzed using a Chi-square test of independence. A chi-square statistic was selected to answer the quantitative research question because the data set included categorical and nominal data. Chi-square statistics are reported with degrees of freedom and sample size (in parentheses), the Pearson chi-square value, and the significance level. The significance level in the SPSS software systems defaults to $95 \%$. However, for this study, a 99\% significance level was used as that is a lower likelihood of Type I error, meaning producing a significant result when the Null Hypothesis is true.

\section{Results}

Research Question One: Is graduation of a TEC cohort program independent of a student's level (high school and postsecondary)?

To answer research question one, a Chi-square test of independence was used. Based on the results of the Chi-square test of independence found in Table 2, this study 
indicated the number of students who graduated from a TEC cohort program differed by high school and postsecondary levels, $\chi^{2}(1, \mathrm{~N}=3308)=114.27, \mathrm{p}<.001$.

[Insert table 2]

Since the $p$-value is less than our chosen significance level $(\alpha=0.01)$, we can reject the null hypothesis and conclude that there is an association between high school and postsecondary student level and whether or not they graduated from a TEC cohort program. The data shown in Table 3 revealed postsecondary students were more likely to graduate than high school students. Postsecondary students graduated 1643 students, whereas only 1509 postsecondary students were expected to graduate. Additionally, fewer postsecondary students did not graduate (512) than were expected not to graduate (647). For the high school students only 673 students graduated, whereas 808 students were expected to graduate. Also, there were more high school students who did not graduate (480) than expected (346). The expected values were gained from the results of the Person's Chi-Square.

[Insert table 3]

Research Question Two: What are the reasons for students' continued enrollment in the TEC cohort program?

To answer this qualitative research question, the researcher interviewed ten TEC cohort faculty members and three students. Simultaneously, an open-ended survey was sent to TEC cohort students, a total of 42 students participated in the survey. The students who participated in the survey were enrolled, completed, or had not taken a course within one year out of a TEC cohort program. 
After the conclusion of all the interviews, the responses were transcribed and reviewed for themes. Several themes emerged about students' reasons for continued enrollment in a TEC cohort program. For example, the faculty believed the TEC cohort program provided students with hands-on learning opportunities and experiences. The faculty also mentioned that many of the students in the program preferred hands-on learning rather than traditional academic learning. Therefore, the TEC programs were a good fit with their strong hands-on approach. The students' responses from the survey supported the faculty in this regard. Students mentioned that the hands-on training, program training, and learned skills provided motivation for their continued enrollment in the program.

Another theme that appeared was the cohort structure as a reason for students' continued enrollment. A faculty member said, "The cohort's concentrated structure actually saved students, because students are aware of the duration upfront, they are focused and motivated to continue." Students do not have to select courses each semester as the courses are pre-selected for them. Students do not have to worry about their schedule changing or accommodating a schedule adjustment each semester. They also noted how the program courses build on each other as the students' progress through the program. Some programs are able to have self-paced elements, which faculty thought students appreciated. One faculty member said, "I think students like to do it on their own time, make sure they master a skill before moving onto the next one." Other program faculty member said that there was not an opportunity for self-pacing and some students struggled to keep up. Another faculty member said, "Some students just cannot 
keep up, they fall behind for non-attendance, academic challenges, all kinds of reasons and they cannot get caught back up."

Both students and faculty expressed that relationships were a reason for continued program enrollment. Students included friendships with fellow students as reasons for continuous enrollment in the program. The faculty observed similar interactions, including students forming friendships, helping each other out, and providing encouragement among each other. For instance, one faculty member discussed the importance of the students' relationships as he witnessed the friendship extending beyond the program. He observed students staying connected once they graduated and working in the desired industry.

The dynamic between the high school students and postsecondary students was also discussed by the faculty who had both student types in class. Ultimately, the faculty indicated the students connected regardless of their student status. Some program faculty mentioned the secondary students tried to impress the postsecondary students. One faculty member said, "The postsecondary students avoided the high school students until group work required them to work together and bonds were eventually formed." Some program faculty discussed how secondary students would ask high school students for help and then connections started to develop. The faculty indicated group work was very important as it is mirrored workplace situations. Faculty did mention occasional tensions would take place between students; however, the tensions were resolved quickly. The surveys and interviews included competitions against other colleges including how those experiences benefited students and encouraged continued enrollment. The competitions allow the students to continue to build strong relations with their classmates and receive 
direct support from their professors. Not only did the competitions enhance relationships but they also created a sense of pride and loyalty to the TEC cohort program and the college. A faculty member said, "The students get to work on a project of their own with another classmate, seeing some assistance, and they develop a sense of pride, loyalty, and establish a different kind connection.”

Career options after program completion was repeated theme from both students and faculty. Students shared that they wanted to complete the program to gain knowledge for employment or start their own business. For example, one student described how his culinary program had a classroom set up like a home kitchen for him to work so he could get comfortable being in other people's homes while making repairs. He said, "It was really nice to have an idea of what it would be like to work in a customer's home." Faculty expressed that they strive to provide students with real workplace settings and situations so they can experience it before employment. The main objective of this is to determine if this is the right career field and to help students be more comfortable when they start a job. One faculty member shared a story about a student that did not realize he was afraid of heights until he had to go up on a forklift. Afterward, the student had to determine if that was the right career field for him. Creating these situations is better for the students because they are in a controlled environment with support from the faculty and other students rather than in the workplace, according to faculty.

Completing the certificate to obtain an associate or bachelor's degree was sighted as a reason for continued enrollment by the faculty and students. The faculty mentioned high school students have an opportunity to earn college credits before they even 
graduate high school and they felt this provided opportunities to students. Many faculty members had stories about their students being accepted into advanced programs or universities and how much further ahead they were than other students. Students also mentioned they wanted to start what they finished and complete the certificate. Some students indicated they had future educational goals and the TEC cohort program was the foundation needed to achieve their goals.

Some faculty identified a student's attitude as a reason for students' continued program enrollment. One faculty member said, "I've seen students overcome repeated challenges to complete the program while other students are just looking for a reason to drop out of the program, even if that student is outstanding." Students tended to agree. Students' comments that supported the faculty observations included: "I wanted to make a dream a reality," "I've always wanted to do more for myself," and "I'm self-driven." Students also noted they valued the faculty and their own family or kids as reasons for continued TEC cohort program enrollment. One student who stopped out of the program indicated the TEC cohort program did not promote continuous enrollment for them as they were "only enrolling in the program because of personal interest."

\section{Research Question Three: What forms of support within the TEC cohort program encouraged students' program completion?}

Qualitative data obtained from the TEC cohort program faculty and student interviews, along with an open-ended student survey, was used to answer this research question. The faculty interviewed provided an array of support methods that were extended to students to help them complete the TEC cohort program. As to be expected, many faculty shared KCKCC provided resources and external resources with students. 
They believed students had no idea what opportunities were open to them since many were first-generation college students and would have no way of knowing what they do not know. They thought it was their responsibility to share this information with students. "These kids don't know what they don't know," one faculty member said about supportive resources for students. Faculty also felt it was their obligation to provide reallife lessons for the students beyond the curriculum. They use analogies and talk to them about future life planning outside of the students' careers. One faculty member said, "Without trying to sound like a parent, I try to use classroom situations and draw parallels to real-life scenarios and try to talk about how to make good choices." The faculty genuinely care about their students and want them to be successful. Since the faculty spend so much time with the students, they felt invested in the students. They can tell if something is wrong with the student and they will pull that student aside and have a conversation to check-in with the student. A faculty member said, "I look at their faces when they walk in the classroom and how they are walking, and I can tell if something is up with a student because I have really gotten to know the students.” Many faculty members mentioned having side conversations with students to chat about goals and followed-up if there was a class conflict. The faculty member said these side conversations were invaluable and allowed them to connect with the students. Also, students in the TEC cohort program from the USD 500 school district have assigned facilitators who regularly check in with faculty to see how students perform in class. The faculty mentioned this is another resource of support for high school students. Similarly, the high school students' parents contact the faculty for status updates. The faculty found the follow-up from the parents to be useful for high school students. A faculty member 
mentioned, "I got an email from a parent about a kid in class and I told them how the kid was really doing, then next day, I noticed a big difference in the kid was back on track."

The TEC cohort program structure and assignments were described as tools to promote student support and program completion. One faculty member stated, "I believe the structure leads to success." They felt it was important for students to be aware of the ultimate goal and how each class helped the students achieve that goal. Students did not need to select their classes, and the faculty thought it was one less thing for them to worry about. However, the faculty mentioned the structure of the program also had some limitations. These limitations included (1) multiple cohorts in the program at once, (2) the variable amount of time the high school students and the postsecondary students spent in the program, and (3) the number of credits taught each semester. They did not mention that these challenges directly impacted the student's success.

Not only did the faculty consider the structure of the TEC cohort programs but they also discussed the assignments. Faculty all tried to deliver creative assignments that taught the curriculum and provided real-life learning lessons. Faculty in many programs tried to have customized projects for students or allow students to have a self-paced opportunity to work through the curriculum. However, not all programs were able to extend that mode of learning to students. All faculty felt students struggled with math and reading skills. A faculty member said, "it can be hard, some of these kids cannot even read or do basic math." Students agreed, as they mentioned that was the more challenging part of their programs during student interviews. To help support the students, the faculty worked to teach those skills practically. They realized their students are hands-on learners, so they have adapted their teaching style to include hands-on 
learning for math and reading. One instructor provided extra credit when a student found his intentional spelling errors. This faculty member said, "When I type up the recipe instructions for students, I intentionally have spelling errors it the recipe. When a student points out the spelling error to me, I give them extra credit. This is how I know they are reading." Many instructors ask the students to double or reduce their work as a way to introduce mathematical fractions. A faculty member said, "I will have the students double something or cut in half to build their confidence and let them see how fractions work." Faculty utilize group work activities to allow other students who understand the concepts an opportunity to explain to those who are still struggling. Frequently, hearing the information explained another way or by a classmate helps students grasp the information. A faculty member said, "sometimes they just need to hear it from someone else other than me to get it." Some faculty paired students specifically so one student could help another student. A faculty member shared a story about how he had two very talented students, and he did not allow them to work together until later in the semester. He said, "Students need to learn how to help others, and others needed to learn their techniques." He went on to say, "Later in the semester I did let those two students work together and they outpaced all the other student groups." However, this is not the only reason faculty use group work in their curriculum. Faculty claim students ultimately form groups on their own, so they use the natural group dynamics to simulate industry work-like atmospheres. The faculty member said the students must work out personality differences and encourage each other, just like in the workplace.

Exposure to workplace simulations and settings was important to the faculty, and they felt job preparation helped to support students. The faculty felt they supported 
students by receiving annual industry feedback to incorporate into their program to help students be prepared for employment. They also tried to provide students with opportunities to meet potential employers to network. One faculty member ran his program as much like a workplace as he could. He told the students, "earning an F grade would be the equivalent of getting fired."

Relationships were intertwined throughout many of the examples, but students and faculty mainly discussed student relationships. According to the student survey, $76 \%$ of students who graduated from the program felt the support provided by others encouraged them to continue in the TEC cohort program. The students revealed relationships with professors and classmates provided this encouragement. Ten of the 11 students who were currently enrolled in a TEC cohort program felt the support provided by others encouraged them to continue the program. One student stated, "my classmates and teachers lift me up." As mentioned earlier, the faculty felt a strong connection to the students and developed a relationship with them. The students also build relationships with each other. A faculty member shared that a student climbed up a ladder and then had a panic attack and was afraid to move or come down. The students all rushed to help support the stranded student. They provided encouragement, and the student ultimately made it down the ladder. Another faculty member said, "students have group text messaging chats, and they send reminder notes about upcoming tests and to bring workbooks to class." These relationships help to provide encouragement and confidence for the students, according to faculty. 


\section{Research Question Four: According to students, why do TEC cohort models support program completion?}

The responses to this question were gathered from the TEC cohort student survey and the interviews of the three TEC cohort students. For the student interviews, all three students interviewed completed their program(s). Two of the students completed two different TEC programs. One student was female and the other two were males. Two students started the TEC program as high school students. The postsecondary student was angry about his experience with the college. He did not feel that he was treated fairly by the students and faculty in one TEC program. Despite these feelings, he still actively participated in the interview.

The top theme provided by the students to answer this research question was being part of a cohort because of the relationships formed. Students did not feel alone, as they were able to develop friendships with their classmates. They said their classmates made it fun, and they created bonds with each other. One student stated, "Working with the same group of students encouraged me to continue in the TEC program. I loved working with all of my peers and being able to learn from all of them and created a bond." The students enjoyed being with the same people. They said their classmates motivated them and helped to give them courage. A student said, "You see a lot of courage." Students liked how the cohort model kept everyone on the same page. A high school student directly mentioned the importance of forming relationships with postsecondary students. He said the postsecondary students provided important information and served as a guide. 
Aside from the one student who had a negative experience with a faculty, students also discussed the positive relationships they experience with faculty. It should be noted that the dissatisfied student mentioned the faculty in his program was still very supportive. A student said, "The teachers were the ones that I always wanted to come back and learn more from." Other students mentioned how helpful the faculty were. Specifically, they provided support for student competitions and helped to build confidence. One student mentioned how a faculty member said she was like a whole different girl after the first two semesters. She went on to talk about the confidence she had gained and how she was not as shy and more comfortable with students socially.

Lastly, students appreciated the program's hands-on experience, and they liked coming back to learn and experience more. Students appreciated how they had an opportunity to practice their skills and learn various techniques. They also enjoyed the workplace setting faculty created. One student said, "I would have even liked more opportunities for workplace situations, like working outside in the rain, snow, hot days, just to have more work-like experiences."

\section{Research Question Five: According to the TEC cohort faculty, what supportive} contributions do they perceive should be provided to students?

To answer this research question, only the TEC cohort faculty interviews were considered since the question specifically focuses on the faculty's viewpoint about the supportive contributions they perceive should be provided to students. Many of their responses included a more profound or more elaborate version of the support, tools, techniques, regular program reviews, and current structure. For example, one faculty member said the "program's design was supportive to students," but several faculty also 
mentioned the "structure could be enhanced to serve students better." The faculty mentioned the amount of classroom and lab time makes it hard for them to offer office hours for students, particularly high school students. A faculty member said, "the high schools arrive on a bus from the school before class starts and they have to ride the bus back to school, so there is not any time outside of class, because they are not here outside of class." They also said it makes it more challenging to keep up with grading, picking up supplies, serving on committees, and so on. One faculty member said, "I teach up to 25 credit hours per semester, and I teach students in a face-to-face format every Monday through Friday from 7:30 am until 3:00 pm with an hour lunch break." Some of the faculty mentioned this structure is hard when there are multiple cohorts going on at once. This makes the student cohort model harder to follow and for the students to make connections and increase the number of credit hours taught by faculty. On the other hand, the faculty suggested having different levels for students because not all students are at the same level when they begin the cohort program. For some students, it is a struggle to keep up, some are at the appropriate level, and others are more advanced. Along similar lines, some faculty thought it would be beneficial for students to have two tracks, a full-time track, and a part-time track. The full-time track would be as the program is currently, and the part-time track would have fewer hours per semester but require more semesters for completion. The latter would allow students the opportunity to work while in the program. Many faculty members said their students need financial assistance and cannot afford not to work. It was mentioned by a few faculty members that students could benefit from experience in some other related programs to broaden their skill sets. However, the faculty noted this would extend the program completion 
time for students. Yet, they thought the variety and skills learned would be useful for students.

All faculty mentioned that students could benefit from math and reading support. Some faculty said there are students who cannot read in the program. Placement testing is not required for program admissions for most of the TEC cohort programs. Many faculty members thought it would be beneficial to have some minimum proficiency level. Also, more support for tutoring in math and reading beyond the classroom is definitely needed for students, according to faculty.

The faculty discussed the need for individual goal support for students, including life skills assistance, leadership skills, confidence building, and financial resources. All of the faculty try to work these skills into the class. Still, many faculty members feel that students need more knowledge and resources in these areas to be successful. One faculty member said, "these students have all kinds of challenges, money, support, kids, rides, health." The faculty try to help the students, but when the students do not attend class the faculty members are limited as to the help they can provide.

Lastly, the faculty mentioned the need for a formalized job placement opportunity for students who complete the program. The faculty felt that if the students knew the program would lead to guaranteed employment, students would be more likely to graduate. One faculty member said, "We are creating a workforce for tomorrow, so I always want to make sure we're doing things to help them get a job." Each program has different avenues that they use to help students obtain employment, but they felt there was an opportunity to create a clear pathway to employment. 


\section{Discussion}

The principle outcomes of the study can be considered from the quantitative and qualitative analysis. For the quantitative analysis, it was found that students at the postsecondary student level graduate at a higher rate than students at the high school level. The postsecondary students could be in a different place in their lives as adults with a more direct focus on their education providing more motivation to complete the TEC cohort program than the high school students. At the same time, the high school students could be attending the program because they were directed to attend. While high school students might have more time, fewer distractions, less transportation issues, and more support for their education, much of this assistance tends to drop off after high school graduation. The high school students do not continue to complete the program at the same rate as the postsecondary students. A variety of factors could contribute to this educational halt. The qualitative analysis offers some possible inferences.

The qualitative analysis revealed three overarching themes that contributed to the KCKCC TEC program completion for students. The top four themes were (1) relationships with classmates and faculty, (2) student attitude/desire to meet goals, (3) academic preparedness/personal challenges, and (4) cohort structure. KCKCC TEC cohort faculty and students both indicated that relationships were a key factor that contributed to students' continued enrollment in the program and program completion. Relationships between students at the postsecondary and high school levels were shared repeatedly. Additionally, those relationships continued into transportable networks that students utilized after program completion. Yet again, the faculty and students both provided comments about the student's desire to complete the program as a reason for 
program completion. Students were goal-focused and had a focused attitude to complete the program. Many students indicated the skills they were learning were their passion. Other students who were not as focused or dedicated to the program were more likely to drop out of the program. Often, these were students who faced transportation, financial, or academic challenges and were all too willing to discontinue the program. Lastly, interweaved throughout the student and faculty responses was the cohort structure and curriculum.

Considering the connections between the qualitative and the quantitative data, the postsecondary students could be more focused and self-driven than the high school students. Each group of students faced challenges and academic difficulties. Both groups formed relationships with the faculty and other students of the same and different levels. However, these factors were not enough for the high school students to finish the program. For the high school students, their program downfall could happen during the transition from a high school student level to the postsecondary student level. The postsecondary students do not have this transition, and their program is much more concentrated. They attend all day every day for a shorter period, whereas the high school students attend half days every day for double the length of time. High school students might have fewer life responsibilities than postsecondary students. However, high school students become postsecondary students, and then they abruptly have adult responsibilities. Moreover, the high school students do not have to pay tuition for the TEC programs, but when they transition to postsecondary student, they are responsible for the tuition. Federal financial aid is available to these students, but the process could seem too daunting and overwhelming for many students. All in all, there might be too 
many changes for the high school students to adjust to as they transition to the postsecondary status. Their priorities could change, and education might not be as prominent once they are out of high school and have new life responsibilities. Ultimately, the program's structure is broken for the high school students, the relationships formed are not strong enough to prevail, the symbolism is no longer envisioned, and the commitment to the program is lost in the competition of real-life factors.

The results of this study are comparable to that of other cohort studies. The findings regarding relationship and group dynamics were prominent, just as in past studies (Nimmer, 2009; Scribner \& Donaldson, 2001; Seed, 2008; Sathe, 2009; Stearns, Margulus, \& Shinsky, 2012; Unzueta, Moores-Abdool, \& Donet, 2010). Faculty and student characteristics were all factors in this study, just as they were other cohort studies (Browne-Ferrigno \& Muth, 2004; Jaffee, 2010; Maher, 2005: McCarthy, Trenga, \& Weiner, 2005; Potthoff, Dinsmore, \& Moore, 2001; Santicola \& Morris, 2013; Scribner \& Donaldson, 2001). Lastly, the structure was a contributing factor in other cohort studies and this study (Barnett, et al., 2000; Lamb \& Jacob, 2009; Potthoff, et al., 2001; Unzueta, Moores-Abdool, \& Donet, 2010).

This study's challenges and limitations include a need to interview more of the faculty from the other TEC programs that were not represented. Student interviews were lacking in participation. Interviews with more students and students from each level would have provided a richer understanding of the TEC program experience. Lastly, more representation from students who dropped out of the TEC cohort program would have been valuable. 
Considering immediate job placement would be beneficial to consider in the future. Additionally, a longitudinal study specifically focusing on high school students who transition to postsecondary would be an excellent follow up to this study. This would allow for the possibility of a direct understanding of the students who have the most challenges in completing the program to determine the causes for dropping out of the program. It would also allow for the understanding of the reasons for program completion.

\section{Conclusion}

Not all the responses can be specifically attributed to the cohort model. Some responses could be due to the specific nature of the TEC program or the students' high school or postsecondary levels. Nevertheless, the study was consistent with the current literature surrounding cohort models. Student and faculty characteristics, cohort program advantages and disadvantages, curricular and program organization, relationship dynamics, pedagogical focus were all elements of this study. The TEC cohort programs have faculty members who are passionate about their disciplines and students. However, the program has some constraints due to the high school student type, service area demographics, and state requirements.

\section{Recommendations}

Based on the findings of this study, a few recommendations should be considered. Four recommendations emerged from the study, (1) prior enrollment academic testing and program interest, (2) career and internship placement, (3) part-time enrollment options for postsecondary students, and (4) clear pathways for students to transition from high school to postsecondary status. The first two recommendations apply to high school 
and postsecondary students. The third applies mainly to postsecondary students, and the fourth directly relates to high school students. All recommendations would have an impact on the KCKCC TEC cohort faculty. The recommendations were developed based on the ultimate goal of KCKCC TEC program completion.

\section{Recommendation One: Prior enrollment academic testing and program interest}

Based on the comments about students' attitudes in the program it would be beneficial for students to learn more about the program before being enrolled in the program. This could happen through campus tours, program skill demonstration events, faculty information sessions, or requiring students to submit a narrative about their interest in the selected program. This will allow the high school students to determine if they are truly interested in the program. Some of these items are already in place but not required of all students for all programs. Specifically, the high school students appeared to need additional knowledge about the program rather than being automatically placed in the program without showing any interest.

Requiring placement testing or minimum earned grades in high school math or English would be useful to the students and for the faculty. Students and faculty both mentioned the challenges students face with math and reading. It might be advantageous to have a time limit on the minimum earned grades and offer placement testing to those with expired or lower grades. The specific recommendation about the minimum grade or test score necessary for success would need to be provided by the KCKCC TEC cohort program faculty. Alternatively, just requiring the student to complete the placement test without a minimum score would allow the faculty to ascertain students' incoming ability. Providing the faculty with this baseline academic level would allow the faculty to better 
plan their curriculum and identify resources the students need prior to the classes

beginning. For students with lower scores or the inability to read, required tutoring could be provided. On the other hand, academically advanced students could be given more complex assignments or activities.

\section{Recommendation Two: Career and internship placement}

TEC cohort programs are applied in nature. During the faculty interviews and the student survey, career opportunities were mentioned several times. Subsequently, career opportunities are of importance. Some programs assist students by utilizing faculty's field networks and experience to secure student employment prospects. Many of the faculty mentioned they stay in contact with potential employers and adjust their curriculum according to the industry needs. However, there is no standard pathway directly to an internship experience or employment after completing a TEC cohort program. Programs could have direct placement for students upon program completion. There could be a career fair, or students could go directly to the businesses on scheduled days and times to interview for various positions. Alternatively, some programs do not offer courses during the summer, and those programs could have summer internships for students. Students would appear to benefit from a forged pipeline of employment security. This opportunity could attract more students to the program and foster additional networking prospects. The faculty would need to be involved in utilizing their contacts to secure positions and internship opportunities for their students.

\section{Recommendation Three: Part-time enrollment options for postsecondary students}

The TEC cohort programs range from four months to two years of enrollment, depending on the program. The faculty mentioned the intense pace of the program could 
be a challenge for students. They also revealed how the class schedule makes it difficult for students to obtain employment outside the program. For some students, the full-time program is not an issue, and they do not need any other work. However, a part-time enrollment option could be advantageous for many students. Each program would have three tracks: a full-time track of postsecondary students, and two part-time tracks for morning and afternoon postsecondary and high school students. The high school students are currently on a part-time morning or afternoon track since they attend high school the other half of the day. The part-time track students would take longer to complete the program than the full-time track students. However, this might allow some postsecondary students the flexibility they need to be successful. This would provide the faculty with an opportunity to plan and organize their curriculum based on two options, full-time or part-time rather than high school or postsecondary student levels. These tracks would allow high school students to develop bonds with postsecondary students, as those students would be in their cohort for the program's duration. Lastly, it was revealed in the faculty interviews that many faculty make exceptions for postsecondary students and allow them to participate part-time in the program. They have separate classes created for those students. This practice causes more work for all involved, the faculty teaching load is increased, and the cohort model foundation is convoluted with this practice. The extra work would be reduced by having a part-time track for postsecondary students, and the cohorts would stay intact. 


\section{Recommendation Four: Clear pathways for students to transition from high school to postsecondary status}

The transition from a high school student to a postsecondary student could be the disconnect that causes students to stop out of the TEC cohort program. High school students have a designated time to attend classes with provided transportation to and from college. Additionally, students are held accountable for attendance by the faculty, the high school, and their parents. Once they shift to the postsecondary level, that accountability subsides. The program should have a clear pathway for these students not to have a break that would allow other distractions to deter them from their educational goals. The path should include advising to discuss goal planning, program completion, financial aid, logistics, support, and career options. This advising session should take place before high school graduation. Having the students commit to enrolling in the next semester before they graduate could help them be dedicated to attending. If a student graduates in May, it would be best to have the student continue their enrollment in the summer rather than waiting until August to attend or they could participate in a summer internship opportunity. All these options would allow the students to remain engaged in the program. Students would not have a break in their momentum and could finish the program more quickly. This could apply the summer before $12^{\text {th }}$ grade for students who begin the KCKCC TEC cohort program in $11^{\text {th }}$ grade. Those students could participate in an internship or continue with the program course work. However, the option would need to be consistent for all students to keep the cohort model intact. If a part-time track is established, as mentioned in recommendation three, this pathway would be identified 
and established for the high school students to follow and the part-time postsecondary students. 


\section{Journal Article References}

Barnett, B. G. \& Muse, I. D. (1993). Cohort groups in educational administration: Promises and challenges. Journal of School Leadership, 3, 400-415.

Barnett, B. G., Basom, M. R., Yerkes, D. M., \& Norris, C. J. (2000). Cohorts in educational programs: Benefits, difficulties, and the potential for developing school leaders. Educational Administration Quarterly, 36(2), 255-282.

Bista, K. \& Cox, D. W. (2014). Cohort-based doctoral programs: What we have learned over the last 18 years. International Journal of Doctoral Studies, 9, 1-20.

Browne-Ferrigno T., \& Muth, R. (2004). On being a cohort leader: Curriculum integration, program coherence, and shared responsibility. Educational Leadership and Administration: Teaching and Program Development, 16, 77-95.

Hadfield, J. (2003). Recruiting and retaining adult students. New directions for student services, 2003(102), 17-25.

Jaffee, D. (2010). Peer cohorts and the unintended consequences of freshman learning communities. College Teaching, 55(2), 65-71.

Lamb, L.C. \& Jacobs, V. R. (2009). Establishing and maintaining programming coherence in a cohort-based graduate program. The Teacher Educator, 44I(2), 126-142.

Maher, M. (2005). The evolving meaning and influence of cohort membership, Innovative Higher Education, (30)3, 195-211.

Matheny, C, Chan, H., \& Wang, X. (2015). Assembling a career. Community College Review, 43(4), 380-406.

McCarthy, J., Trenga, M., \& Weiner, B. (2005). The cohort model with graduate student 
learners: Faculty-Student perspectives. Adult Learning, 6(3\&4), 22-25.

Nimer, M. (2009). The doctoral cohort model: Increasing opportunities for success. College Student Journal. 43(4), 1373-1379.

Pfund, G., Bono, T., \& Hill, P. (2020). A higher goal during higher education: The power of purpose in life during university. American Psychological Association, 6(2), 97-106.

Potthoff, D.E. Batenhorst, E.V. Frederickson, S. A., and Tracy, G. E. (2001) Learning about cohorts: A masters degree program for teachers. Action in Teacher Education, 23(2), 36-42.

Santicola, L.\& Morris, R. (2013) Pressing on Persistence through a doctoral cohort program in education. Contemporary Issues in Educational Research - Second Quarter, 6(2), 253-263.

Sathe, R. S. (2009). Using the cohort model in accounting education. Accounting Education, 18(1), 33-49.

Scribner, J. P. \& Donaldson, J. F. (2001). The dynamics of group learning in a cohort: From nonlearning to transformative learning. Educational Administration Quarterly, 37(5), 605-636.

Seed, A. H. (2008). Cohort building through experiential learning. Journal of Experiential Education, 31(2), 209-224.

Stearns, M., Margulus, L., \& Shinsky, J. (2012). Theory into practice: A study to assess the influence of a customized leadership development program on a cohort of aspiring urban leaders. International Journal of Educational Leadership Preparation, 7(2), 1-13. 
Unzueta, C. H., Moores-Abdool, W., \& Donet, D. V. (2010). Perceptions of special education professors and culturally linguistically diverse doctoral students on cohorts. Teacher Educator and Special Education, 33(2), 169-182. 


\section{Tables}

Table 1

Age of TEC Cohort Program Participants

\begin{tabular}{|lr|}
\hline Age & Total Participants \\
\hline $10-14$ & 1 \\
\hline $15-19$ & 1738 \\
\hline $20-24$ & 529 \\
\hline $25-29$ & 322 \\
\hline $30-34$ & 231 \\
\hline $35-39$ & 166 \\
\hline $40-44$ & 98 \\
\hline $45-49$ & 80 \\
\hline $50-54$ & 69 \\
\hline $55-59$ & 47 \\
\hline $60-64$ & 18 \\
\hline $65-69$ & 5 \\
\hline $70-74$ & 1 \\
\hline Age not provided & 3 \\
\hline
\end{tabular}

Table 2

Chi-Square Test for Graduation based on TEC Cohort Program Student Level

\begin{tabular}{lc|r|r|r|r|} 
& Value & df & $\begin{array}{c}\text { Asymptotic } \\
\text { Significance } \\
\text { (2-sided) }\end{array}$ & $\begin{array}{c}\text { Exact Sig. } \\
\text { (2-sided) }\end{array}$ & $\begin{array}{c}\text { Exact Sig. } \\
\text { (1-sided) }\end{array}$ \\
\hline Pearson Chi-Square & 114.269 & 1 & .000 & .000 & .000 \\
\hline
\end{tabular}


Table 3

TEC Cohort Program High School and Postsecondary Student Actual and Expected Graduation Status

\begin{tabular}{llllc}
\hline & & Not Graduated & Graduated & Total \\
\hline Postsecondary Students & Actual Count & 512 & 1643 & 2155 \\
& Expected Count & 647 & 1509 & 2155 \\
\hline High School Students & Actual Count & 480 & 673 & 1153 \\
& Expected Count & 346 & 808 & 1153 \\
& & & & 3308 \\
\hline Total & Actual Count & 992 & 2316 & 3308 \\
& Expected Count & 992 & & \\
\hline
\end{tabular}




\section{Figures}

Figure 1

Gender of TEC Cohort Program Subjects

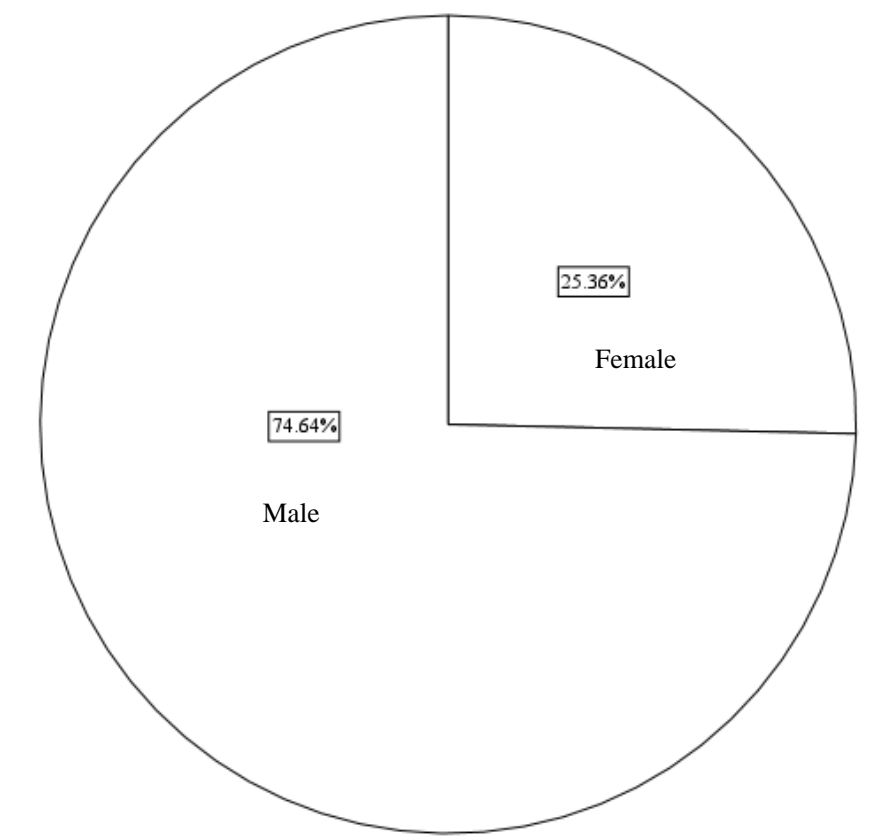

Figure 2

High School or Postsecondary TEC Cohort Program Student Levels of Participants

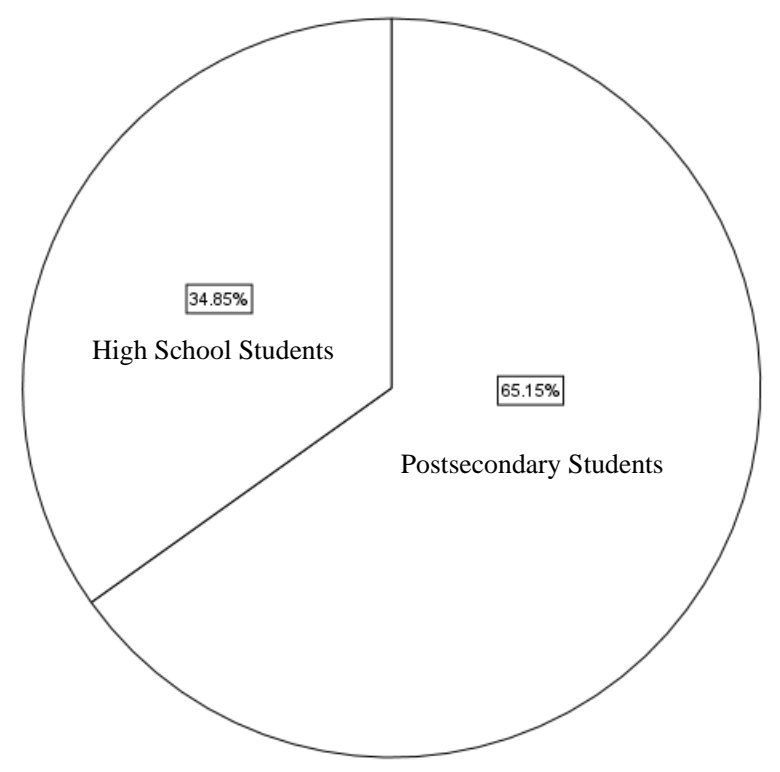




\section{SECTION SIX}

SCHOLARLY PRACTIONER REFLECTION 


\section{Introduction}

This program has provided me with the skills to understand which theoretical approaches best align with a given situation to yield the most excellent significant results. Overall, I have learned about different leadership theories, approaches, and when it is best to combine leadership styles to produce the best results.

An important concept I have learned from this program is that different situations call for specific leadership styles. No one type of leadership fits all situations and people. To select an appropriate leadership style, the individual must evaluate the situation and identify the best leadership techniques. After each leadership situation, the leader must reflect on the situation, as reflection allows leaders to redefine their skills and learn from the situation to identify what worked well and what could be improved. This section is a reflection of my leadership journey throughout this program and the dissertation process.

\section{Leadership theory}

Leadership can be viewed differently based on various situations, and those situations require distinctive leadership styles, techniques, and characteristics. According to Northouse (2019), leadership is a process whereby an individual influences a group of people to achieve a common goal. This definition of leadership can be applied in a variety of situations. While examining this definition of leadership, the focus is twofold: (1) leadership influence and (2) goal achievement. One of the most substantial leadership challenges is determining the best way to influence. Ideally, once the influence is set, the movement toward goal achievement should fall into place. However, that is not always the case, as barriers can prevent goal attainment. Northouse (2020) described various leadership theories and their strengths and weaknesses, such as trait approach, skills 
approach, style, situational approach, transformational leadership, and team leadership, to name a few.

When I first started my career, my responsibilities were predominantly technical. As I have advanced within my positions, I realized my attention and responsibilities are directed toward human and conceptual skills rather than technical skills. Tasks were more individualized, and I was taught the functionality of the task and just expected to complete those tasks efficiently. As I advanced in my career, I shifted from completing tasks to leading projects. I was not taught how to conceptualize a project and think it through from the beginning to the end or to examine all the components of the project. I was not taught how to manage the people involved in the project. Of course, I was taught techniques given advice, but I did not have any formal training or manuals. The responsibilities changed, and I had to rely on my traits rather than skill alone.

The situational approach to leadership has always resonated with me because not all situations demand the same leadership type. According to Northouse (2019), leaders who use the situational approach adapt their styles to their employees' needs. The situational approach is a matrix of four different styles based on directive and supportive behavior. The styles are delegating, supporting, coaching, and directing. Each of the styles is comprised of various levels of supportive behavior and directive behavior. Directive behavior is more specific directions about how to achieve a goal and involves one-way communication.

On the other hand, supportive behavior involves two-way communication and focuses on making group members feel comfortable and showing emotional support. Throughout my career, I have used each of these approaches in various situations. For 
instance, when a new employee begins working with me or is facing a challenging situation, I engage in a coaching style of leadership with that person. When working with an employee to build their confidence or take ownership of a task, the supportive style is ideal. When hosting a significant event such as graduation or orientation, I must be involved on multiple levels and make quick decisions. During the event, I engage in directing and delegating styles. Delegating has been one of the biggest challenges I have had to overcome as I advance as a leader. It is incredibly challenging since I started at the bottom and knew all the tasks. I have difficulty asking staff to engage in a task that I know how to do. However, I discovered that I am preventing them from growing within their careers and skillsets.

Transformational leadership is the ability to change and transform people to work toward a common goal. This is a skill that not many people can execute. According to Northouse (2019), this type of leader motivates intrinsically through emotions, standards, values, ethics, and long-term goals while incorporating charisma. Transformational leaders emphasize intrinsic motivation and follower development, inspiring them to succeed in times of uncertainty and transform people. Throughout my career, I have not had an opportunity to work with this type of leader. Personally, I aspire to become a transformational leader. I hope to motivate my team to collaborate and contribute at a deeper level.

A servant leader demonstrates leadership in the form of serving others (Northouse, 2019). Serving students and others is a top priority, and I work to ensure service is one of the guiding principles in my leadership. I strive to make sure projects and initiatives have an element that is focused on the benefits of others and service to 
students. Often serving our coworkers and subordinates is not a priority; expectations are placed on these individuals, and they are simply expected to meet those expectations. A servant leader focuses on these individuals and serves them as much as they would serve a student or customer.

According to Northouse (2019), the cultural approach occurs when there is a defined set of terms, concepts, etc., that are common to a group of people. Foreign cultures have different views on the meaning of teams and how the teams should operate (Levi, 2014). One of the challenges of cultural leadership is understanding how other cultures define terms, concepts, and motivations. Cultural leadership has proven valuable in my current and past positions, as I have had international admissions and affairs responsibilities. Therefore, I have had to learn to understand what motivates and encourages individuals from different cultures. This was a trial-and-error process since I did not always know how to bridge the cultural divide between the staff and incoming students. Prejudice is a significant challenge to overcome in cultural leadership. Northouse (2019) discussed how leaders not only need to overcome their bias, but they also have the problem of dealing with the prejudice of their followers. Levi (2014) noted awareness of cultural differences and one's own cultural biases is critical for effective cooperation. After overcoming personal challenges, I have helped others understand and appreciate our students' cultural differences.

To help others with this understanding, I have started by talking to people about cultural differences and explaining that there are multiple viewpoints from other countries that need to be considered before judgments are passed. I have shared this information informally and given formal presentations on the topic. Also, I have spoken 
directly with people when I see they have not considered cultural differences in a situation. Using firsthand experience has also helped with these situations. In addition to traveling throughout Europe, I was able to travel to India and Mexico. Many of the students I worked with were from these counties. Experiencing each culture was impactful and allowed me to relate to the students who originated from those countries.

According to Goleman (1998), emotional intelligence is a crucial characteristic of leaders. Emotional intelligence allows people to use different types of leadership in different situations. Often, I assume that other people have the same emotional range as I do or react to a situation similar to how I would respond. However, I have discovered that is not always the case. After working on group projects throughout the program, I have learned the importance of relationships and communication, and I am more understanding and sensitive to others.

Kotter (1990) explained how management involves coping with complexity, whereas leadership is about coping with change. A manager focuses on planning, organizing, staffing, and problem-solving. In contrast, leadership is about dealing with change, meaning setting a direction, aligning people, motivating, and inspiring. As I advanced through my career, I am trying to progress from management to leadership.

A leader should never become stagnate. Instead, the leader should be willing to break a long-standing behavior of providing leadership in the form of solutions. The leader should ask tough questions rather than just providing answers, taking a bird's eye view approach (Heifetz \& Laurie, 1997). One of the best questions that were proposed to me during this program was, "Why should anyone be led by you?" Reflecting on this question made me consider my style, my strengths, and my weaknesses from others' 
perspectives. Goffee and Jones (2000) provided a few tips to help leaders, reveal your weakness; be a sensor; practice tough empathy, and dare to be different.

Throughout history, great leaders are remembered for making a positive impact and willingness to take risks. While I may not be remembered several hundreds of years from now, I know I will be remembered in the near future, and I want to positively impact those that I lead. Throughout this program, I have learned about a variety of leadership styles and techniques, including the characteristics of non-effective leaders. Having learned this distinction is useful when critically reviewing and studying programs, specifically the cohort program at KCKCC, and how my leadership could impact the program. One critical lesson I have learned is that leadership must be authentic and displayed in ordinary activities, not just when leading large projects or initiatives.

This program instilled new strategies to view situations using a variety of lenses to make strategic decisions, allowing me to be an effective leader. Leadership theories have taught me how to capitalize and tailor my leadership skills to maximize a positive outcome. For instance, it is valuable to examine a situation from several perspectives while understanding the desired result. This insight has allowed me to review the various leadership theories and draw upon each to ensure the best possible outcome.

Being a female in a leadership role has encouraged me to look to other successful women as role models. I need to be a leader that inspires others to overcome the challenges of being a female leader. With this in mind, I have examined groups of decision-makers in hopes of evidence of gender diversity. Sometimes there is diversity, but there are still many groups that lack women in leadership roles or more women 
represented as leaders. I have worked hard to be present more often when decisions are being made. I realize it is essential to share my ideas with others and not to hold back valuable thoughts. I strive to be more active in the decisions that directly affect my career and not just move through the motions. I try to accept challenges even when I think they might be difficult. "It's up to us to end the self-fulfilling belief that 'women can't do this; woman can't do that.' Throwing up our hands and saying, 'It can't be done' ensures that it will never be one" (Sandberg \& Scovell, 2013, pp. 171). The knowledge I have gained from this program has encouraged me to step up and assume new leadership, even if I have reservations. I allow myself to believe I can find resources and solutions to handle any situation. Having participated in the program, I realize that I have the qualities and resources to be an effective leader, and I will continue to see more opportunities in the future. However, I will also continue to refine my leadership skills and learn a new method of leadership. Sandberg and Scovell (2013) proposed these questions, "How can I do better? What am I doing that I don't know? What am I not doing that I don't see?" (2013, p. 83). These questions are essential to be mindful of as a leader, and I will use them to reflect on my leadership for continued improvement.

\section{Dissertation project reflection}

Overall, the dissertation process has far exceeded my expectations regarding the level of difficulty, coordination efforts, and self-determination. Throughout the process, I learned to overcome personal and professional challenges, stay focused on this project, navigate professional political relationships, and sharpen my logistical skills. The leadership opportunities this project has created for me are invaluable. 
The topic selection was of great interest to me since I have participated in a cohort model program myself. After completing this project, I learned so much more about cohort programming from various viewpoints. The literature review provided a foundation of information that allowed me to consider as the project was unfolding. Gathering data was eye-opening as I was able to see firsthand how the faculty viewed cohorts. The student data were insightful and familiar, given my experience as a cohort student. Drawing connections between the study results and the theoretical framework broadened my intellectual competence. Analysis of the data was inspiring because I was able to see the results of the study. After the conclusion of the analysis, I enjoyed determining the recommendations to promote program completion at the KCKCC TEC cohort program. When thinking of the recommendations, I was working to think about what would work not only for KCKCC but also for other colleges.

This project has contributed to colleges with technical education programs, cohort programs, or any college interested in offering a new program or changing their existing programs. Additionally, high schools that provide vocational and technical education could benefit from the information in this study.

\section{Summary}

This program has taught me that leadership consists of a valuable set of characteristics and skills that are both natural and learned. This program has instilled a sense of how outstanding leadership is in my career and how the decisions I make will impact the success of my career. Selective leadership is impossible. A true leader handles each situation with dignity, compassion, and empathy. It is vital to make sure I am a good role model for those around me and other women so they can build their 
confidence to be leaders. "The more women help one another, the more we help

ourselves. Action like a coalition truly does produce results" (Sandberg \& Scovell, 2013, pp, 165). I cannot help but lead based on the skills, theories, and lessons I have learned from the literature, instructors, and classmates. 


\section{References}

Agnew, M., Mertzman, T., Longwell-Grice, H., \& Saffold, F. (2008). Who's in, who's out: Examining race, gender, and the cohort community. Journal of Diversity in Higher Education, 1(1), 20-32.

Baker, S., \& Pomerantz, N. (2001). Impact of learning communities on retention at a metropolitan university. Journal of College Student Retention, 2(2), 115-126.

Barnett, B. G., Basom, M. R., Yerkes, D. M., \& Norris, C. J. (2000). Cohorts in educational programs: Benefits, difficulties, and the potential for developing school leaders. Educational Administration Quarterly, 36(2), 255-282.

Barnett, B. G. \& Muse, I. D. (1993). Cohort groups in educational administration: Promises and challenges. Journal of School Leadership, 3, 400-415.

Beck, C. \& Cosnik, C. (2001). From cohort to community in a preservice teacher education program. Teaching and Education, 17, 925-948.

Bell, J. S. \& Michell, R. (2000). Competency-based versus traditional cohort- based technical education: A comparison of students' perceptions. Journal of Career and Technical Education, 17(1), 5-22.

Bentley, T., Zhao, F., Reames, E., \& Reed, C. (2004). Frames we live by: Metaphors for the cohort. The Professional Educator, 5, (2), 39-44.

Bernauer, J. A., Semich, G., Klentzin, J. C. \& Holdan, E. G. (2013). Themes of tension surrounding research methodologies education in an accelerated, cohort-based doctoral program. International Journal of Doctoral Studies, 8, 179-193.

Bista, K. \& Cox, D. W. (2014). Cohort-based doctoral programs: What we have learned over the last 18 years. International Journal of Doctoral Studies, 9, 1-20. 
Bolman, L. G., \& Deal, T. E. (2017). Reframing organizations: Artistry, choice and leadership ( $6^{\text {th }}$ ed.). Hoboken, NJ: Jossey-Bass.

Brayman, J., Grey, M., \& Stearns (2010). Taking fight to literacy and leadership. AASA, New York, NY. Rowman \& Littlefeld Publishers Inc.

Brill, J. L., Balcanoff, K.K., Land, D.D., Gogarty, M.M., \& Turner, F. (2014). Best practices in doctoral retention: Mentoring. Higher Learning Research Communications, 4(2).

Browne-Ferrigno T., \& Muth, R. (2004). On being a cohort leader: Curriculum integration, program coherence, and shared responsibility. Educational Leadership and Administration: Teaching and Program Development, 16, 77-95.

Butterwick, S., Cockell, J., McArthur-Blair, J., MacIver, S., \& Rodrigues J. (2012). Connectivity and collectivity in a doctoral cohort program: An academic memoir in five parts. Alberta Journal of Educational Research, 54(4), 446-459.

Carrell, S. E., Fullerton, R. L., \& West, J. E. (2009). Does your cohort matter? Measuring peer effects in college achievement. Journal of Labor Economics, 27(3), 439-464.

Case, K. F., \& Hernandez, R. (2013). But still, I'm Latino and I'm proud: Ethnic identity exploration in the context of a collegiate cohort program. Christian Higher Education, 12(1/2), 74-92.

Choy, S., Delahaye, B., \& Saggers, B. (2015) Developing learning cohorts for postgraduate research degrees. Australian. Educational Researcher, 42, 19-34.

Cope, D. G. (2014). Methods and Meanings: Credibility and Trustworthiness of Qualitative Research. Oncology Nursing Forum, 41(1), 89-91. 
Creswell, J. W. (2014). Research design: Qualitative, quantitative, and mixed methods approaches $\left(4^{\text {th }}\right.$ ed.). Thousand Oaks, CA: Sage.

Conrad, D. (2005). Building and maintaining community in cohort-based online learning. Journal of Distance Education, 20(1), 1-20.

Cuddapah, J. L. \& Clayton, C. D. (2011). Using Wenger's communities of practice to explore a new teacher cohort. Journal of Teacher Education, 62(1), 62-75.

Cushman, K. (2007). Facing the culture. Educational Leadership, 44-47.

Dinsmore. J. \& Wener, K. (2006). Relationships in preservice teacher preparation: From cohorts to communities. Teacher Education Quarterly, 33(1), 57-74.

Doolen, T. (2014) The impact of a cohort model learning community on first-year engineering student success. American Journal of Engineering Education, 5(1), $27-40$.

Drago-Severson, E., Helsing, D., Kegan, R., Popp, N., Broderick, M. \& Portnow, K. (2001). The power of a cohort and of collaborative groups. Focusing on Basics Connecting Research and Practice, 5(b), 15-22.

Engstrom, M. E., Santo, S. A., \& Yost, R. M. (2008). Knowledge building in an online cohort. The Quarterly Review of Distance Education, 9(2), 151-167.

Fahlman, D. (2011). Stories from the first cohort in doctor of education in distance education. The Journal of Distance Education, 25(1), 1-8.

Fedor, J. (2017). Cohort models of learning: Adapting content to women's learning styles. Journal of Leadership, Accountability and Ethics, 14(4), 31-44.

Field, A. (2013). Discovering statistics using IBM SPSS statistics $\left(4^{\text {th }}\right.$ ed.). Thousand Oaks, CA: Sage. 
Fink, A. (2013). How to conduct surveys: A step-by-step guide ( $5^{\text {th }}$ ed.). Thousand Oaks, CA: Sage.

Goffee, R. \& Jones, G. (2000). Why should anyone be led by you? Harvard Business Review, September-October, 63-70.

Goleman, D. (1998). Working with emotional intelligence. New York: Bantam Books.

Govender, K \& Dhunpath, R. (2011). Student experiences of the PhD cohort model: Working within or outside communities of practice? Perspectives in Education, 29(3), 88-99.

Greenlee, B. \& Karanxha, Z. (2010). A study of group dynamics in educational leadership cohort and non-cohort groups. Journal of Research on Leadership Education, 5(11), 357-382.

Hadfield, J. (2003). Recruiting and retaining adult students. New directions for student services, 2003(102), 17-25.

Hagedorn, L. S. (2005). How to define retention: A new look at an old problem. In A. Seidman (Ed.), College retention: Formula for student success (pp. 89-106). Westport: ACE/Praeger.

Hasinoff, S. \& Mandzuk, D. (2005). Bonding, bridging, and becoming a teacher: Student cohorts and teacher identity. Alberta Journal of Educational Research, 51(3), 231-245.

Hanushek, E. A., Kain, J.F., Markman, J. M., \& Rivkin, S.G. (2003). Does peer ability affect student achievement? Journal of Applied Econometrics, 18 (5), 527-544.

Heifetz, R. A., \& Laurie, D. L. (1997). The work of leadership. Harvard Business Review, 75, 124-134. 
Hess, M, \& Mason, M. (2005). The case for learning communities. Community College Journal. 76(1), 30-35.

Hossler, D. \& Kalsbeek, D. (2008). Enrollment management and managing enrollment: Setting the context for dialogue. College and University, 83 (4), 2-9.

Hotchkiss, J.L., Moore, R.E., \& Pitts, M.M. (2006). Freshman learning communities, college performance, and retention. Education Economics, 14(2), 197-210.

Huerta, J. C. (2004). Do learning communities make a difference? PS: Political Science and Politics, 37(2), 291-196.

Huerta, J. C. \& Bray, J. J. (2013). How do learning communities affect first-year Latino students? Learning Communities Research and Practice, 1(1), 1-18.

Jaffee, D. (2010). Peer cohorts and the unintended consequences of freshman learning communities. College Teaching, 55(2), 65-71.

Johnson, J. (2000). Learning communities and special efforts in the retention of university students: What works, what doesn't, and is the return worth the investment? Journal of College Student Retention, 2(3), 219-238.

Johnson, J. \& Romanoff, S. (1999). Higher education residential learning communities: What are the implications for student success? College Student Journal, 33(3), 385-415.

Kansas State Department of Education. (2020). Excel in CTE (formerly Senate Bill 155). Retrieved from https://www.ksde.org/Agency/Division-of-LearningServices/Career-Standards-and-Assessment-Services/CSAS-Home/CareerTechnical-Education-CTE/Initiatives/Senate-Bill-155 
Killingsworth, M. F., Cabezas, C. T., Kensler, L. W., \& Brooks, J. S. (2010). The gender dynamics of educational leadership preparation: A feminist postmodern critique of the cohort experience. Journal of Research on Leadership Education, 5(12.9), 531-567.

Kotter, J. P. (1990). A force for change: How leadership differs from management. New York, NY: Free Press.

Lamb, L.C. \& Jacobs, V. R. (2009). Establishing and maintaining programming coherence in a cohort-based graduate program. The Teacher Educator, 44I(2), 126-142.

Lawrence, R. L. (2002). A small circle of friends: Cohort groups as learning communities. New Directions for Adult and Continuing Education. 95, 83-92.

Lei. S., Gorelick, D., Short, K., Smallwood, L., \& Wright-Porter, K. (2011). Academic cohorts: Benefits and drawbacks of being a member of a community of learners. Education, 131(3), 497-504.

Lencioni, P. (2002). The five dysfunctions of a team: A leadership fable. San Francisco, CA: Jossey-Bass.

Levi, D. J. (2014). Group dynamics for teams (4th ed.). Los Angeles, CA: Sage.

Lichtenstein, M. (2005). The importance of classroom environments in the assessment of learning community outcomes. Journal of College Student Development. 46(4), $341-356$.

Lieberman, A. (1996). Creating intentional learning communities. Educational Leadership, 54(3), 51-55. 
Maher, M. (2005). The evolving meaning and influence of cohort membership, Innovative Higher Education, (30)3, 195-211.

Maher, M. (2004). What really happens in cohorts? About Campus, 3, 18-23.

Mandzuk, D., Hasinoff, S., \& Seifert, K. (2003). Inside a student cohort: Teacher education from a social capital perspective. Canadian Journal of Education, 28(1\&2), 168-184.

Maslow, A. (1954). Motivation and personality. New York, NY: Harper.

Matheny, C, Chan, H., \& Wang, X. (2015). Assembling a career. Community College Review, 43(4), 380-406.

Mather, D. \& Hanley, B. (1999). Cohort grouping and preservice teacher education: Effects on pedagogical development. Canadian Journal of Education, 24(3), 235250.

McCarthy, J., Trenga, M., \& Weiner, B. (2005). The cohort model with graduate student learners: Faculty-Student perspectives. Adult Learning, 6(3\&4), 22-25.

McGrath, J. E., Arrow, H., \& Berdahl, J. L. (2000). The study of groups: Past, present, and future. Personality and Social Psychology Review, 4(1), 95-105.

McPhail, C. J., Robinson, M. \& Scott, H. (2008). The cohort leadership development model: Student perspectives. Community College Journal of Research and Practice, 32, 362-374.

Mello, R. (2003). The integrated cohort program: An elevation of a preprofessional course of study. The Educational Forum, 67(4), 354-362.

Melnychuk, N. (2001). A cohort practicum model: Physical education student teachers' experience. Alberta Journal of Educational Research, 47(3), 259-275. 
Merriam, S. B. (2009). Qualitative research: A guide to design and implementation. San Francisco, CA: Jossey-Bass.

Mintzberg, H., (1994). The rise and fall of strategic planning: Reconceiving roles for planning, plans, planners. New York, NY: The Free Press, A division of Simon \& Schuster.

Mohn, C., \& Machell, J. (2005). Reconceptualizing school leader learning: Blurring the lines between staff development and university-based principal preparation programs. Planning and Changing, 36(1-2), 120-128.

Moller-Wong, C., Shelley, M., \& Ebbers, L. (1999). Policy goals for educational administration and undergraduate retention: Toward a cohort model for policy and planning. Review of Policy Research, 16(3-4), 243-277.

Mountford, M. (2005). The journey toward transformational learning in a statewide doctoral program. Innovative High Education, 30, 213-227.

Mukeredzi, T. G. (2017). Mentoring in a cohort model of practicum: Mentors and Preservice teachers' experiences in a rural South African school. South African Journal of Education, 7(2), 1-15.

Neir, P. M., Toledo, R., Baptiste, D., Maliszewski, B., \& Borries, K. (2016). Increasing the number of certified registered nurses in an emergency department. Journal for Nurses in Professional Development, 32(5), 262-264.

Nimer, M. (2009). The doctoral cohort model: Increasing opportunities for success. College Student Journal. 43(4), 1373-1379.

Northouse, P. G. (2013). Leadership: Theory and practice (6th ed.). Los Angeles, CA: Sage. 
Pemberton, C. A., \& Akkary, R. K. (2010). A cohort, is a cohort, is a cohort...or is it? Journal of Research on Leadership Education, 5(5), 179-208.

Perez, N. M., Fegadel, A. R., \& Bromley, M. L. (2015). Students' perceptions of a cohort-style graduate program: A descriptive analysis of feedback obtained from MACJA graduates. Journal of Criminal Justice, 26(3), 316-329.

Pfund, G., Bono, T., \& Hill, P. (2020). A higher goal during higher education: The power of purpose in life during university. American Psychological Association, 6(2), 97-106.

Potthoff, D., Dinsmore, J. A., \& Moore, T. J. (2001). The diversity cohort - A professional development program for college faculty. The Teacher Educator, 37(2), 145-149.

Potthoff, D., Fredrickson, S., Batenhorst, E., \& Tracy, G. (2001). Learning about cohorts: A master's degree program for teachers. Action in Teacher Education, 23(2), 3642.

Preis, S., Grogan, M., \& Sherman, W. (2007). What the research and literature say about the delivery of educational leadership preparation programs in the United States. Journal of Research on Leadership Education, 2(2), 1-36.

Rausch, D. W., \& Crawford, E. K. (2012). Cohorts, communities of inquiry, and course delivery methods: UTC best practices in learning--The hybrid learning community model. Journal of Continuing Higher Education, 60(3), 175-180.

Reed, B., Archer, L., \& Leathwood, C. (2003). Challenging cultures? Student conceptions of 'belonging' and 'isolation' at a post-1992 university. Studies in Higher Education, 28(3), 261-277. 
Reynolds, K. C. \& Hebert, F. T. (1998). Learning achievements of students in cohort groups. The Journal of Continuing Higher Education, 46(3), 34-42.

Reynolds, K. C. \& Sirharaman, S. (2000). Business education in cohorts: does familiarity breed learning? Journal of Business and Training Education, 9, 29-44.

Rocconi, L. M. (2011). The impact of learning communities on first year students' growth and development in college. Research Higher Education, 52, 178-793.

Ross, D. D., Stafford, L., Church-Pupke, P., \& Bondy, E. (2006). Practicing collaboration: What we learn from a cohort that functions well. Teacher Education and Special Education, 29(1), 32-43.

Sandberg, S., \& Scovell, N. (2013). Lean in: Women, work, and the will to lead. First edition. New York: Alfred A. Knopf.

Santicola, L.\& Morris, R. (2013) Pressing on Persistence through a doctoral cohort program in education. Contemporary Issues in Educational Research - Second Quarter, 6(2), 253-263.

Sapon-Shevin, M. \& Chandler-Olcott, K. (2001). Student cohorts, communities of critique or dysfunctional families? Journal of Teacher Education, 52(5), 350-364.

Sathe, R. S. (2009). Using the cohort model in accounting education. Accounting Education, 18(1), 33-49.

Scribner, J. P. \& Donaldson, J. F. (2001). The dynamics of group learning in a cohort: From nonlearning to transformative learning. Educational Administration Quarterly, 37(5), 605-636.

Seed, A. H. (2008). Cohort building through experiential learning. Journal of Experiential Education, 31(2), 209-224. 
Slater, C. L., \& Trowbridge, S. (2000). Master's level cohorts combat teacher isolation: University/School district collaboration. Action in Teacher Education, 22(1), 15 22.

Stearns, M., Margulus, L., \& Shinsky, J. (2012). Theory into practice: A study to assess the influence of a customized leadership development program on a cohort of aspiring urban leaders. International Journal of Educational Leadership Preparation, 7(2), 1-13.

Strauss, W., \& Howe, N. (1991). Generations: The history of America's future. New York, NY: William Morrow and Company, Inc.

Swayze, S. \& Jakeman, R. C. (2014). Student perceptions of communication, connectedness, and learning in a merged cohort course. The Journal of Continuing Higher Education 62, 102-111.

Teitel, L. (1997). Understanding and harnessing the power of the cohort model in preparing educational leaders. Peabody Journal of Education, 72(2), 66-85.

Tinto, V (1993). Leaving College: Rethinking the Causes and Cures of Student Attrition. Chicago, IL: University of Chicago Press.

Tinto, V. (1994). Student success and the construction of inclusive education communities. Prepared for Beyond 2000: Demographic change, education, and the workforces conference proceedings, Boston, MA.

Tinto, V. (1997). Classrooms as communities. The Journal of Higher Education, 68(6), $599-623$.

Tinto, V. (2000). Learning better together: The impact of learning communities on student success. Journal of Institutional Research, 9, 1-8. 
Tinto, V (2000). What have we learned about the impact of learning communities on students? Assessment Update, Progress, Trends, and Practices in Higher Education, 12(2), 1-14.

Tisdell, E. J., Strohschen, G. I. E., Carver, M. L., Corrigan, P., Nash, J., Nelson, M., Royer, M., Storm-Mackey, R., \& O'Connor, M. (2004). Cohort learning online in graduate higher education: Constructing knowledge in the cyber community. Educational Technology \& Society, 7(1), 115-127.

Umekubo, L. A., Chrispeels, J. H., \& Dalay, A. J. (2015). The cohort model: Lessons learned when principals collaborate. Journal of Educational Change, 16, 451482.

Unzueta, C. H., Moores-Abdool, W., \& Donet, D. V. (2010). Perceptions of special education professors and culturally linguistically diverse doctoral students on cohorts. Teacher Educator and Special Education, 33(2), 169-182.

Weick, K. E. (1976). Educational organizations as a loosely coupled system. Administrative Science Quarterly, 21(1), 1-19.

Wisker, G., Robinson, G., \& Shacham, M. (2007). Postgraduate research success: Communities of practice involving cohorts, guardian supervisors and online communities. Innovations in Education and Teaching International, 44(3), 301320.

Wyatt, L. G. (2011). Nontraditional student engagement: Increasing adult student success and retention. The Journal of Continuing Higher Education, 59, 10-20.

Zhao, C. \& Kuh, G. D. (2004). Adding value: Learning communities and student engagement. Research in Higher Education, 45(2), 115-138. 
Zobac, S., Spears, J., \& Barker, G. (2014). Identical profiles, different paths: Addressing self-selection bias in learning community cohorts. Learning Communities Research and Practice, 2(1/3), 1-13. 
APPENDIX 


\section{APPENDIX A}

A1: Student survey questions

A2: Faculty interview questions

A3: Student interview questions 
Appendix A1: Student survey questions

\section{Section 1: Consent Form (all students)}

○ Branching question: Would you like to participate in the survey?

○ No-ends the survey

- Yes-Moves to the next question

○ Branching question: Are you at least 18 years old?

- No-ends the survey

- Yes-Moves to the next section

\section{Section 2: Demographics (all students)}

○ Gender:

○ Male, Female, Other

○ Race:

- American Indian or Alaskan Native, Black or African American, Native

Hawaiian or Other Pacific Islander, White, Asian, Other, Two or more

○ Ethnicity:

- Hispanic/Latino or Non-Hispanic/Latino

○ Branching question: Are you currently in the TEC program?

- No-Move to section 4

- Yes-Moves to the next section

\section{Section 3: Currently enrolled students}

○ Which TEC program are you enrolled in at KCKCC?

- List of all TEC programs

○ How old were you when you started the TEC program?

$\circ$ How old are you currently?

- What is your student type?

- Current High School Student (Not yet graduated high school)

- Postsecondary Student (already graduated high school or earned GED)

○ When do you anticipate completing the TEC program?

○ fall 2020, spring 2021, summer 2021, fall 2021, spring 2022

- Why did you select this TEC program?

$\circ$ How does this TEC program help to meet your goal(s)?

- What might prevent you from completing the program?

- What are the main reasons for your continued enrollment in the TEC program?

- A cohort program consists of the same group of students going through a program together, enrolling in the same courses, with specific class time. Do you feel that being a part of a cohort program has encouraged your continued enrollment in the TEC program?

○ If yes, how?

- A cohort program consists of the same group of students going through a program together, enrolling in the same courses, with specific class time. Do you feel that being a part of a cohort program has encouraged your continued enrollment in the TEC program?

○ If no, why not? 
○ Do you feel the support provided by others (i.e., classmates, faculty, enrollment process, advisors) encourages you to continue the program?

If yes, who and how?

- Do you feel the support provided by others (i.e., classmates, faculty, enrollment process, advisors) encourages you to continue the program?

- If no, what type of support would encourage you to continue in the program?

\section{Section 4: graduated students}

Branching question: Have you graduated from a TEC program at KCKCC?

- No-Move to Section 3

- Yes - Questions listed below

- Which TEC program did you graduate from at KCKCC?

○ List of all TEC programs

- How old were you when you started the program?

- What was your age when you completed the program?

- What was your student type when you were in the program?

- Current High School Student (Not yet graduated from high school)

- Postsecondary Student (already graduated high school or earned GED)

○ Which semester did you complete the TEC program?

○ Fall, Spring, Summer

O What year did you complete the TEC program?

○ Why did you select this TEC program?

$\circ$ How did this program help to meet your goal(s)?

o Where there any challenges that you had to deal with that might have prevented you from completing the program?

- If you did not face any challenges that might have prevented, you from completing the program you can type N/A in the text box below.

- What were the main reasons for your continued enrollment in the TEC program?

- A cohort program consists of the same group of students going through a program together, enrolling in the same courses, with specific class time. Do you feel that being a part of a cohort program has encouraged your continued enrollment in the TEC program?

○ If yes, how?

- A cohort program consists of the same group of students going through a program together, enrolling in the same courses, with specific class time. Do you feel that being a part of a cohort program has encouraged your continued enrollment in the TEC program?

- If no, why not?

○ Do you feel the support provided by others (i.e., classmates, faculty, enrollment process, advisors) encouraged you to continue the TEC program?

If yes, who and how? 
○ Do you feel the support provided by others (i.e., classmates, faculty, enrollment process, advisors) encouraged you to continue the TEC program?

I If no, what type of support would you have found helpful?

\section{Section 5: students who did not complete a TEC program}

Branching question: Did you start a KCKCC TEC program and not finish the program?

- No-Move to Section 3

- Yes-Questions listed below

- Which TEC program did you graduate from at KCKCC?

- List of all TEC programs

○ Why did you select this TEC Program?

- How old were you when you started the program?

○ How old were you when you stopped the TEC program?

○ Approximately, how many months where you enrolled in the TEC program?

- What was your student type when you started the program?

- Current High School Student (had not yet graduated from high school)

- Postsecondary Student (graduated high school or earned GED)

- What was your student type were you when you stopped the TEC program?

- Current High School Student (had not yet graduated from high school)

- Postsecondary Student (graduated high school or earned GED)

- What were the challenges that you had to deal with that prevented you from completing the program?

- What were the main reasons that lead to your decision to stop the TEC program?

- A cohort program consists of the same group of students going through a program together, enrolling in the same courses, with specific class time. Do you feel that being a part of a cohort program was beneficial?

- If yes, how?

- A cohort program consists of the same group of students going through a program together, enrolling in the same courses, with specific class time. Do you feel that being a part of a cohort program was beneficial?

○ If no, why not?

- Do you feel the support provided by others (i.e., classmates, faculty, enrollment process, staff, advisors) encouraged you to continue the TEC program?

If yes, who and how?

○ Do you feel the support provided by others (i.e., classmates, faculty, enrollment process, staff, advisors) encouraged you to continue the TEC program?

- If no, what type of support would you have found helpful? 


\section{Quantitative Research Questions}

1. Is there a statistically significant difference between TEC programs cohort completion rates among high school and postsecondary students? *

2. Is there a statistically significant difference between TEC cohort programs completion rates based on students' race/ethnicity? $*$

3. Is there a statistically significant difference between TEC cohort programs completion rates based on students' age? $*$

4. Is there a statistically significant difference between TEC cohort programs completion rates based on students' gender according to the program? *

Qualitative Research Questions

5. What are the reasons for students' continued enrollment in the TEC cohort program?

6. What forms of support within the TEC cohort program encouraged students' program completion?

7. According to students, why do TEC cohort models support program completion?

8. According to the TEC cohort faculty, what supportive contributions do they feel they provided to students? $* *$

*addressed using past data

**addresses using a faculty interview 
Appendix A2: Faculty interview questions

Begin with an introduction of the study, provide consent/assent information, and share a definition of cohort models used for this study.

1. How long have you been a TEC cohort faculty member?

i. Have you ever taught in a non-cohort program outside of KCKCC?

2. In general, what are your thoughts about cohort programs?

i. Also, what are your thoughts about non-cohort programs?

3. What makes the TEC cohort program different than other non-cohort TEC programs?

4. What do you think are the benefits for students who are enrolled in a TEC cohort program rather than a non-cohort program?

5. Alternatively, what do you think are the challenges for students who are enrolled in a TEC cohort program rather than a non-cohort program?

6. How do you support the students in the TEC cohort beyond the instruction of the curriculum?

7. Do you think the students in the cohort program support each other?

i. How so?

8. Do you think the students in the cohort programs get tired of each other since they spend so much time together?

i. On the other hand, do you see the students forming bonds and connections?

9. Do you see the high school students and postsecondary students forming connections and bonding?

i. How so?

10. In general, do you see an individual student, or a group of students, speak for the whole cohort?

11. How do you think the cohort program specifically supports underrepresented students?

12. What challenges do you see that your students face while in the program?

i. Do you think the TEC cohort helps students to overcome these challenges?

13. In what ways do you think the TEC cohort program could be improved? 


\section{Appendix A3: Student interview questions}

Begin with an introduction of the study, provide consent/assent information, and share a definition of cohort models used for this study.

1. Questions to identify the student's current standing in the program -

i. Did you graduate from the TEC cohort program at Kansas City Kansas Community College?

ii. Are you still enrolled in the program?

iii. Did you stop out of the program?

i. Why?

2. What motivated you to enroll in a TEC program?

3. What were some of the things you liked the most about the TEC cohort program at $\mathrm{KCKCC}$ ?

4. What were some of the things you did not like so much about the TEC program?

5. Were you a high school or postsecondary student while enrolled in the program?

i. What was your relationship like with the high school students in the program?

ii. What was your relationship like with the postsecondary students in the program?

6. If you are/were a high school student, will you finish the program while in high school?

i. If no, do you plan to finish the program as a postsecondary student?

i. If you do not plan to finish, why not?

ii. Do you have any concerns about finishing the program?

7. Can you provide a time when the faculty helped you out?

i. Were there any times that you wish the faculty would have done more to help or support you?

1. How so?

8. Were there any instances when a student or group of students seemed to speak for the whole class?

i. Were they speaking on your behalf, or did you feel that what they shared was contrary to your thoughts?

ii. Would you share an example?

9. How do you think the TEC cohort program could improve?

10. Give an example of a time when you felt supported in the TEC program. 
11. What made you decide to enroll in this TEC cohort program?

12. What academic or personal challenges have you had to deal with while enrolled in the TEC cohort program?

13. If you could go back and start the program over again, would you still enroll in this program?

14. How do you see your life changing after graduating from the TEC cohort program? 
APPENDIX B

B1: University of Missouri IRB Approval 
October 24, 2020

Principal Investigator: Tina Lewandowski (MU-Student)

Department: Bducational Leadership-EDD

Your IRB Application to project entitled An analysis of cohort models in technical education at Kansas City Kansas Community College was reviewed and approved by the MU Institutional Review Board according to the terms and conditions described below:

IRB Project Number

IRB Review Number

Initial Application Approval

Date

IRB Expiration Date

Level of Review

Project Status

Exempt Categories (Revised Common Rule)

Risk Level

Approved Documents
2029742

274105

October 23, 2020

October 23, 2021

Exempt

Active - Exempt

45 CPR $46.104 \mathrm{~d}(1)$

Minimal Risk

Survey consent form for students

Parental consent form

faculty and student consent for interview participation

Script used for the student and faculty interviews

Student survey questions

Student interview questions

Interview questions for faculty

Recruitment information and image of post that will be placed on Social Media

Email templates to students, faculty, high school points of contact, parents of students under age 18

The principal investigator (PI) is responsible for all aspects and conduct of this study. The PI must comply with the following conditions of the approval:

\section{COVID-19 Specific Information}

Enrollment and study related procedures must remain in compliance with the University of Missouri regulations related to interaction with human participants following guidance at research.missouri.edu/about/covid-19-info.php

In addition, any restarting of in-person research activities must comply with the policies and guiding principles provided at research.missouri.edu/about/research-restart.php, including 
appropriate approvals for return to work authorization for individuals as well as human subject research projects.

2. No subjects may be involved in any study procedure prior to the IRB approval date or after the expiration date.

3. All changes must be IRB approved prior to implementation utilizing the Exempt Amendment Form.

4. The Annual Exempt Form must be submitted to the IRB for review and approval at least 30 days prior to the project expiration date to keep the study active or to close it.

5. Maintain all research records for a period of seven years from the project completion date.

If you are offering subject payments and would like more information about research participant payments, please click here to view the MU Business Policy and Procedure: http:// bppm.missouri.edu/chapter2/2_250.html

If you have any questions or concerns, please contact the MU IRB Office at 573-882-3181 or email to muresearchirb@missouri.edu.

Thank you,

MU Institutional Review Board 
dissertation in practice, T. Church Lewandowski

\section{APPENDIX C}

C1: Student survey consent with waiver of documentation/assent

C2: Faculty and student consent with waiver of documentation/assent for virtual interview

C3: Parental consent form for students under age 18 


\section{Appendix C1: Student survey consent with waiver of documentation/assent}

\section{CONSENT WITH WAIVER OF DOCUMENTATION FOR PARTICIPATION IN A RESEARCH STUdy}

\section{InVESTIGATOR'S NAME: TINA CHURCH LEWANDOWSKI}

STUDY TITLE: An analysis of cohort models in technical education at Kansas City Kansas Community College

We would like to invite you to take part in a research study that we are doing to learn more about the KCKCC TEC cohort programs. If you are interested, this form will explain what will happen if you join the study.

If there is anything in this form that you do not understand, please email tmc6w3@umsystem.edu for an explanation. Tina Church Lewandowski, in the Educational Leadership and Policy Analysis department, is the Principal Investigator

Research studies help us to learn new things and test new ideas. Taking part in a research study is voluntary. You are free to say yes or no, and you can stop taking part at any time without giving us a reason. There will be no penalty to you.

The purpose of this research is to provide a faculty perspective of the Kansas City Kansas Community College Technical Education cohort program. We are inviting you to take part in this research because you are a faculty member of the Technical Education certificate program. We will only include you in the study if you first give us your permission.

\section{What AM I Being Asked To Do?}

If you decide to take part in this study, we will ask you to participate in a zoom interview inquiring about your experience in the Kansas City Kansas Community College Technical Education certificate program. This interview will take around 20-30 minutes.

\section{Who Can I Call If I Have Questions, Concerns, Or Complaints?}

If you have more questions about this study at any time, you can call Dr. Sandy Hutchinson at 660-543-4720. You may contact the University of Missouri Institutional Review Board (IRB) if you have questions about your rights as a research participant. The IRB can be reached at 573-882-3181 or irb@missouri.edu. If you want to talk privately about your rights or any issues related to your participation in this study, you can contact the University of Missouri Research Participant Advocacy by calling 888280-5002 (a free call) or emailing MUResearchRPA@ missouri.edu.

If you have any questions right now, please contact Tina Church tmc6w3@umsystem.edu or 913-288-7201.

Would you like to participate in the interview? If yes, contact respond to this email (tchurch@kckcc.edu) to schedule a virtual interview. 


\section{Appendix C2: Faculty and student consent with waiver of documentation/assent for}

\section{virtual interview}

KCKCC Technical (TEC) Program Survey | Please read the informed consent below:

Principal Investigator's Name: Tina Church Lewandowski

Study Title: An analysis of cohort models in technical education at Kansas City Kansas Community College

- We would like to invite you to take part in a research study that we are doing to learn more about the KCKCC TEC cohort programs. If you are interested, this form will explain what will happen if you join the study.

- If there is anything in this form that you do not understand, please email tmc6w3@umsystem.edu for an explanation. Tina Church Lewandowski, in the Educational Leadership and Policy Analysis department, is the Principal Investigator

- Research studies help us to learn new things and test new ideas. Taking part in a research study is voluntary. You are free to say yes or no, and you can stop taking part at any time without giving us a reason. There will be no penalty to you.

- The purpose of this research is to provide a student perspective of the Kansas City Kansas Community College Technical Education cohort program. We are inviting you to take part in this research because you are a student in the Technical Education certificate program. We will only include you in the study if you first give us your permission.

What Am I Being Asked To Do?

- If you decide to take part in this study, we will ask you to participate in an online survey inquiring about your experience in the Kansas City Kansas Community College Technical Education certificate program. The survey will take about 20 minutes to complete.

Who Can I Call If I Have Questions, Concerns, Or Complaints?

- If you have more questions about this study at any time, you can call Dr. Sandy Hutchinson at 660-543-4720.

- You may contact the University of Missouri Institutional Review Board (IRB) if you have questions about your rights as a research participant. The IRB can be reached at 573-882-3181 or irb@missouri.edu.

- If you want to talk privately about your rights or any issues related to your participation in this study, you can contact the University of Missouri Research Participant Advocacy by calling 888-280-5002 (a free call) or emailing MUResearchRPA@missouri.edu.

- If you have any questions right now, please contact Tina Church tchurch@kckcc.edu or 913-288-7201. 


\section{Appendix C3: Parental consent form for students under age 18}

\section{Parental Consent Form For A Child to Participate IN A RESEARCH STUDY}

\section{NAME(S) Of Researcher(S): Tina ChURCh LeWANdowski}

STUDY TITLE: An analysis of cohort models in technical education at Kansas City Kansas Community College

This research study is about Kanas City Kansas Community College TEC cohort programs.

We ask your permission for your child to take part in this research study, because they have enrolled in the TEC cohort program and we would like their feedback about the program. This consent form tells you why we are doing the study, and what will happen if your child joins the study.

If there is anything in this form that you do not understand, please email tmc6w3@umsystem.edu for an explanation. Tina Church Lewandowski, in the Educational Leadership and Policy Analysis department, is the Principal Investigator

Please take as much time as you need to read this consent form. You can discuss it with your family, friends, or anyone you choose. If there is anything you do not understand, please ask us to explain. Then you can decide if you want your child to take part in the study or not.

Research studies help us to answer questions that may improve our understanding of human behavior, attitudes, beliefs, and interactions. Taking part in a research study is voluntary. You are free to say yes or no. We will only include your child in this study if you give us your permission first by signing this consent form.

\section{WHAT WILL HAPPEN IF MY CHILD TAKES PART IN THIS STUDY?}

If you agree, you child will be emailed a survey link and will click on the link to participate in the survey. Your child may exit the survey at any time or skip any question they do not want to answer. The survey will take about 20 minutes to complete. Your child will also have the opportunity to participate in a virtual interview to answer questions about the KCKCC TEC program. The interview will take about 20 minutes.

\section{HOW LONG WILL MY CHILD BE IN THE STUDY?}

Your child will be in the study during the duration of the survey, approximately 15- 20 minutes.

WHO CAN I CALL IF I HAVE QUESTIONS, CONCERNS, OR COMPLAINTS? If you have more questions about this study at any time, you can call Dr. Sandy Hutchinson at 660-543-4720. 
You may contact the University of Missouri Institutional Review Board (IRB) if you have questions about your rights as a research participant. The IRB can be reached at 573-882-3181 orirb@missouri.edu.

If you want to talk privately about your child's rights or any issues related to their participation in this study, you can contact University of Missouri Research Participant Advocacy by calling 888-280-5002 (a free call) or emailing MUResearchRPA@ missouri.edu.

We will give you a copy of this consent form. Please keep it where you can find it easily

\section{Signature of Parent/Guardian}

\section{Consent to Participate in Research}

By signing my name below, I confirm the following:

- I have read/had read to me this entire consent form.

- All my questions were answered to my satisfaction.

- I voluntarily agree to allow my child take part in this research study. I have been told that my child can stop taking part at any time.

Student's Email Address (this is the email we will use to provide your student with the survey link and request to set up a virtual interview). 


\section{APPENDIX D}

D1: Kansas City Kansas Community College Technical Education Certificate Cohort Programs 


\section{D1: Kansas City Kansas Community College Technical Education Certificate \\ Cohort Programs}

- Auto Collison Repair

- Automotive Technology

- Building Engineering Maintenance Technology

- Commercial Residential Equipment Technology

- Computer Repair

- Computer Support Specialist

- Construction Technology

- Cosmetology

- Culinary Arts

- Electrical Technology

- Heating and Refrigeration

- Machine Technology

- Multimedia/Video Production

- Nail Technology

- Welding Technology 


\section{VITA}

Tina has been working in education since 2004 in a variety of capacities such as community college, K-12 education, international, and graduate level settings.

Previously, Tina worked with graduate and international students overseeing all levels of graduate programming from recruitment and admissions to degree planning and graduation. Recently, Tina has transitioned to working at a community college and now serves as the interim dean of enrollment management at Kansas City Kansas Community College. Tina earned her bachelor's degree in psychology, has graduate coursework in psychology, career and technology education, college student personnel administration, women and gender studies. Her master's degree is in career and educational technology and she has a graduate certificate in women, gender studies. She has an Educational Specialist Degree in Technology and Occupational Education. Recently she completed her doctorate in Educational Leadership and Policy Analysis with the University of Missouri. This degree will help her to be a leader and mentor for others. Ultimately, she plans to stay in higher education administration and use effective leadership skills to help others be successful and meet their goals. 